Florida International University FIU Digital Commons

10-10-2017

\title{
Transgneic Endothelin 3 Regulates Murine Pigment Production and Coat Color
}

Javier Pino

jpino004@fiu.edu

DOI: $10.25148 /$ etd.FIDC004033

Follow this and additional works at: https://digitalcommons.fiu.edu/etd

Part of the Biology Commons, Cell Biology Commons, Developmental Biology Commons, Genetics Commons, and the Other Cell and Developmental Biology Commons

\section{Recommended Citation}

Pino, Javier, "Transgneic Endothelin 3 Regulates Murine Pigment Production and Coat Color" (2017). FIU Electronic Theses and Dissertations. 3533.

https://digitalcommons.fiu.edu/etd/3533

This work is brought to you for free and open access by the University Graduate School at FIU Digital Commons. It has been accepted for inclusion in FIU Electronic Theses and Dissertations by an authorized administrator of FIU Digital Commons. For more information, please contact dcc@fiu.edu. 


\title{
FLORIDA INTERNATIONAL UNIVERSITY
}

Miami, Florida

\section{TRANSGENIC ENDOTHELIN 3 REGULATES MURINE PIGMENT PRODUCTION AND COAT COLOR}

\author{
A dissertation submitted in partial fulfillment of \\ the requirements for the degree of \\ DOCTOR OF PHILOSOPHY \\ in \\ BIOLOGY \\ by \\ Javier Pino
}

2017 
To: Dean Michael R. Heithaus

College of Arts, Sciences and Education

This dissertation, written by Javier Pino, and entitled Transgenic Endothelin 3 Regulates Murine Pigment Production and Coat Color, having been approved in respect to style and intellectual content, is referred to you for judgment.

We have read this dissertation and recommend that it be approved.

Manuel Barbieri

Marcus Cooke

Yuan Liu

Jose Eirin-Lopez

Lidia Kos, Major Professor

Date of Defense: October 10, 2017

The dissertation of Javier Pino is approved.

Dean Michael R. Heithaus College of Arts, Sciences and Education

Andrés G. Gil

Vice President for Research and Economic Development and Dean of the University Graduate School

Florida International University, 2017 


\section{DEDICATION}

I dedicate this Dissertation to my father, Javier Pino, my mother, Chary Pino, my sister, Jennifer Richard, and my brother, Joseph Pino. Your love, support and encouragement throughout my studies were essential in the achievement of this degree. 


\section{ACKNOWLEDGMENTS}

I would like to thank my research advisor Dr. Lidia Kos for everything she has done for me. Dr. Kos has been an essential component of my professional development. Thank you for supporting my interest in research, allowing me to take on this project and working with me in the development and expansion of this project. Thank you for always being an amazing mentor both inside and outside the lab, something that I will always be grateful for.

I would also like to thank all my committee members Dr. Manuel Barbieri, Dr. Yuan Liu, Dr. Marcus Cooke, and Dr. Jose Eirin-Lopez. Thank you for your guidance and assistance during this project.

I would like to thank all the Kos Lab members that have worked with me over the years. Thank you to Dr. Flavia Brito and Natasha Fernandez for taking me under your wings when I started in the lab, teaching me the techniques I needed to know and for being such great mentors and friends. I would like to give a special thanks to Dr. Ana Paula Benaduce, Dr. Amy Saldana, Dr. Alejandro Conde and Dr. Nikeisha Chin for assistance in the lab and putting up with my many questions, especially during the early years in the laboratory. I would like to acknowledge and thank Juliano Freitas and Xiaoshuang Li, the three of us started our graduate studies within a year of each other and embarked on this journey together and have helped me immensely throughout my graduate studies. Additionally, I would like to acknowledge Dr. Erasmo Perera for his help and suggestions on my project and for all you do in the Tissue Culture Facility. I would also like to acknowledge all the undergraduate students from the Kos Lab. 
In addition to the other lab members, I would like to acknowledge and thank Alexander Durango. Alex worked alongside me in the lab over the last two years of my graduate studies and without him I would not have been able to complete my project in the time that I did. Thank you Alex for all your help with experiments, double checking my work, giving your input when things did or did not work and for your company in the lab. All the Kos Lab members throughout the 8 years that I have been in the lab have really made an impact on my life, we formed memories that will never be forgotten and created friendships that went beyond the lab, thank each and everyone of you for some of the best memories of my life.

Furthermore, I would like to acknowledge the FIU Teaching Assistantship and the MBRS/RISE (NIH/NIGMS R25 GM061347) fellowship for their support and I would like to give a very big thank you to all the staff from the MBRS-RISE office. In particular I would like to acknowledge Dr. Charles H. Bigger, Aileen Soto, Thelma Robles, Dr. Robert Lickliter and Courtney Aiken. These individuals really made my time as an undergraduate and graduate student at FIU a great experience and assisted me in various aspects of my training. From Biology, I would like to give a very special thank you to Ms. Helen Forlong for always being extremely helpful with my travel, making the endless room reservations and for her kindness throughout my time at FIU. I would like to acknowledge the entire staff from the FIU Animal Care Facility for caring for the mice and all their help with acquiring resources.

I would not have been able to complete some experiments without the kindness of Dr. Noriega, Marcela and the rest of the Noriega lab. They assisted me and allowed me to use their nanodrop and RT-PCR machine. 
Additionally, I would like to thank the Nova Science Publishers, Inc. for allowing me to use the published chapter from Skin Pigmentation: Genetics, Geographic Variation and Disorders, Volume 1, MC1R. EDNRB, and KIT Signaling in Pigmentation Regulation and Related Disorders, pages 57-88, copyright (2013), Javier Pino and Lidia Kos.

Finally, I would like to thank my family and friends, without you I would not have been able to accomplish this degree. Thank you for putting up with my stories and frustrations from the lab, my rants about mice and pigmentation, and for being my support. 


\title{
ABSTRACT OF THE DISSERTATION
}

\section{TRANSGENIC ENDOTHELIN 3 REGULATES MURINE PIGMENT PRODUCTION AND COAT COLOR}

\author{
by \\ Javier Pino \\ Florida International University, 2017 \\ Miami, Florida \\ Professor Lidia Kos, Major Professor
}

Pigmentation plays a protective role against damage caused by ultraviolet (UV) irradiation. Humans with fair skin and light hair have a higher susceptibility to UVinduced DNA damage that can lead to the development of skin cancers. The melanocytes found in the skin and hair follicles depend on different signaling molecules for their proper development and pigment production. $\alpha$-Melanocyte Stimulating Hormone $(\alpha-$ msh) binds to the Melanocortin 1 receptor (Mc1r) to regulate pigment production and the switch between eumelanin and pheomelanin. Lethal yellow mice $\left(\mathrm{A}^{\mathrm{y}}\right)$ overexpress the agouti signaling protein, which inhibits the binding of $\alpha$-msh, resulting in a yellow coat color phenotype. Endothelin 3 (Edn3) encodes for a ligand involved in melanocyte development by regulating the differentiation, proliferation and migration of melanocyte precursors. A tetracycline inducible transgenic mouse in which Edn3 was placed under the keratin 5 promoter (K5-tTA;TRE-Edn3-lacZ) displays a hyperpigmentation phenotype due to the accumulation of melanocytes in the skin and an increase in hair pigment. Comparative analysis of dorsal hairs from $\mathrm{A}^{\mathrm{y}}$ and $\mathrm{A}^{\mathrm{y}}$; K5-tTA;TRE-Edn3-lacZ mice using high performance liquid chromatography showed that transgenic Edn3 
expression significantly increased both eumelanin and pheomelanin. No significant difference in the number of follicular melanocytes between Edn3 transgenic and nontransgenic mice was evidenced by immunofluorescence using an antibody against Tyrosinase related protein 1. Gene expression analysis of hair follicles showed that Edn3 upregulates the expression of melanogenic genes. Deactivation of transgenic Edn3 is possible with doxycycline (dox) treatment. To test if transgenic Edn3 expression is required to rescue and maintain a dark pigmentation phenotype in $\mathrm{A}^{\mathrm{y}}$ mice, dox was administered during embryonic and postnatal development to manipulate transgenic Edn3 expression. Results showed that transgenic Edn3 expression is required to maintain a dark pigmentation phenotype after birth but is independent of a developmental requirement. Transgenic Edn3 expression in $\mathrm{Mc} 1 \mathrm{r}^{\mathrm{e} / \mathrm{e}}$ mice also resulted in a darkened coat color. Our results indicate that the paracrine expression of Edn3 from keratinocytes is capable of generating and maintaining a dark coat color by the regulation of melanogenic genes independent of Mc1r signaling. The results of this study may open new approaches to the treatment of hypopigmentation disorders. 


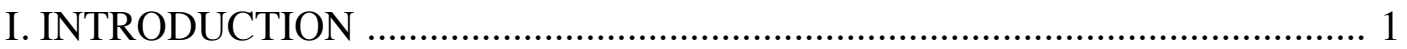

1.1 Published paper information …………………………………....... 2

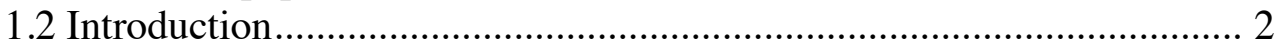

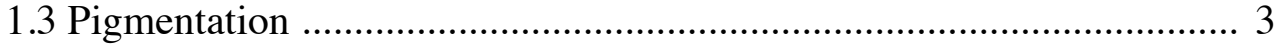

1.3.1 Pigment Production................................................................. 3

1.3.2 Pigment Cell Development ................................................... 5

1.4 Melanocortin 1 Receptor ................................................................ 7

1.4.1 The Melanocortin 1 receptor pathway .................................... 7

1.4.2 MC1R in Pigmentation ………………………….............. 9

1.4.3 Disruption of the MC1R Signaling in Mice and Humans ....... 10

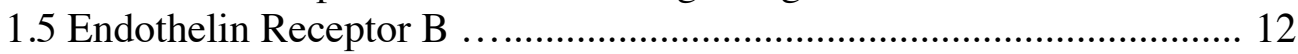

1.5.1 The Endothelin Receptor B Pathway …………………........... 12

1.5.2 EDNRB in Melanocyte Development and Pigmentation ......... 13

1.5.3 Disruption of the EDNRB Signaling in Mice and Humans .... 14

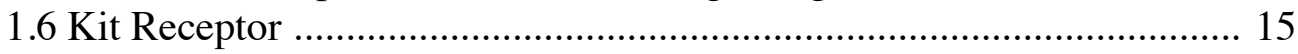

1.6.1 The Kit Receptor Pathway ………………………………....... 15

1.6.2 Kit Signaling in Melanocyte Development and Pigmentation 17

1.6.3 Disruption of the Kit Signaling in Mice and Humans ............. 18

1.7 Interactions Among Signaling Pathways ................................................ 20

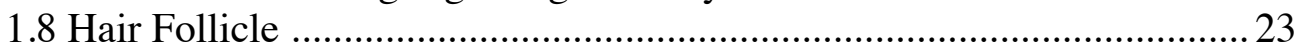

1.8.1 Hair Follicle Development and Morphology ............................23

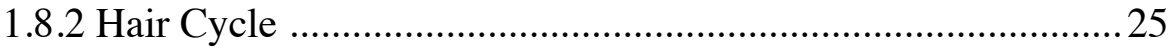

1.8.3 Stem Cell Niche and Hair Follicle Signaling ………................27

1.9 Research Questions ............................................................................ 30

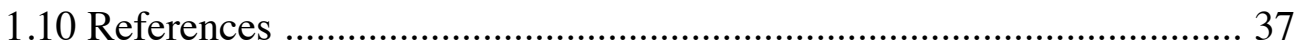

II. TRANSGENIC EDN3 BYPASSES THE REQUIREMENT FOR MC1R SIGNALING IN PIGMENT PRODUCTION ………......................................... 56

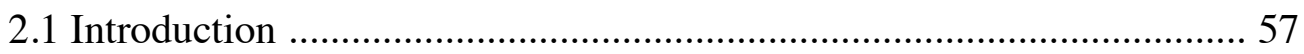

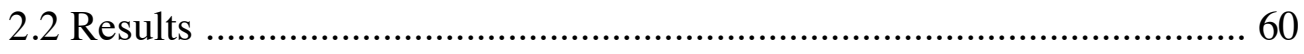

2.2.1 Overexpression of Edn3 increases overall melanin levels in follicular melanocytes.

2.2.2 Overexpression of Edn3 does not increase the number of follicular melanocytes..................................................................... 61

2.2.3 Overexpression of Edn3 increases the expression of melanogenic genes in isolated hair follicles

2.2.4 Overexpression of Edn3 darkens the skin and coat color of Mc1r mutant mice.

2.2.5 Sustained overexpression of Edn3 is required to maintain a dark pigmentation phenotype.

2.2.6 Overexpression of Edn3 during development is not required for a dark coat phenotype in the adult 


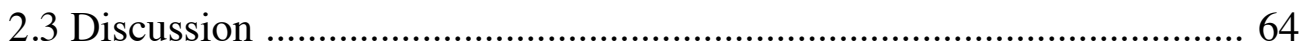

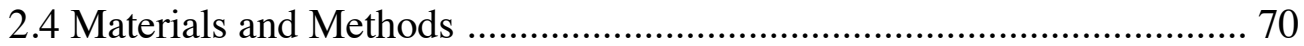

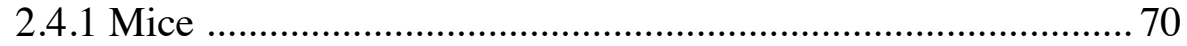

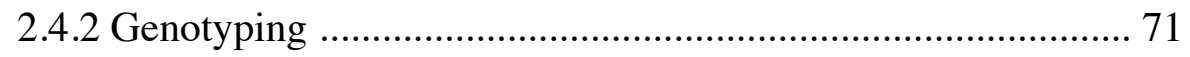

2.4.3 Melanin concentration analysis .......................................... 72

2.4.4 Dox treatment ................................................................ 72

2.4.5 Sample collection and numerical analysis of melanocyte numbers in hair follicles...................................................................... 73

2.4.6 Gene expression analysis of follicular melanocytes .................74

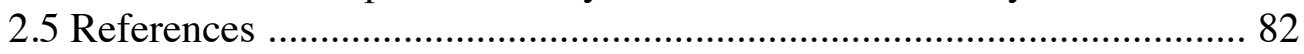

III. CONCLUSIONS, FUTURE DIRECTIONS AND IMPLICATIONS ............... 88

3.1 Conclusions, Future Directions and Implications …………………..... 89

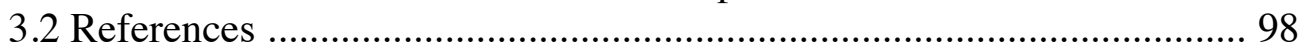

IV. APPENDIX FAILED EXPERIMENTAL APPROACHES .............................. 102

4.1 Failed Experimental Approaches ....................................................... 103

4.1.1 Quantification of follicular melanocytes in lethal yellow

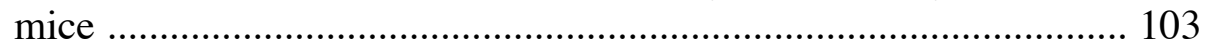

4.1.2 In vivo application of downstream inhibitors in pigment production ............................................................................... 104

4.1.3 In vitro studies to determine Base Excision Repair activity ... 105

4.1.4 In vivo studies to determine Base Excision Repair activity .... 106

4.1.5 in vitro studies to determine Nucleotide Excision Repair

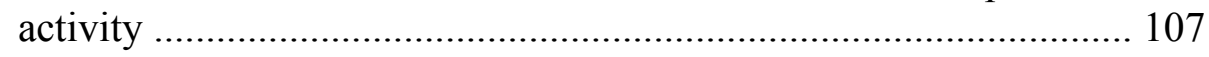

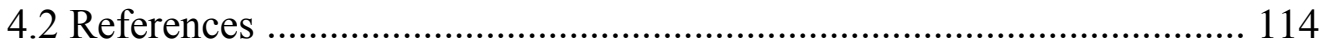

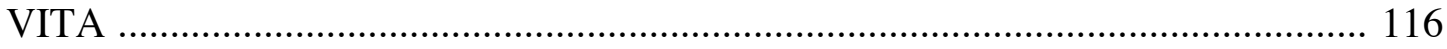




\section{CHAPTER I}

1.1 MC1R, EDNRB and KIT signaling pathways in melanocytes

1.2 Mouse mutants reveal the role of signaling pathways in

pigment production 34

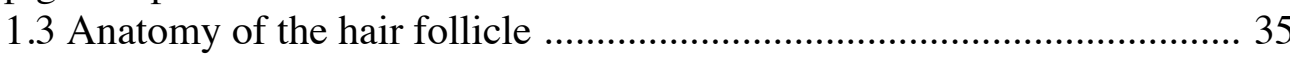

1.4 Melanocyte lineage during different phases of the hair cycle .............. 36

\section{CHAPTER II}

2.1 Dark coat color and hair melanin levels of

$A^{y} ;$ K5-tTA;TRE-Edn3-lacZ mice

2.2 Transgenic Edn 3 overexpression does not increase the number of

Trp1+ cells

2.3 Gene expression analysis of isolated hair follicles from

$A^{y}$; K5-tTA;TRE-Edn3-lacZ and non-transgenic $A^{y}$ littermates

2.4 $\mathrm{Mclr}^{e / e} ; \mathrm{K} 5$-tTA;TRE-Edn3-lacZ mice display a dark pigmentation

phenotype

2.5 Dox treatment of $A^{y} ;$ K5-tTA;TRE-Edn3-lacZ and non-transgenic

$A^{y}$ littermates

2.6 E0 to P0 Dox treatment of $A^{y} ;$ K5-tTA;TRE-Edn3-lacZ and

non-transgenic $A^{y}$ littermates

\section{CHAPTER IV}

4.1 Trp1 antibody staining of Lethal Yellow mouse skin ............................ 110

4.2 BER protein activity biochemical assay in melan-a cell lines

4.3 BER protein activity biochemical assay in K5-tTA;TRE-Edn3-lacZ

mice

4.4 Gene expression analysis of melan-a and melan-e cells induced with

Edn3 


\section{LIST OF SYMBOLS, ABBREVIATIONS AND ACCRONYMS}

AgRP Agouti-related protein

AKT Protein kinase B

APE1 Apurinic/apyrimidinic endonuclease 1 ASP Agouti signaling protein ASIP Agouti signaling protein (Human) ATCH Adrenocorticotropic hormone ATP Adenosine triphosphate $\mathrm{A}^{\mathrm{y}}$ Lethal yellow

$\mathrm{Bcl} 2$ B-cell lymphoma 2

BER Base Excision Repair

Bmp Bone morphogenic protein cAMP Cyclic adenosine monophosphate

CPD Cyclobutane pyrimidine dimers

CREB cAMP response element binding protein

CRTC CREB-regulated transcription co-activators

DCT Dopachrome tautotomerase DHICA 5,6-dihydroxyindole-2-carboxylic acid

DHI 5,6-dihydoxindole DOPA Dihydoxyphenylalanine DP Dermal papilla e Extension 
Eda Ectodysplasin A

Edn Endothelin

$\operatorname{Edn} 3^{\text {ls }}$ Lethal spotting

ENDRA Endothelin receptor A EDNRB Endothelin receptor B Ednrb $^{\mathrm{s} / \mathrm{sl}}$ Piebald Lethal

ERK Extracellular signal-regulated kinase FEN1 Flap endonuclease 1 Fgf Fibroblast growth factor

FPHH Familial progressive hyperpigmentation and hypopigmentation GSK3 Glycogen synthase kinase 3

$\mathrm{H}_{2} \mathrm{O}_{2}$ Hydrogen Peroxide

HFSC Hair follicle stem cell

HGF Hepatocyte growth factor

IR Ionizing radiation

IRS Inner root sheath

Kit Tyrosine kinase receptor Kitl Kit ligand LPP Lower Permanent Portion MAPK Mitogen activated protein kinase MC1R Melanocortin 1 receptor $\mathrm{Mc}^{\mathrm{e}} \mathrm{r}^{\mathrm{e}}$ Recessive yellow 

Neural crest

NER Nucleotide Excision Repair $\mathrm{nM}$ Nanometer

OGG1 8-oxoguanine glycosylase PI3K Phosphoinositide 3-kinase

PKA Protein kinase A PKC Protein kinase C PMEl17 Premelanosome protein 17 $\operatorname{Pol} \beta$ DNA polymerase $\beta$ POMC Proopiomelanocortin RAF Rapidly activated fibrosarcoma

RAS Proto-oncogene protein $\mathrm{P} 2$ cyclin-dependent kinase inhibitor 1 RNA Ribonucleic acid ROS Reactive oxygen species

SCID Severe combined immunodeficiency

SH2 Src homology 2 SIK Salt-inducible kinases 

Tyrosinase related protein 1 Xeroderma Pigmentosum a agouti Alpha-melanocyte stimulating hormone $\mu \mathrm{M}$ Micrometer 


\section{CHAPTER I}

INTRODUCTION 


\section{INTRODUCTION}

\subsection{Published Paper Information}

A portion of this chapter was reprinted from: Skin Pigmentation: Genetics, Geographic Variation and Disorders, Volume 1, MC1R. EDNRB, AND KIT SIGNALING IN PIGMENTATION REGULATION AND RELATED DISORDERS, pages 57-88, copyright (2013), Javier Pino and Lidia Kos with permission from Nova Science Publishers, Inc.

\subsection{Introduction}

Throughout the three domains of life, organisms display a variety of colorations and patterns because of the pigments they produce. Pigments are found in single celled organisms, plants, and animals. In some prokaryotes and plants, pigments are used in the production of nutrients using photosynthesis Colyer et al. (2005), (Grotewold, 2006). In animals, pigments play a large role in camouflage, and most importantly, confer overall fitness and survival. Brightly pigmented male house finches are shown to have a greater reproductive success than males with dull colors (Hill, 1990). Similar observations were seen with male mandrills that showed higher dominance and hierarchical success in harems (Setchell et al., 2008). Pigmentation can also be used as warning signals or camouflage to avoid predation and increase survivorship as shown in poison frogs and reef-dwelling fish, respectively (Coker et al., 2009, Maan and Cummings, 2012).

Pigment acts as a barrier to provide defense against ultraviolet (UV) radiation that may be harmful to melanocytes, keratinocytes and other cells found in mammalian skin (Kaidbey et al., 1979, Kobayashi et al., 1998, Murphy et al., 2001). Although UV 
exposure is essential for providing vitamin $\mathrm{D}$ for bone health, increased immunity, and the prevention of cancers and heart disease, there are also various adverse effects associated with it (Holick, 2004). Recently it was shown that UV radiation negatively affects the ability of the skin to act as a mechanical barrier by changing its cell cohesion properties and the mechanical integrity of the skin cells (Biniek et al., 2012). Ultraviolet exposure increases oxidative stress and mutations in skin cells that can ultimately lead to cell death and the formation of various skin cancers (Janssen et al., 1993). An increase in the activity of signaling molecules involved in the normal production of pigment follows UV radiation resulting in a rise in pigment levels found in the skin, also known as tanning (Corre et al., 2004, Friedmann and Gilchrest, 1987). These molecules are mostly secreted by the keratinocytes and include alpha-Melanocyte Stimulating Hormone ( $\alpha$ MSH), Endothelins (EDNs), KIT ligand (KITL), Hepatocyte Growth Factor, Leukocyte Inhibiting Factor, Granulocyte-Macrophage Colony-Stimulating Hormone, and basic Fibroblast Growth Factor (FGF). Other neighboring cells such as fibroblasts, endothelial cells, inflammatory cells and neurons also secrete factors that contribute to the overall levels of pigmentation (Hirobe, 2011, Yamaguchi and Hearing, 2009).

\subsection{Pigmentation}

\subsubsection{Pigment Production}

In mammals, melanocytes can be divided into two major groups: the cutaneous melanocytes that are found in the skin and hair, and non-cutaneous melanocytes associated with other parts of the body such as the inner ear, eye, and valves of the heart (Aoki et al., 2009, Brito and Kos, 2008, Cable and Steel, 1991). Irrespective of their 
location, the major differentiation characteristic of these cells is the production of the pigment melanin. Melanin is produced and stored in melanocyte-specific organelles, known as melanosomes. Protein analysis confirmed that melanosomes contain proteins specific to other organelles such as endoplasmic reticulum, lysosomes, and endosomes (Basrur et al., 2003). Melanosomes undergo a four-stage maturation process with gradual accumulation of pigment (Kushimoto et al., 2001, Seiji et al., 1963). The latest stage melanosomes are transported to the cell membrane via cytoskeletal filaments and are finally transferred to keratinocytes. Although the transfer is essential for the final distribution of pigment in the skin the exact mechanism and the factors involved with this process are still not fully understood (Van Den Bossche et al., 2006). Some hypotheses have been put forth such as the release of melanosomes into the extracellular space and their uptake through phagocytosis by the keratinocytes and filopodia mediated melanosome transfer (Marks and Seabra, 2001, Scott G. et al., 2002). Recent studies suggest that pigment globules made up of densely packed melanosomes bud out of various parts of the dendrites and are phagocytized by the keratinocytes (Ando et al., 2012, Wasmeier et al., 2008).

Melanocytes produce two types of pigment: the black/brown eumelanin and the yellow/red pheomelanin (d'Ischia et al., 2015, Prota, 1980). The production of melanin involves the oxidation of tyrosine to DOPA and DOPA into Dopaquinone in the presence of the enzyme Tyrosinase (TYR) (Burchill et al., 1991). Eumelanin synthesis involves the activity of the Microphthalmia Transcription Factor (MITF), the tyrosinase related enzymes Tyrosinase Related Protein 1 (TYRP1) and Dopachrome tautomerase (DCT) and the melanosome associated protein PMEL17(d'Ischia et al., 2015, Hearing, 2005). 
The process of pheomelanin production is independent of the melanocytic genes expression. Melanocytes that produce higher amounts of pheomelanin present less dendricity, have lower survival rates and exhibit lower photoprotective properties. The regulation of all the melanogenic genes and resulting pigment production is dependent on the signaling pathway activated downstream of the Melanocortin 1 Receptor (MC1R), a transmembrane G-coupled receptor found on the cell surface of melanocytes (Donatien et al., 1992).

\subsubsection{Pigment Cell Development}

Melanocytes are derived from a multipotent population of cells, the neural crest (NC), which arise from the dorsal aspect of the developing neural tube and the border with the prospective epidermis (Saldana-Caboverde and Kos, 2010, Thomas and Erickson, 2008). In the mouse, NC cells migrate from the neural tube between embryonic day (E) 9 and E9.5 (Thomas and Erickson, 2008). In the trunk of the mammalian embryo, the first group of cells that leave the neural tube take a ventral pathway and give rise to neurons and glial cells of the peripheral nervous system, and some endocrine cells. They are followed by the melanocyte precursors, the melanoblasts, that take a dorsolateral pathway (Henion and Weston, 1997). These cells start expressing melanocyte markers as early as E9.5, as observed by the expression of Mitf (Opdecamp et al., 1997). In mice, melanoblasts enter the ectoderm at E16.5 to populate the epidermis of the skin and the hair follicles as differentiated melanocytes and start producing melanin (Serbedzija et al., 1990). A recent study suggests the existence of a second cell lineage for the population of melanocytes that migrate to the skin (Adameyko et al., 2009). Instead of taking the dorsolateral pathway, these cells follow the ventral pathway and are 
found along the developing nerves. Depending on the presence or absence of neuregulin signaling they can either become Schwann cells or melanocytes.

During development, various signaling pathways are involved in the specification and differentiation of melanocytes including those triggered by the ligands Wnt, Endothelin 3 (EDN3), and Kitl (Baynash et al., 1994, Bondurand et al., 1998, Cooper and Raible, 2009, Hou et al., 2000, Phung et al., 2011). All the pathways contribute to the transcriptional activation of MITF, which in turn regulates the expression of most of the melanogenic genes including TYR, TYRP1,DCT and PMEL17.These same pathways continue to play a role in the adult regulating pigment production and maintenance of the pigmentation patterns.

Although the cascade of intracellular events that occur downstream of the activation of the major signaling pathways that control pigmentation have been well characterized biochemically and molecularly, how these pathways interact in vivo to produce the ultimate pigmentation phenotypes has not been fully established. Three major pathways contribute to establish normal pigmentation in mice and humans and have been shown to interact genetically. Alterations in these pathways lead to pathological conditions that include pigmentation manifestations. Activity of MC1R and its ligand $\alpha-\mathrm{MSH}$ are at the center of the establishment of pigmentation patterns and are critical in the switch between eumelanin and pheomelanin production. Deactivation of this pathway, through mutation in the receptor and the presence of Agouti Signaling Protein (ASIP in humans and ASP in mice), leads to variations in pigmentation. The Endothelin Receptor B (EDNRB) along with its ligand EDN3 cooperate with the tyrosine kinase receptor KIT and its ligand KITL to properly specify melanocytes, expand the 
population of precursors, and coordinate their migration to the skin. Deactivation of the EDNRB pathway is responsible for human Waardenburg-Shah syndrome and the piebald phenotype in mice (Saldana-Caboverde and Kos, 2010) while human piebaldism results from mutations in KIT (Giebel and Spritz, 1991).

\subsection{Melanocortin 1 Receptor}

\subsubsection{The melanocortin 1 receptor pathway}

Melanocortin receptors are g-coupled protein receptors involved in various processes in mammalian body systems including inflammatory response, steroid secretion, nervous system function, exocrine function and the production of pigments (Gantz and Fong, 2003). The MC1R plays an essential role in pigment production on the cell membrane of skin and hair follicle melanocytes (Donatien et al., 1992).

The agonist ligands for MC1R are $\alpha-\mathrm{MSH}$ and Adrenocorticotropic hormone (ACTH) one of the many melanocortins derived from the proopiomelanocortin (POMC) precursor (Abdel-Malek et al., 1995, Le Pape et al., 2008). The POMC RNA is found in both melanocytes and keratinocytes at low levels and cultured keratinocytes are able to produce $\alpha$-MSH in vitro (Farooqui et al., 1993, Schauer et al., 1994). The $\alpha$-MSH has a high binding affinity to MC1R and, when bound, leads to the synthesis of eumelanin (Aberdam et al., 1998). The binding of the ligand to the receptor activates cyclic adenosine monophosphate (cAMP) which binds to the regulator subunit of protein kinase A (PKA) allowing for the initiation of catalytic activity (Bertolotto et al., 1998). Next, PKA enters the nucleus activating the cAMP response element binding protein (CREB) leading to the production of MITF (Figure 1.1). The MITF is considered a master 
regulator in melanocytes and is essential for the production of $T Y R$ and most other genes required for pigment production (Fuller et al., 1987, Halaban et al., 1984, Price et al., 1998, Yasumoto et al., 1994).

Melanocortin receptors are known to have two antagonist ligands, namely ASP and Agouti-related protein (AgRP). The AgRP is not involved in pigment production and only binds to MC3R and MC4R (Ollmann et al., 1997). Binding of ASIP to MC1R in melanocytes causes a shift in melanin production from eumelanin to pheomelanin (Le Pape et al., 2008). The ASIP competitively inhibits $\alpha$-MSH from binding to MC1R by using the cysteine-rich carboxyl terminus to bind to the receptor, deactivating the signaling pathway (Lu et al., 1994, Willard et al., 1995). Binding of ASIP results in a decrease in cAMP and TYR activity, which are required at lower levels in the production of pheomelanin (Burchill et al., 1986).

In vitro studies in which ASIP was applied to melanocytes did not result in cultures solely producing pheomelanin suggesting that other molecules that are present in vivo may also be involved in pigment type switching (Abdel-Malek et al., 2001, Le Pape et al., 2008). These findings are further corroborated by studies carried out with mouse mutants. Attractin, a type 1 transmembrane protein encoded by Mahogany, expresses low affinity for ASP binding but is essential for ASP to bind to Mc1r (Gunn et al., 1999, He et al., 2001). Mice lacking attractin protein are not able to produce pheomelanin and only express eumelanin even in the presence of ASP (Gunn et al., 2001, He et al., 2003). A mutant that also produces eumelanin in the presence of ASP has been identified in the Mahoganoid gene (He et al., 2003). Mahoganoid encodes for an intracellular E3 ubiquitin ligase known as Mahogunin ring finger-1, but its exact function is not yet 
known. Another ligand, $\beta$-defensin, was recently discovered and characterized in dogs and transgenic mice (Candille et al., 2007). Interestingly, $\beta$-defensin was shown to have high affinity to Mc1r producing a dark pigmentation phenotype and the production of eumelanin in dogs.

\subsubsection{MClR in Pigmentation}

Tyrosinase activity is the rate-limiting component in pigment production and its activation is mostly dependent on the MC1R signaling pathway. Tyrosinase oxidizes tyrosine into DOPA and later into the melanin precursor, Dopaquinone (Foster, 1950, Furumura et al., 1996, Korner and Pawelek, 1982, Raper, 1927). Once Dopaquinone is oxidized, the production of pigment is specified: if cysteine is present pheomelanin is synthesized and in its absence Dopaquinone is transformed into leucodopachome and later dopachrome.

In the presence of cysteine or other sulfhydryl compounds, the thiol adducts of dopa, 5-S-cysteinyldopa and 2-S-cysteinyldopa, will be produced (d'Ischia et al., 2015, Riley, 2003). This is followed by a series of oxidation reactions resulting in cysteinyldopa-quinone production. After the chain of oxidation reactions, 1,4benzothaizine intermediates are formed. Further oxidation will ultimately result in pheomelanin (Hearing, 2011, Land et al., 2003).

During the oxidation cascade following dopachrome in the production of eumelanin, the melanogenic genes TYRP1, DCT and PMEL17 are activated (Kuzumaki et al., 1993). Tyrp1 and Dct are found in the melanosome and are mapped to the mouse brown and slaty loci, respectively (Jackson, 1988, Jackson et al., 1992). Mutations in the 
brown and slaty loci affect eumelanin production and cause changes in the pigmentation phenotype resulting in lighter coat colors (Costin et al., 2005, Guyonneau et al., 2004, Jackson et al., 1992). The TYRP1 is necessary for the production of black over brown pigment (Bennett et al., 1990). Additionally, DCT oxidizes Dopachrome into 5,6dihydroxyindole-2-carboxylic acid (DHICA), preventing the conversion of Dopachrome into 5,6-dihydoxindole (DHI). Then TYRP1 oxidizes DHICA (Tsukamoto et al., 1992). The PMEL17 is found in the matrix of the melanosome and is encoded by the Silver locus (Zhou et al., 1994). Mutations in Silver lead to a progressive greying of coat color in mice due to melanocyte loss of function (Theos et al., 2005).

\subsubsection{Disruption of the MCIR Pathway in Mice and Humans}

A functional MC1R signaling pathway results in the production of eumelanin, while an interrupted pathway leads to the production of pheomelanin. The chang in pigment production is the consequence of the agouti (a) and extension (e) loci. Point mutations in either locus cause variations of yellow coat color in mice (Dickies, 1962, Robbins et al., 1993). Mutations in the $e$ locus result in lack of function of Mc1R because of an early termination of the fourth transmembrane domain that prevents the coupling of the G-proteins to the receptor (Hauschka et al., 1968, Robbins et al., 1993). Recessive yellow mice have mutations in the $e$ locus and display a yellow coat color (Figure 1.2 B).

Lethal yellow mice $\left(A^{y}\right)$ carry a mutation at the agouti locus resulting in the over production of ASP. The mutation consists of a deletion that removes the entire Raly gene except for its promoter and noncoding first exon. The Raly gene maps close to the 3' end of the agouti gene and lies in the same transcriptional orientation (Bultman et al., 1992, 
Miller et al., 1993). In $A^{y}$ mice, the coding region of the agouti gene ends up being under the control of the ubiquitous Raly promoter. Heterozygous $A^{y}$ mice (Figure 1.2 B) display a longer body size, resistance to insulin, obesity and a yellow coat color as a consequence of ASP overexpression (Klebig et al., 1995). Homozygous $A^{y}$ mice are embryonic lethal because of the absence of Raly product (Michaud et al., 1993, Miller et al., 1993).

Application of $\alpha-\mathrm{MSH}$ to $M c 1 r^{e / e}$ mice does not rescue eumelanin production, while it does in $A^{y}$ heterozygous mutants confirming that $M c 1 r^{e / e}$ mice have mutations in the Mc1R receptor, while $A^{y}$ mutants do not. Upon exposure to cAMP, both types of mutants respond by producing eumelanin indicating that these mutations are at the level of the receptor and/or ligand and not in downstream factors (Tamate and Takeuchi, 1984). a locus mutants have lighter coat color than those with mutations in the $e$ locus (Ollmann et al., 1998). The variation in coat color shows that ASP acts more than a simple antagonist to Mc1r signaling. It can also be considered as an agonist for Mc1 R by causing the extreme opposite effect of the binding of $\alpha-\mathrm{MSH}$.

Mechanisms regulating pigmentation in humans work very similarly to those found in mice. Melanocytes found in the hair follicles and epidermis of humans also synthesize both types of pigments and give the visible pigmentation variations (Hunt et al., 1995). The gene that encodes for MC1R in humans is highly polymorphic with various mutations in comparison to that found in the mouse (Garcia-Borron et al., 2005, Wong and Rees, 2005). Many of these mutations result in a loss of function receptor that can no longer bind $\alpha$-MSH (Pino and Kos, 2013). These mutations result in the loss of eumelanin production and the production of red hair (Box et al., 1997, Flanagan et al., 2000). Humans with homozygous and heterozygous alleles for MC1R display paler skin 
and have increased risk of acquiring skin cancers (Bastiaens et al., 2001, Kennedy et al., 2001). The null phenotype for MC1R has been found to be red hair (Beaumont et al., 2008). Specific alleles of ASIP have been associated with pigmentation characteristics such as dark hair (Kanetsky et al., 2002), basal cell carcinoma risk (Nan et al., 2009) and those generally affected by variants in $\mathrm{MC1}$ including skin sensitivity to sun, freckling and red hair (Sulem et al., 2008).

\subsection{Endothelin Receptor B}

\subsubsection{The Endothelin Receptor B Pathway}

Signaling downstream of EDN is triggered by the binding of any of the three ligands, EDN1, EDN2 or EDN3 to the two major receptors, EDNRA or EDNRB. The process of ligand production starts with the cleavage of prepolypeptide precursors by prohormone processing hormones to produce big EDNs. Big EDNs display low activity and are cleaved into smaller, active EDNs by Endothelin Converting Enzyme-1 (Emoto and Yanagisawa, 1995, Manaka et al., 2001, Xu et al., 1994). Final EDN products are made up of 21 amino acid residues that result from the proteolytic cleavages between Trp-21 and Val/Ile-22. The ligand EDN1 was the first described and the best functionally characterized. It was originally shown to be a potent vasoconstrictor and to be involved in hypertension, congestive heart failure, and ovarian cancer (Yanagisawa et al., 1988a, Yanagisawa et al., 1988b). Both EDNRA and EDNRB are seven-transmembrane Gcoupled protein receptors. Both receptors display different binding affinities to the EDNs. EDNRA has higher affinity to EDN1 than EDN2 and EDN3, with EDN3 being the lowest presenting about 100 times lower affinity than EDN1 (Hosoda et al., 1991, Lin 
et al., 1991). EDNRB shows the same affinity for all three EDNs, although EDN3 is the one most readily available to the receptor (Ogawa et al., 1991).

In melanocytes, upon binding of EDN1 or EDN3 to EDNRB, two possible signaling transduction pathways may be elicited (Figure 1.1). Activation of cAMP may occur following the activation of PKC (PKC), which acts along with RAF activating the Mitogen Activated Protein Kinase (MAPK) signaling pathway (Imokawa et al., 1997, Imokawa et al., 1996, Sato-Jin et al., 2008). Next, MAPK phosphorylates MITF, and subsequent activation of a variety of melanocytic and melanogenic genes, including EDNRB itself (Sato-Jin et al., 2008). Activation of cAMP may occur following the activation of PKA, as seen in MC1R signaling, leading to the activation of CREB and the transcription of MITF (Sato-Jin et al., 2008).

\subsubsection{EDNRB in Melanocyte Development and Pigmentation}

The EDNRB signaling plays various roles in the development of melanocytes from NC cells. It is not responsible for the initial commitment of NC cells to the melanocytic fate but participates in most cellular processes after the initial commitment step such as survival, migration, proliferation and final differentiation (SaldanaCaboverde and Kos, 2010). Expression of EDNRB occurs in the neural tube and in most $\mathrm{NC}$ derivatives as they migrate to their final destinations, including the melanoblasts. In vitro, EDN3 markedly increases the proliferation of pluripotent NC cells, stimulates the production of large numbers of melanocyte precursors and eventually leads to their differentiation as pigmented cells (Opdecamp et al., 1998, Reid et al., 1996). In spontaneous Ednrb homozygous null mouse mutants (piebald lethal, Ednrb ${ }^{s l / s l}$ ) as well as 
in mice in which the LacZ gene was inserted downstream of the endogenous Ednrb promoter by homologous recombination there is a drastic reduction in the number of melanocyte precursors by E12.5 (Lee et al., 2003, Pavan and Tilghman, 1994). A study in which Ednrb was expressed at different stages of embryogenesis under the control of the tetracycline inducible system showed that its expression is critical between E10.5 and E12.5 for the generation of a normal coat color (Shin et al., 1999). The over-expression of $E d n 3$ during this same embryonic period is also required for the skin hyperpigmentation phenotype obtained in an inducible transgenic mouse (Garcia et al., 2008).

While activation of EDNRB signaling by EDN3 is critical during melanocyte development, adult skin or UV-induced melanogenesis seems to be mostly maintained or induced by the release of EDN1 from keratinocytes (Imokawa et al., 1997, Imokawa et al., 1995, Imokawa et al., 1996). This is further supported by the findings that EDN1 is down regulated in the hypopigmented skin of the palms and soles and upregulated in the hyperpigmented skin of lentigo senilis (Hasegawa et al., 2008, Kadono et al., 2001).

\subsubsection{Disruption of the EDNRB Pathway in Mice and Humans}

Mice with mutations in the Edn3/Ednrb signaling pathway have hypopigmentation defects. The $E d n r b^{s l}$ mutants do not produce Ednrb and, as homozygous, display a white coat color with pigmented spots on the head or rear (Hosoda et al., 1994) (Figure 1.2 C). Additionally, these mice lack the enteric ganglia of the distal colon and develop mega colon causing premature death. The spontaneous lethal spotting $\left(E d n 3^{l s}\right)$ mice, do not produce Edn3 and present with partial loss of 
pigmentation, possibly because of compensation from Edn1(Lane, 1966). Humans carrying mutations in EDNRB or EDN3 present with Waardenburg Syndrome type IV also known as Waardenburg-Shah syndrome $(133,134,135)$. Patients show dystopia canthorum, patchy hypopigmented areas generally in the hair, forehead and chest, and light eyes. (Jabeen et al., 2012). Patients may also have hearing defects, due the lack of melanocytes in the stria vascularis of the inner ear. Most patients also have Hirschsprung disease as a result of the lack of proper innervation of the distal portion of the colon (Pingault et al., 2010). Both heterozygous and homozygous mutants of either EDNRB or EDN3 alleles have been shown to display Waardenburg-Shah syndrome (Attie et al., 1995, Edery et al., 1996). Homozygous mutants have more distinct phenotypes while heterozygous still display some signs of disease, resulting in "not fully recessive-not fully dominant" mutations as described by Jabeen et al. (Jabeen et al., 2012). Missense mutations of EDNRB have also been described in patients with Waardenburg-Shah syndrome, mutations are seen throughout various encoding regions for different components of the receptor (Abe et al., 2000, Puffenberger et al., 1994)

\subsection{Kit Receptor}

\subsubsection{The Kit Receptor Pathway}

Kit signaling is involved in the differentiation, proliferation and survival of a wide variety of cell types during development. These cell types include mast cells, germ cells, interstitial cells and melanocytes (Hou et al., 2000, Kasamatsu et al., 2008, Okayama and Kawakami, 2006, Vincent et al., 1998). Signaling downstream of KIT has also been shown to be associated with the formation of various cancers. KIT is a type III receptor in 
the protein-tyrosine kinase receptor family, which is made up of IX types of receptors (Yarden et al., 1987). It is made up of three components: the extracellular domain made up of five immunoglobulin-like (Ig-like) motifs, the transmembrane portion, and the intracellular domain that contains an ATP and a phosphotransferase region (Qiu et al., 1988, Yarden et al., 1987). The initiation of KIT signaling occurs by the interaction of KITL, also known as Stem Cell Factor, Mast Cell Growth Factor, and Steel Factor with the first Ig-like motif on the extracellular domain of the receptor (Blechman et al., 1993, Copeland et al., 1990, Huang et al., 1990, Lev et al., 1993). KITL is biologically active during development in two isoforms, membrane-anchored and soluble (Anderson et al., 1990, Martin et al., 1990). The cleavage of the mature, membrane-anchored isoform of the post-translated sequence at Ala164 results in the soluble isoform of KITL (Lu et al., 1991). Soluble KITL activates KIT quicker but leads to a faster degradation of the receptor in comparison to the membrane-bound isoform (Miyazawa et al., 1995). Since the membrane-bound isoform maintains signal transduction for a longer period of time, the production of downstream signaling molecules, such as MAPK, occurs more commonly (Hemesath et al., 1998, Kapur et al., 2002).

Binding of KITL to the receptor causes a dimerization and activation of the receptor's tyrosine kinase activity. Autophosphorylation of the receptor allows for signaling proteins containing a Src homology 2 (SH2) domain to bind to the tyrosine residues located on the intracellular domain of the receptor (Ronnstrand, 2004). These proteins lead to the recruitment of RAS, RAF and subsequent activation of the MAPK pathway ultimately leading to the phosphorylation of MITF at Ser73 (Hemesath et al., 1998) (Figure 1.1). 


\subsubsection{Kit Signaling in Melanocyte Development and Pigmentation}

During development, KIT signaling is required for the proper migration, proliferation, differentiation and survival of melanocytes and their precursors (Keshet et al., 1991). Expression of Kit occurs at all developmental stages and into adulthood. In situ hybridization studies in mouse embryos showed the expression of Kit in melanoblasts migrating along the dorsolateral pathway (Guo et al., 1997, Wehrle-Haller et al., 2001). One study had identified a small population of Kit positive cells on the most dorsomedial aspect of the neural tube that subsequently migrate exclusively into the developing dermis and express melanocyte differentiation markers. The presence of these cells indicates that some $\mathrm{NC}$ cells are already committed to the melanocytic fate prior to emigration from the neural tube (Wilson et al., 2004).

KIT signaling plays a role in the migration of melanocyte precursor cells into the dermis, epidermis and hair follicle during mid to late development (Nishikawa et al., 1991, Wehrle-Haller et al., 2001, Yoshida et al., 1996). Transgenic mice that overexpress Kitl in the keratinocytes had increased numbers of melanocytes in the epidermis and displayed hyperpigmentation sites on the footpads and oral epithelium, which do not normally display pigmentation (Kunisada et al., 1998). The administration of functional Kit antibodies during development and postnatally resulted in apoptosis of melanocytes in vivo (Ito et al., 1999).

Not many studies have directly addressed the role of KIT in skin and hair pigmentation but its direct link to MITF regulation would implicate it as an important contributor. The analysis of mouse follicular skin showed an increase in membrane- 
bound Kitl and the application of Kit functional antibody caused reversible hair depigmentation in mouse hairs and human hair organ culture supporting a role for kit signaling in the maintenance of hair follicle pigmentation (Hachiya et al., 2009). As for EDN1, the expressions of KITL and KIT were found to be down regulated in areas of hypopigmented skin in humans such as the palms and soles further suggesting the importance of this pathway in the maintenance of skin pigmentation (Hasegawa et al., 2008). In the pathological condition of dermatofibroma where the overlying skin is hyperpigmented, KITL along with hepatocyte growth factor were found to be overexpressed in the underlying dermis further suggesting the involvement of KITL in pigment production the human skin (Shishido et al., 2001). Exposure to UV leads to enhanced KITL secretion and the consequent increase in pigment production in human melanocytes in vitro and the skin of guinea pigs in vivo (Hachiya et al., 2001). Application of KIT inhibitory antibodies to guinea pig skin prevented the production of pigment.

\subsubsection{Disruption of the Kit Pathway in Mice and Humans}

The Dominant White Spotting $(W)$ and Steel (Sl) loci encode for Kit and Kitl in mice, respectively (Bennett et al., 1998, Huang et al., 1990). There are several alleles that arose spontaneously and are mostly semidominant. Heterozygous mutants have spotting in the trunk area of the coat, while homozygous mice are generally lethal, but those that survive are completely white with black eyes (Figure 1.2 D). These mutants are also anemic and sterile as a consequence of accompanying defects in the red blood cell and

germ cell lineages (Brannan et al., 1991). The Dickie mouse mutant has a 4-kb deletion of 
the sequence encoding for Kitl resulting in a translated protein that only has the extracellular domain of the ligand and blocks the existence of the membrane-bound form (Flanagan et al., 1991). Heterozygous have spotted coats but are fertile while homozygous are completely white and die perinatally.

In humans KIT mutations cause piebaldism (Wasag et al., 2012). Piebaldism is a rare, autosomal dominant disorder that result in the loss of melanocytes in midline areas, resulting in a loss of pigmentation (Spritz, 1997). Areas affected include the medial portion of the forehead, eyebrows, chin, chest, abdomen and the extremities. Some patients with piebaldism also present with deafness because of the lack of melanocytes in the inner ear where they are required for the maintenance of the endochoclear potential (Steel and Barkway, 1989). Most piebald patients carry heterozygous mutations in KIT (158). The site of the mutation in the KIT gene is often associated with the severity of the clinical phenotype. Mild forms of piebaldism have been shown to result from mutations in the extracellular ligand-binding domain while the most severe ones are caused by dominant negative missense mutations in the tyrosine-kinase domain.

Recently, studies have shown that gain of function mutations in the gene encoding KITL result in familial progressive hyperpigmentation and hypopigmentation (FPHH) (Amyere et al., 2011, Wang et al., 2009). The pigmentation disorder FPHH is characterized as hyperpigmentation of melanophages and keratinocytes in the dermis at an early age that becomes progressively darker and larger as aging occurs (Zanardo et al., 2004). Furthermore, FPHH is associated with lentiginosis, hypopigmentation and caféau-lait macules. The hypopigmented macules display limited pigmentation in the basal epidermis with few to no melanophages in the upper dermis. 


\subsection{Interactions Among Signaling Pathways}

The various signaling pathways that regulate pigment production in melanocytes act synergistically in many instances and for the most part, converge on the activation of the transcription factor MITF which in turn is responsible for activation of all the melanogenic genes (Hou and Pavan, 2008) (Figure 1.1). Although MITF is required for the activation of melanogenic genes, this does not mean that pigment production relies exclusively on MITF. Other transcription factors such as $P A X 3$ and $S O X 10$ directly regulate the expression of TYR and its related genes (Jiao et al., 2004, Ludwig et al., 2004, Murisier and Beermann, 2006, Potterf et al., 2001). It is also likely that some of the signaling pathways controlling pigmentation have effects on the melanogenic genes such as post-transcriptional and post-translational modifications that are independent of MITF (Newton et al., 2007). For example, the enzyme diacylglycerol kinase, which phosphorylates diacylglycerol and may act downstream of different hormones and growth factors, seem to have a melanogenic effect by modulating the posttranslational processing of TYR (Kawaguchi et al., 2012).

When specific ligands or receptors are mutated and become dysfunctional, overt effects on skin and/or hair pigmentation are observed underscoring the significant contribution of each individual pathway. Some of these effects can be compensated by the over-activation of a different pathway demonstrating the utilization of common downstream intracellular targets for the generation of a normal pigmentation phenotype. The EDNs and KITL pathways act synergistically on melanocyte proliferation and skin pigmentation. Treatment of cultured human melanocytes with EDN1 and KITL caused 
enhanced activity of RAF-1, MEK and MAPK (Imokawa et al., 2000). The addition of KITL and EDN1 to human skin xenografts on Severe Combined Immunodeficiency (SCID) mice led to a significant increase in melanin content and TYR gene expression when compared to treatment with each factor alone (Sriwiriyanont et al., 2006). The cross talk appears to occur at least partially at the KIT receptor level with its phosphorylation resulting from EDN1 binding to EDNRB (Imokawa et al., 2000). Another possible point of convergence is the activation of RAF by PKC that occurs after the stimulation of melanocytes with EDN1 (Nakajima et al., 2011) and subsequent MITF phosphorylation. The interaction between pathways is further supported by experiments carried out with neural crest explant cultures (Hou et al., 2004). Murine NC cells lacking Ednrb are not capable of producing Tyr positive melanocytes. The addition of Kitl to these Ednrb deficient cells can, however, rescue their capacity to produce Tyr. In vivo, the overexpression of Edn3 or G-proteins associated with Ednrb could partially rescue the complete absence of dermal skin melanocytes and pigmentation observed in mice with Kit mutations (Aoki et al., 2005, Garcia et al., 2008, Van Raamsdonk et al., 2004). The coat, however, remained devoid of melanocytes and pigmentation demonstrating that Edn3 is not capable of promoting the entry of melanocytes in the epidermis and hair follicles.

The activation of cAMP downstream of MC1R and EDNRB is essential for transcriptional regulation of MITF mediated by CREB and pigment production (Bertolotto et al., 1998, Sato-Jin et al., 2008). The convergence between pathways may explain why the over-activation of Edn3 signaling can compensate, at least partially, for the lack of Mc1r signaling in $A^{y}$ mice (Garcia et al., 2008, Kaelin et al., 2012). Since in $A^{y}$ 
mice Mc1r is not defective and the excessive amounts of ASP block the activation of the downstream events, over-expression of Edn3 could lead to increased expression of $\mathrm{Mclr}$ and make more receptors available at the membrane for $\alpha$-msh binding (Scott M. C. et al., 2002). The partial rescue could also be explained by the phosphorylation of Mitf that occurs downstream of Ednrb via the activation of the MEK/ERK pathway (Sato-Jin et al., 2008). The involvement of the latter pathway exclusively does not seem to be sufficient for eumelanin production given that mice deficient in Mc1r signaling crossed to transgenic mice that over-express Kitl do not present with darkened skin (D'Orazio et al., 2006). However, over-activation of downstream components of the KIT pathway such as RAS and RAF do cause hyperpigmented skin in mice (Dhomen et al., 2009, Milagre et al., 2010, Powell et al., 1995) and café-au-lait spots or macules in patients with Rasopathy syndromes such as Noonan, Legius, Leopard and Neurofibromatosis type 1 (Martinez-Quintana and Rodriguez-Gonzalez, 2012, Tartaglia et al., 2011). It is unclear whether hair pigmentation is also affected in the transgenic mice and human patients with altered RAS and RAF activity. It has been proposed that particular subgroups of melanocytes respond differently to signaling molecules (Aoki et al., 2009, Van Raamsdonk et al., 2009) and this maybe another example where the production of eumelanin in hair melanocytes requires higher levels of activation of the cAMP pathway than what is necessary in skin melanocytes.

Furthermore, MC1R interacts with downstream targets of the Wnt signaling pathway by the elevation of cAMP levels. In human melanocytes, it induced the phosphorylation of $\beta$-catenin, the stabilization of $\beta$-catenin protein, and the attenuation of GSK3, further stimulating the activity of $\beta$-catenin in the nucleus where it binds to the 
MITF promoter (Bellei et al., 2011). $\beta$-catenin has also been shown to be a part of pigment type switching regulation by acting upstream of Mc1r (Enshell-Seijffers et al., 2010). In the dermal papilla $\beta$-catenin suppresses ASP expression and activates Corin, a negative regulator of ASP. A loss of function of $\beta$-catenin in the dermal papilla leads to a yellow coat color and its gain of function results in a darkened coat phenotype. In mouse melanocytes, another consequence of the elevation of cAMP levels that occur upon the binding of $\alpha$-Msh to Mc1r is the activation of the MAPK pathway. In human melanocytes and melanoma cells, the MAPK pathway is activated downstream of MC1R independently of changes in cAMP via Src tyrosine kinase-mediate transactivation of KIT (Herraiz et al., 2011). These and other still to be uncovered functional links among the different signaling pathways demonstrate that the production of hair and skin pigmentation is a complex process. Nevertheless, the establishment of a complete picture of the many functional links involved will facilitate the development of optimal strategies for correcting and ameliorating conditions of hypo- and hyperpigmentation.

\subsection{Hair Follicle}

\subsubsection{Hair Follicle Development and Morphology}

During development, the embryonic skin and hair follicles are formed by interactions between various cell types including melanocytes, keratinocytes, Schwann cells, and fibroblasts (Sennett et al., 2015). Once the skin is formed, a series of signaling pathways are activated creating a crosstalk between the epidermis and dermis to form hair follicles. Hair follicle development begins in the mouse at embryonic day (E) 13.5 with the cessation of Bone Morphogenic Protein (Bmp) signaling and the secretion of Wnt from 
the epidermal cells activating Wnt signaling in the dermis (Chen et al., 2012, Huh et al., 2013, Zhang et al., 2009). Simultaneously, dermal cells secrete Ectodysplasin A (Eda) and Fibroblast growth factor 20 (Fgf20) which will activate Eda receptors in the epidermis (Chen et al., 2012, Huh et al., 2013, Zhang et al., 2009). These interactions result in the thickening of the epidermis to produce a placode and the dermal condensate, known as the hair germ, in the dermis. Fate mapping studies have linked the placode to the adult epithelial cells that make up the hair follicle, including hair follicle stem cells (HFSMs) and the dermal condensate to the cells that make up the dermal papilla (DP) (Grisanti et al., 2013, Levy et al., 2005). Further signaling between the placode and dermal condensate, including Sonic hedgehog (Shh), orchestrates the downward growth of the hair follicle by the differentiation of neighboring cells to give rise to structures that make up the hair follicle such as the inner root sheath, outer root sheath and hair matrix (Chiang et al., 1999, Duverger and Morasso, 2014). Melanoblasts populating the outer root sheath and bulge are Kit negative, while Kit positive melanocytes are expressed close to the DP (Peters et al., 2002).

After birth, mouse hair follicles produce four distinct hair types that are predetermined during development depending on the wave of hair placode formation. These four hair types include guard, awl, auchene and zigzag hairs. Zigzag hairs make up about $70 \%$ of hairs in the coat, awl constitute about $30 \%$, and guard and auchene hairs make up less than $1 \%$ of the coat (Duverger and Morasso, 2014).

Developed hair follicles consist of permanent and cycling portions (Figure 1.3). The permanent portion of the hair follicle is the uppermost aspect of the hair follicle including the subbulge and bulge, Isthmus, and the insertions of the arrector pili muscle and 
sebaceous glands (Myung and Ito, 2012, Slominski et al., 2005). The immune privileged bulge and subbulge areas that are located on the basal aspect of the lower permanent portion (LPP) of the hair follicle and provide a stem cell niche for populations of stem cell that are critical for hair growth and regeneration (Nishimura, 2011). These stem cells include melanocytic stem cells (MSCs) that give rise to the melanocytes involved in melanin synthesis and the HFSCs, the keratinocyte stem cells. Together, these cells will reconstitute the hair follicle and produce the hair shaft. The lower, cycled, aspect of the hair follicle consists of the DP, hair bulb, and hair matrix. The hair bulb is the location in which differentiated melanocytes produce pigment that is transferred to keratinocytes to be incorporated in the hair shaft (Greco et al., 2009).

\subsubsection{Hair Cycle}

The fully developed hair follicle undergoes a cyclic regeneration process consisting of a growth phase known as anagen, catagen the regression phase and the resting phase, telogen (Figure 1.4) (Stenn and Paus, 2001). During anagen, keratinocytes will form the cycling portion of the hair follicle and hair shaft, while melanocytes will produce the pigment for the growing hair. Catagen takes place once the hair shaft is grown and consists of programmed apoptosis leading to the regression of the cycling portion of the hair follicle. During telogen, there is quiescence where no activity occurs; in late telogen the hair shaft is shed.

A more detailed description of the various phases of the murine hair cycle was established using C57/B16 mice by Muller-Rover et al. (Muller-Rover et al., 2001). They proposed the following phases: telogen, anagen I-VI and catagen I-VIII (Muller-Rover et 
al., 2001). The increasing length of the hair follicle corresponds to the stages of anagen while decreasing length corresponds to catagen and all stages include changes in hair follicle morphology. During telogen the DP is compact and bell-shaped connected to the secondary hair germ and no inner root sheath (IRS) is present. By The end of telogen, the previous hair shaft is shed and the new club hair remains (Stenn and Paus, 2001).

During anagen I, the hair follicle is encased by the dermis, as it is in late telogen, but there is a thickening of keratinocytes and increased distance between the DP and the club hair (Muller-Rover et al., 2001). Anagen II follows with an enlargement of the DP and an increased keratinocyte numbers make up the developing hair bulb. Anagen III is the longest stage of the hair cycle and is divided into three subgroups. Anagen III begins when the hair bulb surrounds the DP and extends to the border of the dermis. Anagen IIIa is marked by the appearance of melanin and the beginning of the IRS. During anagen IIIb, the hair shaft begins to form and is surrounded by the inner root sheath. In the final stage of anagen III, the IRS and the hair shaft are just below the sebaceous gland. Once the hair shaft and IRS have passed the sebaceous gland and entered the hair canal the hair has reached anagen IV. When the hair shaft has reached the epidermis it is considered to be in anagen $\mathrm{V}$ and when it passes the surface of the skin it enters anagen VI.

Shortly after anagen VI, keratinocytes in the bulb begin to undergo apoptosis beginning catagen I. During catagen II and III, the bulb and DP decrease in size accompanied by a drastic reduction of melanin granules. During catagen IV shortening of the hair follicle occurs along with a thinning of the skin and only the distal portion of the hair follicle is pigmented. During catagen $\mathrm{V}$ the hair follicle length is reduced as it begins to separate from the DP producing the club hair and the secondary germ capsule which 
houses the club hair is made up of the ORS. The secondary germ capsule housing the club hair continues to move distally and the IRS continues to disappear as cells undergo apoptosis during catagen VI. The upward movement of the DP characterizes catagen VII. Lastly, catagen VIII occurs when the club hair and the secondary hair germ are in the dermis and the DP is at the border of the dermis (Muller-Rover et al., 2001).

Depilation of mouse hairs remove the club hair and eliminates the subbulge and cycling portion of the hair follicle (Myung and Ito, 2012). Bulge stem cells are responsible for the regeneration of the stem cell populations in the subbulge and allow for the hair cycle to begin (Stenn and Paus, 2001).

\subsubsection{Stem Cell Niche and Hair Follicle Signaling}

The MSCs and HFSCs are located in the bulge and subbulge region of the hair follicle located in the basal aspect of the lower permanent portion of the hair (Hsu et al., 2014a). Unlike melanocytes found in the skin that have the ability to survive throughout most of a person's life with very little proliferative capacity, the cells in human and mouse hair follicles undergo induced apoptosis during the catagen phase of the hair cycle and are replenished in the hair follicle during the start of the anagen phase by the SCs (Myung and Ito, 2012).

To maintain the SCs in quiescence during catagen and telogen, cells in the inner bulge express Bmp6 and Fgf-18 while fat cells express Bmp2 and dermal fibroblasts express Bmp4 (Hsu et al., 2011, Plikus et al., 2008). The HFSC secrete Tgf- $\beta$, which maintains immaturity and quiescence of MSCs (Nishimura et al., 2010, Tanimura et al., 2011). During late telogen, the subbulge stem cells are taken out of their quiescent state 
and become activated first with stimulation from the DP. The DP secretes activating factors Wnt, Tgf- $\beta$, Fgf-10, Fgf-7 and noggin, a Bmp inhibitor (Greco et al., 2009, Oshimori and Fuchs, 2012). Subbulge HFSCs form the inner root sheath of the hair follicle and initiate hair growth before bulge cells are activated (Greco et al., 2009). Activation of MSCs occurs through the joint expression of Kitl by the DP and Edn1, a ligand for Ednrb downstream of Wnt produced by the DP and both SC populations (Rabbani et al., 2011). Interestingly, ectopic expression of Edn2 prevents melanocyte differentiation by activating Ednra (Chang et al., 2013).

Once activated, MSCs become dependent on Kit signaling. Mice treated with a functional anti-Kit antibody had a depletion of melanocytes in the hair follicles, but not MSCs in the niche and resulted in hair graying seen upon the completion of the hair cycle (Ueno et al., 2014). These results were reversible in the following hair cycle upon removal of inhibitor. Once activated, approximately $50 \%$ of the stem cells enter a state of high proliferation in order to replenish the stem cell pool, giving them their self-renewing properties, and to produce fully differentiated melanocytes and keratinocytes (Ueno et al., 2014). The other $50 \%$ of the stem cells remain in the stem cell niche in a slow-cycling state (Myung and Ito, 2012).

After subbulge cells are activated, the stem cells in the bulge follow. It is thought that signaling from these transient, high proliferating cells from the subbulge are the ones that activate HFSC and MSCs in the bulge area since the DP is continuously growing further from the bulge (Greco et al., 2009, Myung and Ito, 2012). Some studies suggest that signaling of Shh from matrix transient cells may be activating cells in the bulge (Hsu et al., 2014a, 2014b). The HFSCs contribute to the completion of the outer root sheet and 
maintain the matrix to support hair growth (Greco et al., 2009). Upon activation of MSCs, Melanogenic genes Tyr, Trp1, Dct and Pmel17 are up regulated, cells become dendritic and cell division begins.

The progeny of the MSCs can be found throughout the hair follicle during anagen as amelanotic, differentiated melanocytes and semi-differentiated melanocytes (Figure 1.4) (Nishimura, 2011). Amelanotic cells are positive for Gp100/Pmel17 and Mitf but negative for Tyr and Tyrp1 expression and are located in the outer root sheath, around the bulb and in the LPP. These cells share qualities to MSCs and can differentiate into melanocytes. Differentiated melanocytes are located in the basal layer of the ifindulum, around the upper DP and close to the hair matrix (Slominski et al., 2005). A small population of semi-differentiated melanocytes is also found around the sebaceous gland. Around mid-anagen, the MSCs are inactivated and lose their dendricity, become smaller and return to quiescent inactive state in the niche. Decreased Shh signaling results from an increased distance from the progeny cells in matrix is thought to cause the inactivation, although matrix cells continue to secrete Shh which signals to the DP which maintains expression of noggin and Fgf-7 (Hsu et al., 2014b).

Catagen is initiated with an increase in Bmp and expression of other factors (Hsu et al., 2011, Plikus et al., 2008). During catagen, apoptosis of the matrix and lower outer root sheath occurs resulting in the retraction of the hair follicle in which no hair melanocytes remain. During this process, $70 \%$ of the hair follicle is reduced; the cyclic portion, and the DP will sit directly under the hair shaft (Stenn and Paus, 2001). A small population of the less differentiated cells derived from the HFSCs and MSCs survive the programmed apoptosis. As the hair follicle begins to enter the telogen phase, 
keratinocytes form the club hair follicle while entering telogen, which will sit adjacent to the next growing hair (Myung and Ito, 2012).

Interestingly, studies have shown that HFSCs also play a vital role in the maintenance of MSCs. Diminished HFSC populations result in the loss of MSCs in mice with mutations in Col17A1, a hemidesmosomal transmembrane collagen expressed by HFSCs and essential for the their self-renewal (Tanimura et al., 2011). The knockout of Tgf- $\beta$ resulted in mice that displayed $100 \%$ hair graying, which is normally produced by HFSCs in the bulge and subbulge. Furthermore, ionizing radiation (IR) disrupts HFSC and MSC causing graying. Exposure to IR during the anagen phase leads to a delay in the activation and proliferation of the HFSC population in the bulge, resulting in a loss of the MSC pool and a slight graying that was reversed during the next hair cycle (Aoki et al., 2013). Consequently, IR of active MSCs leads to reversible graying, while IR to quiescent MSCs during the catagen or telogen phases, caused early ectopic differentiation of MSCs causing irreversible hair graying (Ueno et al., 2014).

\subsection{Research Questions}

I previously showed that the Edn3 signaling pathway is able to darken the yellow coat color of lethal yellow mice $\left(A^{y}\right)$ (Kaelin et al., 2012). $A^{y}$ mice are spontaneous mouse mutants that overexpress the ASP, disrupting the Mc1r pathway (Ollmann et al., 1998). Edn3/Ednrb signaling is involved in the control of eumelanin production in vivo by activating important pigment producing genes such as Trp1, Dct, Tyr, and Pmel17 in the skin (Kaelin et al., 2012). These results suggest a putative role for Edn3/Ednrb in pigment-type regulation. 
The objective of this study is to understand the involvement of End3/Ednrb signaling in pigment-type regulation. My central hypothesis is that over-activation of the Edn3/Ednrb signaling pathway can bypass the requirement of a functional Mc1r pathway in the production of eumelanin independent of a developmental time requirement through the expression of melanogenic genes. To test this hypothesis I addressed the following questions:

\section{Question 1: What is the effect of $E d n 3$ over-expression on the amounts of eumelanin and pheomelanin in the hairs of $A^{y}$ mice?}

I hypothesized that $E d n 3$ over-expression increases the amount of eumelanin in the hair of $A^{y}$ mice. I quantified eumelanin and pheomelanin in the hair of $A^{y}$ and $A^{y} ; K 5-$ tTA;TRE-Edn3-lacZ mice that over-express $E d n 3$ by high performance liquid chromatography (HPLC). I quantified the number of melanocytes in the hair of $A^{y}$ and $A^{y}$ mice that over-express Edn3 via immunofluorescent antibody staining to establish whether changes in melanin levels are due to increased numbers of melanocytes.

\section{Question 2: What is the effect of $E d n 3$ over-expression in the expression of melanogenic genes in the hair of $A^{y}$ mice?}

I hypothesized that $E d n 3$ over-expression will increase the levels of melanogenic genes in the hair of $A^{y}$ mice. I used qRT-PCR to compare the expression of melanogenic genes in the hair of $A^{y}$ and $A^{y}$ mice that over-express Edn3. 
Question 3: Does Edn3 over-expression in Mc1r mouse mutants rescue a dark pigmentation phenotype?

I hypothesized that $E d n 3$ over-expression will rescue in dark pigmentation phenotype in Mc1r mutants mice. I crossed K5-tTA;TRE-Edn3-lacZ mice with Mc1r $r^{e / e}$ mutants and visualized the phenotypes of the mice.

Question 4: What is the temporal requirement for $E d n 3$ over-expression in the maintenance and rescue of dark hair in $A^{y}$ mice?

I hypothesized that $E d n 3$ over-expression is required and is capable of darkening the hair of $A^{y}$ mice at any time during embryogenesis and adulthood. I manipulated $E d n 3$ transgene expression in $A^{y}$ mice at different time points and evaluated the rescue and maintenance of the coat color. 


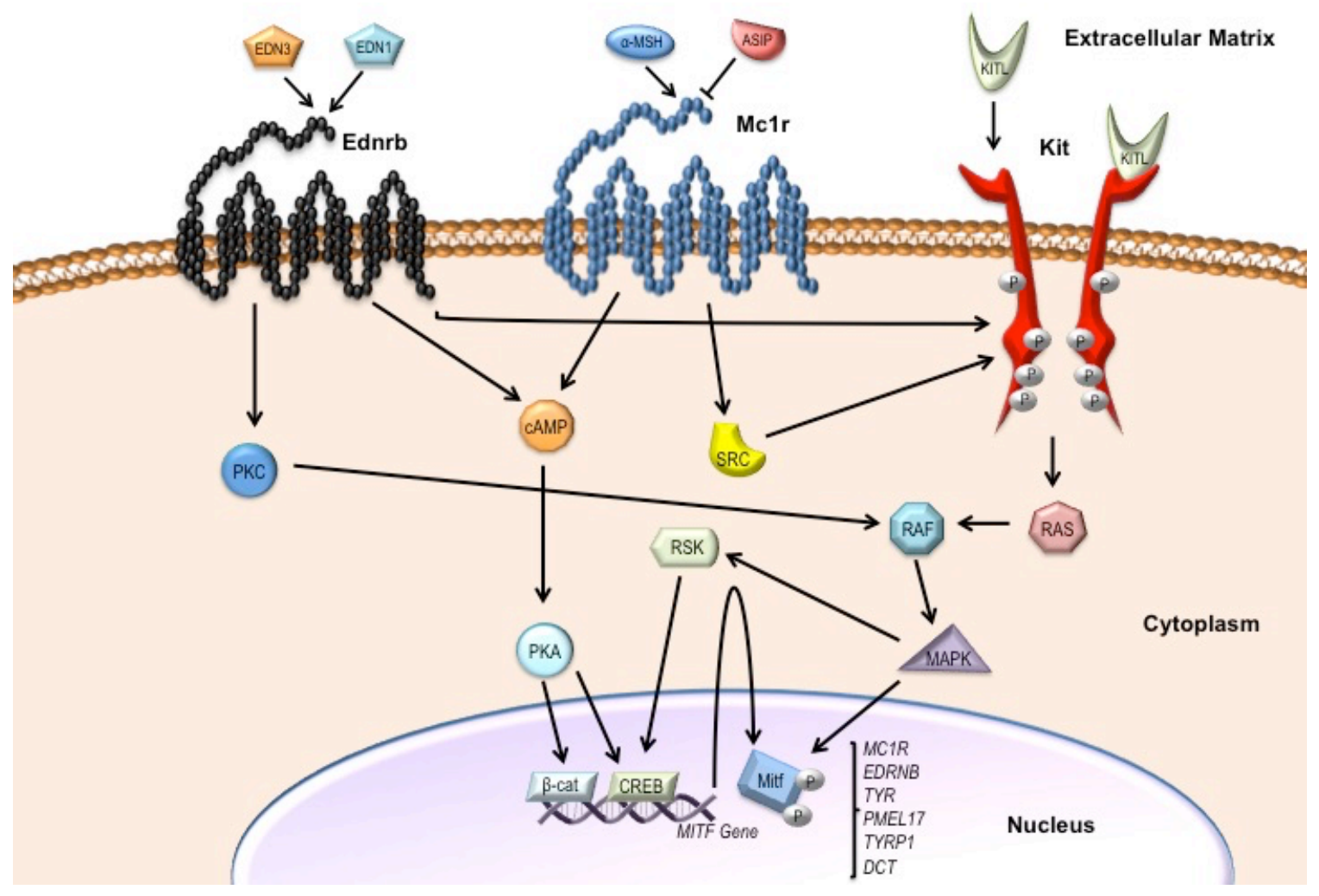

Figure 1.1: MC1R, EDNRB and KIT signaling pathways in melanocytes. Molecular interactions among PKC, PKA and MAPK signaling pathways that converge on the activation of the MITF gene and proteins that leads to the regulation of melanogenic genes and pigment production. 

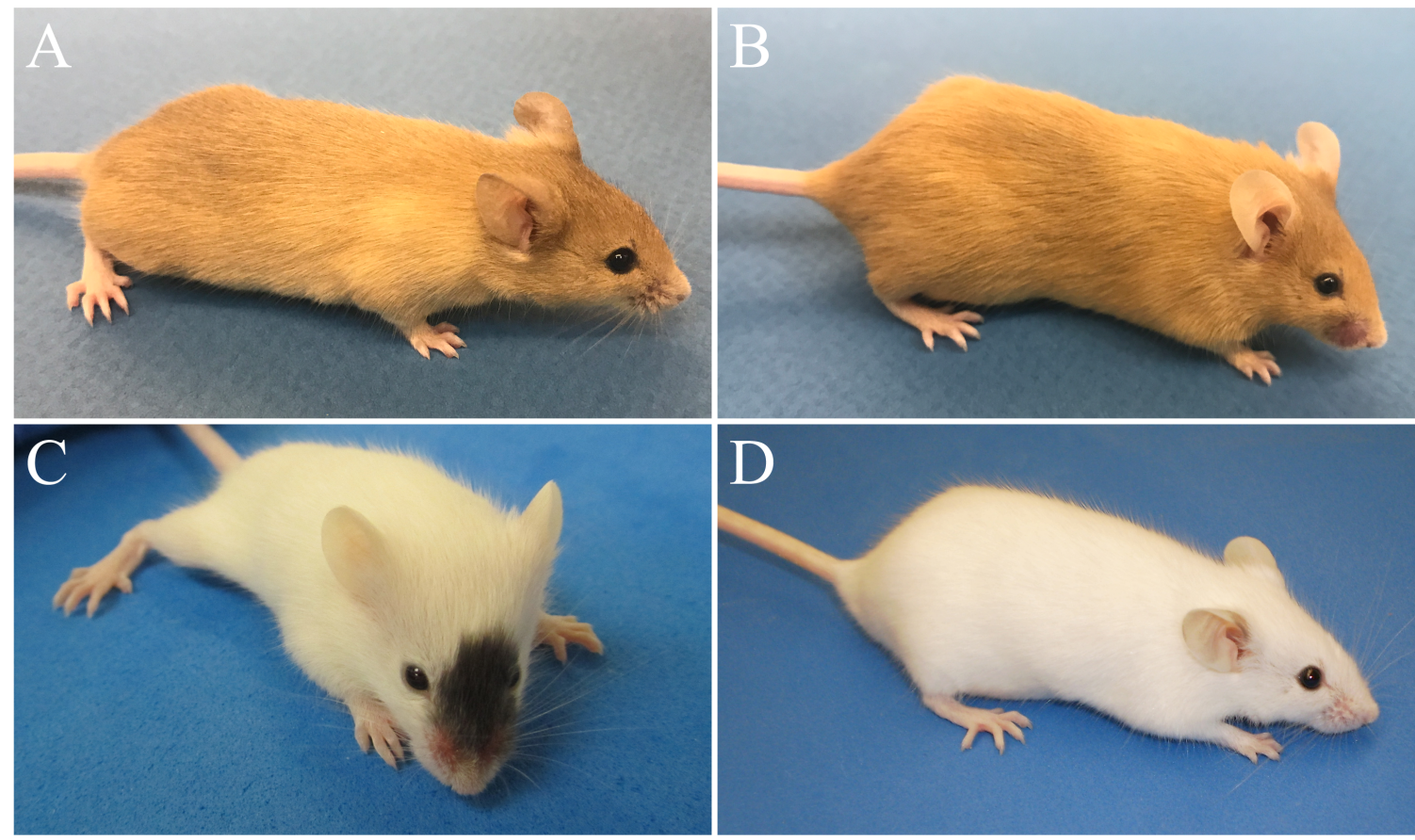

Figure 1.2: Mouse mutants reveal the role of signaling pathways in pigment production. (A) $M c 1 r^{e / e}$ and (B) $A^{y}$ mutant mice display a yellow coat color phenotype due to the inhibition of Mc1r signaling while (C) $E d n r b^{s l / s l}$ and (D) $\mathrm{Kit}^{W v / W v}$ mutants have white coat colors because of improper melanocyte precursor development. 


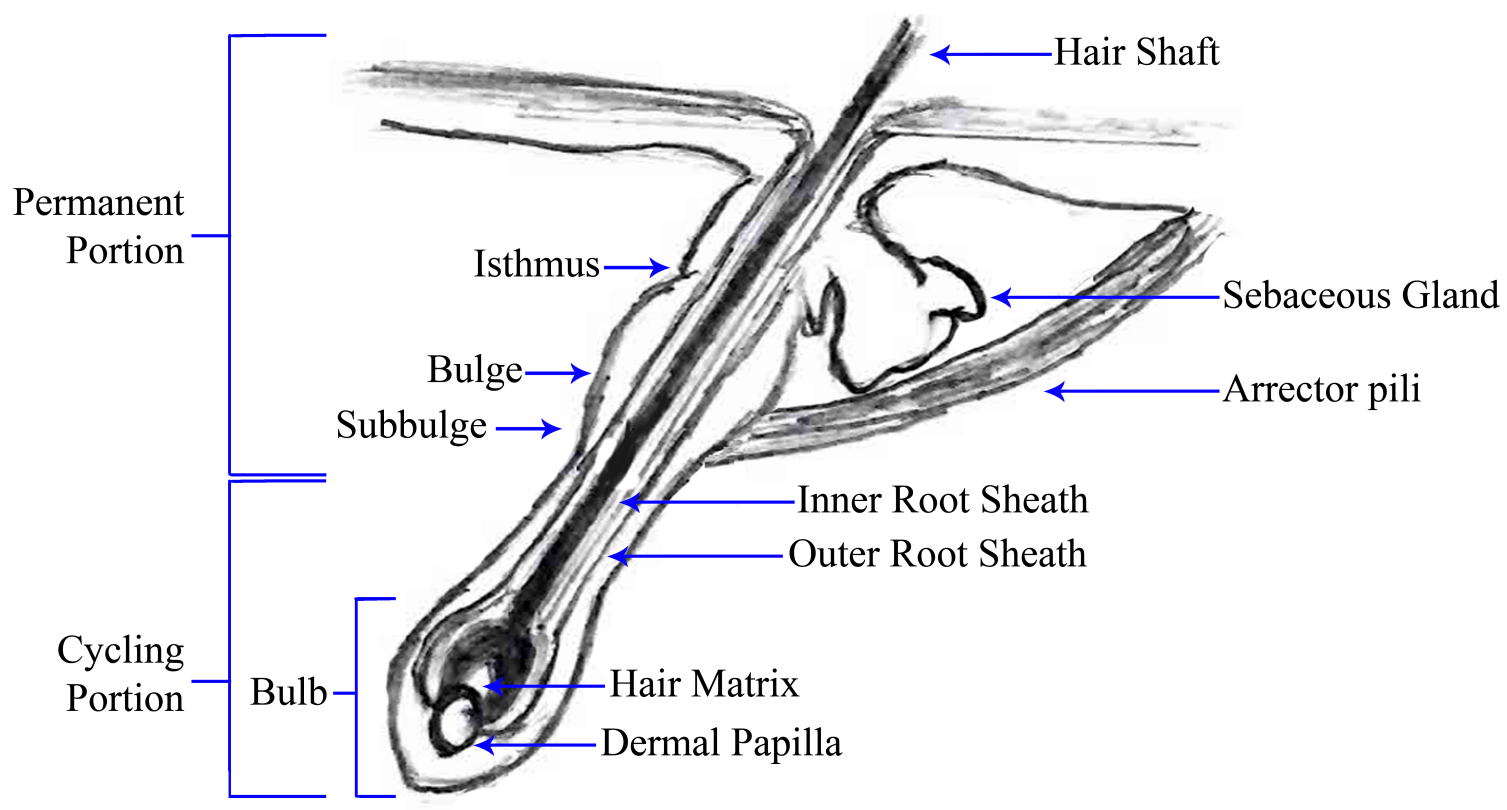

Figure 1.3: Anatomy of the hair follicle. 


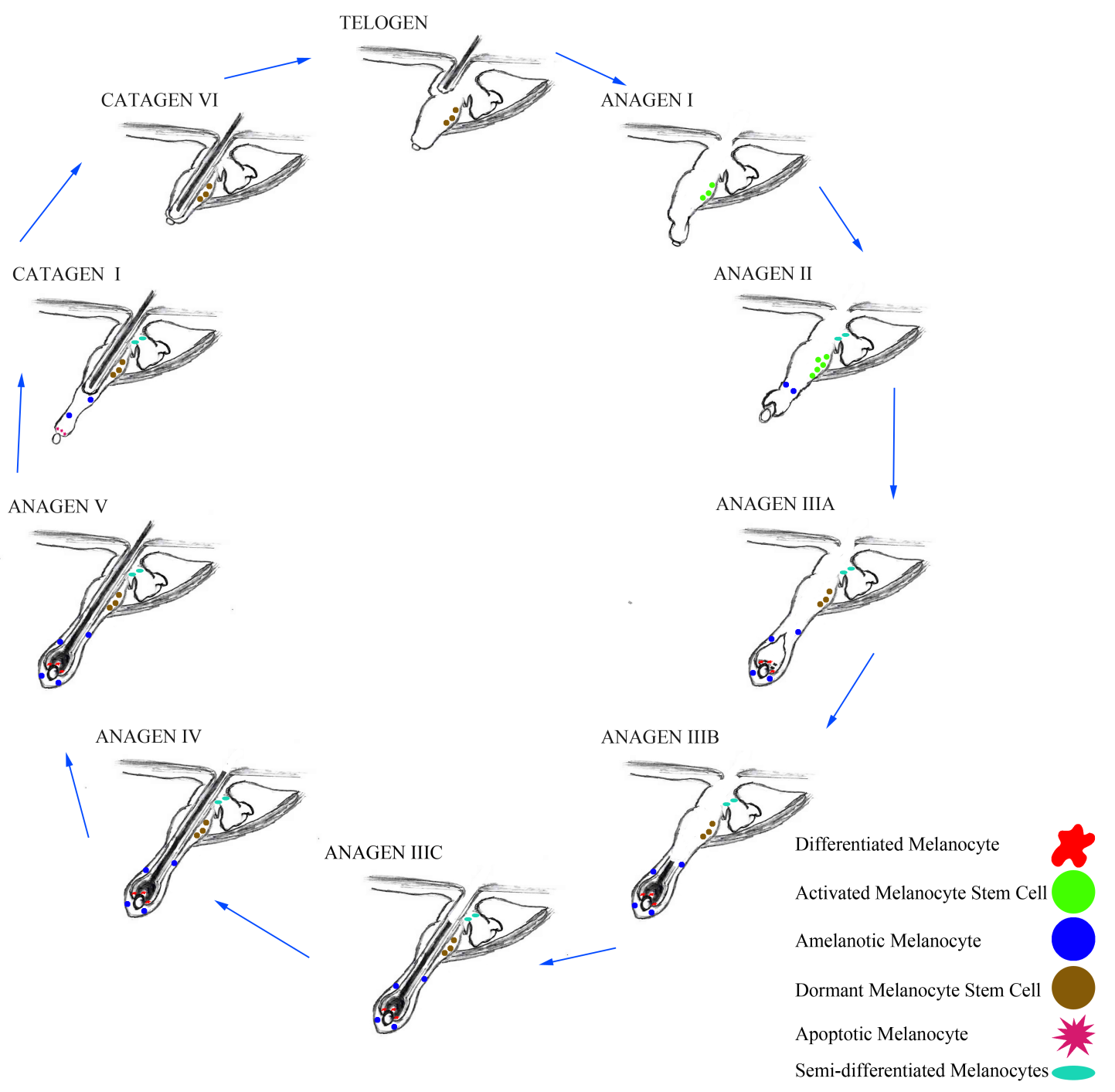

Figure 1.4: Melanocyte lineage during different phases of the hair cycle. 


\subsection{References}

Abdel-Malek Z, Swope VB, Suzuki I, Akcali C, Harriger MD, Boyce ST, et al. Mitogenic and melanogenic stimulation of normal human melanocytes by melanotropic peptides. Proc Natl Acad Sci U S A 1995;92(5):1789-93.

Abdel-Malek ZA, Scott MC, Furumura M, Lamoreux ML, Ollmann M, Barsh GS, et al. The melanocortin 1 receptor is the principal mediator of the effects of agouti signaling protein on mammalian melanocytes. J Cell Sci 2001;114(Pt 5):1019-24.

Abe Y, Sakurai T, Yamada T, Nakamura T, Yanagisawa M, Goto K. Functional analysis of five endothelin-B receptor mutations found in human Hirschsprung disease patients. Biochem Biophys Res Commun 2000;275(2):524-31.

Aberdam E, Bertolotto C, Sviderskaya EV, de Thillot V, Hemesath TJ, Fisher DE, et al. Involvement of microphthalmia in the inhibition of melanocyte lineage differentiation and of melanogenesis by agouti signal protein. J Biol Chem 1998;273(31):19560-5.

Adameyko I, Lallemend F, Aquino JB, Pereira JA, Topilko P, Muller T, et al. Schwann cell precursors from nerve innervation are a cellular origin of melanocytes in skin. Cell 2009;139(2):366-79.

Amyere M, Vogt T, Hoo J, Brandrup F, Bygum A, Boon L, et al. KITLG mutations cause familial progressive hyper- and hypopigmentation. J Invest Dermatol 2011;131(6):1234-9.

Anderson DM, Lyman SD, Baird A, Wignall JM, Eisenman J, Rauch C, et al. Molecular cloning of mast cell growth factor, a hematopoietin that is active in both membrane bound and soluble forms. Cell 1990;63(1):235-43.

Ando H, Niki Y, Ito M, Akiyama K, Matsui MS, Yarosh DB, et al. Melanosomes Are Transferred from Melanocytes to Keratinocytes through the Processes of Packaging, Release, Uptake, and Dispersion. Journal of Investigative Dermatology 2012;132(4):1222-9.

Aoki H, Hara A, Motohashi T, Kunisada T. Keratinocyte stem cells but not melanocyte stem cells are the primary target for radiation-induced hair graying. J Invest Dermatol 2013;133(9):2143-51.

Aoki H, Motohashi T, Yoshimura N, Yamazaki H, Yamane T, Panthier JJ, et al. Cooperative and indispensable roles of endothelin 3 and KIT signalings in melanocyte development. Dev Dyn 2005;233(2):407-17. 
Aoki H, Yamada Y, Hara A, Kunisada T. Two distinct types of mouse melanocyte: differential signaling requirement for the maintenance of non-cutaneous and dermal versus epidermal melanocytes. Development 2009;136(15):2511-21.

Attie T, Till M, Pelet A, Amiel J, Edery P, Boutrand L, et al. Mutation of the endothelinreceptor B gene in Waardenburg-Hirschsprung disease. Hum Mol Genet 1995;4(12):2407-9.

Basrur V, Yang F, Kushimoto T, Higashimoto Y, Yasumoto K, Valencia J, et al. Proteomic analysis of early melanosomes: identification of novel melanosomal proteins. J Proteome Res 2003;2(1):69-79.

Bastiaens MT, ter Huurne JA, Kielich C, Gruis NA, Westendorp RG, Vermeer BJ, et al. Melanocortin-1 receptor gene variants determine the risk of nonmelanoma skin cancer independently of fair skin and red hair. Am J Hum Genet 2001;68(4):88494.

Baynash AG, Hosoda K, Giaid A, Richardson JA, Emoto N, Hammer RE, et al. Interaction of endothelin-3 with endothelin-B receptor is essential for development of epidermal melanocytes and enteric neurons. Cell 1994;79(7):1277-85.

Beaumont KA, Shekar SN, Cook AL, Duffy DL, Sturm RA. Red hair is the null phenotype of MC1R. Hum Mutat 2008;29(8):E88-94.

Bellei B, Pitisci A, Catricala C, Larue L, Picardo M. Wnt/beta-catenin signaling is stimulated by alpha-melanocyte-stimulating hormone in melanoma and melanocyte cells: implication in cell differentiation. Pigment Cell Melanoma Res 2011;24(2):309-25.

Bennett DC, Huszar D, Laipis PJ, Jaenisch R, Jackson IJ. Phenotypic rescue of mutant brown melanocytes by a retrovirus carrying a wild-type tyrosinase-related protein gene. Development 1990;110(2):471-5.

Bennett DC, Trayner ID, Piao X, Easty DJ, Kluppel M, Alexander WS, et al. recessive spotting: a linked locus that interacts with W/Kit but is not allelic. Genes Cells 1998;3(4):235-44.

Bertolotto C, Abbe P, Hemesath TJ, Bille K, Fisher DE, Ortonne JP, et al. Microphthalmia gene product as a signal transducer in cAMP-induced differentiation of melanocytes. J Cell Biol 1998;142(3):827-35.

Biniek K, Levi K, Dauskardt RH. Solar UV radiation reduces the barrier function of human skin. Proc Natl Acad Sci U S A 2012;109(42):17111-6. 
Blechman JM, Lev S, Brizzi MF, Leitner O, Pegoraro L, Givol D, et al. Soluble c-kit proteins and antireceptor monoclonal antibodies confine the binding site of the stem cell factor. J Biol Chem 1993;268(6):4399-406.

Bondurand N, Kobetz A, Pingault V, Lemort N, Encha-Razavi F, Couly G, et al. Expression of the SOX10 gene during human development. FEBS Lett 1998;432(3):168-72.

Box NF, Wyeth JR, O'Gorman LE, Martin NG, Sturm RA. Characterization of melanocyte stimulating hormone receptor variant alleles in twins with red hair. Hum Mol Genet 1997;6(11):1891-7.

Brannan CI, Lyman SD, Williams DE, Eisenman J, Anderson DM, Cosman D, et al. Steel-Dickie mutation encodes a c-kit ligand lacking transmembrane and cytoplasmic domains. Proc Natl Acad Sci U S A 1991;88(11):4671-4.

Brito FC, Kos L. Timeline and distribution of melanocyte precursors in the mouse heart. Pigment Cell Melanoma Res 2008;21(4):464-70.

Bultman SJ, Michaud EJ, Woychik RP. Molecular characterization of the mouse agouti locus. Cell 1992;71(7):1195-204.

Burchill SA, Ito S, Thody AJ. Tyrosinase expression and its relationship to eumelanin and phaeomelanin synthesis in human hair follicles. J Dermatol Sci 1991;2(4):281-6.

Burchill SA, Thody AJ, Ito S. Melanocyte-stimulating hormone, tyrosinase activity and the regulation of eumelanogenesis and phaeomelanogenesis in the hair follicular melanocytes of the mouse. J Endocrinol 1986;109(1):15-21.

Cable J, Steel KP. Identification of two types of melanocyte within the stria vascularis of the mouse inner ear. Pigment Cell Res 1991;4(2):87-101.

Candille SI, Kaelin CB, Cattanach BM, Yu B, Thompson DA, Nix MA, et al. A -defensin mutation causes black coat color in domestic dogs. Science 2007;318(5855):141823.

Chang CY, Pasolli HA, Giannopoulou EG, Guasch G, Gronostajski RM, Elemento O, et al. NFIB is a governor of epithelial-melanocyte stem cell behaviour in a shared niche. Nature 2013;495(7439):98-102. 
Chen D, Jarrell A, Guo C, Lang R, Atit R. Dermal beta-catenin activity in response to epidermal Wnt ligands is required for fibroblast proliferation and hair follicle initiation. Development 2012;139(8):1522-33.

Chiang C, Swan RZ, Grachtchouk M, Bolinger M, Litingtung Y, Robertson EK, et al. Essential role for Sonic hedgehog during hair follicle morphogenesis. Dev Biol 1999;205(1):1-9.

Coker DJ, Pratchett MS, Munday PL. Coral bleaching and habitat degradation increase susceptibility to predation for coral-dwelling fishes. Behavioral Ecology 2009;20(6):1204-10.

Colyer CL, Kinkade CS, Viskari PJ, Landers JP. Analysis of cyanobacterial pigments and proteins by electrophoretic and chromatographic methods. Anal Bioanal Chem 2005;382(3):559-69.

Cooper CD, Raible DW. Mechanisms for reaching the differentiated state: Insights from neural crest-derived melanocytes. Semin Cell Dev Biol 2009;20(1):105-10.

Copeland NG, Gilbert DJ, Cho BC, Donovan PJ, Jenkins NA, Cosman D, et al. Mast cell growth factor maps near the steel locus on mouse chromosome 10 and is deleted in a number of steel alleles. Cell 1990;63(1):175-83.

Corre S, Primot A, Sviderskaya E, Bennett DC, Vaulont S, Goding CR, et al. UVinduced expression of key component of the tanning process, the POMC and MC1R genes, is dependent on the p-38-activated upstream stimulating factor-1 (USF-1). J Biol Chem 2004;279(49):51226-33.

Costin GE, Valencia JC, Wakamatsu K, Ito S, Solano F, Milac AL, et al. Mutations in dopachrome tautomerase (Dct) affect eumelanin/pheomelanin synthesis, but do not affect intracellular trafficking of the mutant protein. Biochem $\mathrm{J} 2005 ; 391(\mathrm{Pt}$ 2):249-59.

d'Ischia M, Wakamatsu K, Cicoira F, Di Mauro E, Garcia-Borron JC, Commo S, et al. Melanins and melanogenesis: from pigment cells to human health and technological applications. Pigment Cell Melanoma Res 2015;28(5):520-44.

D'Orazio JA, Nobuhisa T, Cui R, Arya M, Spry M, Wakamatsu K, et al. Topical drug rescue strategy and skin protection based on the role of Mc1r in UV-induced tanning. Nature 2006;443(7109):340-4.

Dhomen N, Reis-Filho JS, da Rocha Dias S, Hayward R, Savage K, Delmas V, et al. Oncogenic Braf induces melanocyte senescence and melanoma in mice. Cancer Cell 2009;15(4):294-303. 
Dickies MM. A new viable yellow mutation in the house mouse. J Hered 1962;53:84-6.

Donatien PD, Hunt G, Pieron C, Lunec J, Taieb A, Thody AJ. The expression of functional MSH receptors on cultured human melanocytes. Arch Dermatol Res 1992;284(7):424-6.

Duverger O, Morasso MI. To grow or not to grow: hair morphogenesis and human genetic hair disorders. Semin Cell Dev Biol 2014;25-26:22-33.

Edery P, Attie T, Amiel J, Pelet A, Eng C, Hofstra RM, et al. Mutation of the endothelin3 gene in the Waardenburg-Hirschsprung disease (Shah-Waardenburg syndrome). Nat Genet 1996;12(4):442-4.

Emoto N, Yanagisawa M. Endothelin-converting enzyme-2 is a membrane-bound, phosphoramidon-sensitive metalloprotease with acidic $\mathrm{pH}$ optimum. J Biol Chem 1995;270(25):15262-8.

Enshell-Seijffers D, Lindon C, Wu E, Taketo MM, Morgan BA. Beta-catenin activity in the dermal papilla of the hair follicle regulates pigment-type switching. Proc Natl Acad Sci U S A 2010;107(50):21564-9.

Farooqui JZ, Medrano EE, Abdel-Malek Z, Nordlund J. The expression of proopiomelanocortin and various POMC-derived peptides in mouse and human skin. Ann N Y Acad Sci 1993;680:508-10.

Flanagan JG, Chan DC, Leder P. Transmembrane form of the kit ligand growth factor is determined by alternative splicing and is missing in the Sld mutant. Cell 1991;64(5):1025-35.

Flanagan N, Healy E, Ray A, Philips S, Todd C, Jackson IJ, et al. Pleiotropic effects of the melanocortin 1 receptor (MC1R) gene on human pigmentation. Hum Mol Genet 2000;9(17):2531-7.

Foster M. Non-enzymatic oxidation of tyrosine and dopa. Proc Natl Acad Sci U S A 1950;36(11):606-11.

Friedmann PS, Gilchrest BA. Ultraviolet radiation directly induces pigment production by cultured human melanocytes. J Cell Physiol 1987;133(1):88-94.

Fuller BB, Lunsford JB, Iman DS. Alpha-melanocyte-stimulating hormone regulation of tyrosinase in Cloudman S-91 mouse melanoma cell cultures. J Biol Chem 1987;262(9):4024-33. 
Furumura M, Sakai C, Abdel-Malek Z, Barsh GS, Hearing VJ. The interaction of agouti signal protein and melanocyte stimulating hormone to regulate melanin formation in mammals. Pigment Cell Res 1996;9(4):191-203.

Gantz I, Fong TM. The melanocortin system. Am J Physiol Endocrinol Metab 2003;284(3):E468-74.

Garcia RJ, Ittah A, Mirabal S, Figueroa J, Lopez L, Glick AB, et al. Endothelin 3 induces skin pigmentation in a keratin-driven inducible mouse model. J Invest Dermatol 2008;128(1):131-42.

Garcia-Borron JC, Sanchez-Laorden BL, Jimenez-Cervantes C. Melanocortin-1 receptor structure and functional regulation. Pigment Cell Res 2005;18(6):393-410.

Giebel LB, Spritz RA. Mutation of the KIT (mast/stem cell growth factor receptor) protooncogene in human piebaldism. Proc Natl Acad Sci U S A 1991;88(19):8696-9.

Greco V, Chen T, Rendl M, Schober M, Pasolli HA, Stokes N, et al. A two-step mechanism for stem cell activation during hair regeneration. Cell Stem Cell 2009;4(2):155-69.

Grisanti L, Clavel C, Cai X, Rezza A, Tsai SY, Sennett R, et al. Tbx 18 targets dermal condensates for labeling, isolation, and gene ablation during embryonic hair follicle formation. J Invest Dermatol 2013;133(2):344-53.

Grotewold E. The genetics and biochemistry of floral pigments. Annu Rev Plant Biol 2006;57:761-80.

Gunn TM, Inui T, Kitada K, Ito S, Wakamatsu K, He L, et al. Molecular and phenotypic analysis of Attractin mutant mice. Genetics 2001;158(4):1683-95.

Gunn TM, Miller KA, He L, Hyman RW, Davis RW, Azarani A, et al. The mouse mahogany locus encodes a transmembrane form of human attractin. Nature 1999;398(6723):152-6.

Guo CS, Wehrle-Haller B, Rossi J, Ciment G. Autocrine regulation of neural crest cell development by steel factor. Developmental Biology 1997;184(1):61-9.

Guyonneau L, Murisier F, Rossier A, Moulin A, Beermann F. Melanocytes and pigmentation are affected in dopachrome tautomerase knockout mice. Mol Cell Biol 2004;24(8):3396-403. 
Hachiya A, Kobayashi A, Ohuchi A, Takema Y, Imokawa G. The paracrine role of stem cell factor/c-kit signaling in the activation of human melanocytes in ultraviolet-Binduced pigmentation. J Invest Dermatol 2001;116(4):578-86.

Hachiya A, Sriwiriyanont P, Kobayashi T, Nagasawa A, Yoshida H, Ohuchi A, et al. Stem cell factor-KIT signalling plays a pivotal role in regulating pigmentation in mammalian hair. J Pathol 2009;218(1):30-9.

Halaban R, Pomerantz SH, Marshall S, Lerner AB. Tyrosinase activity and abundance in Cloudman melanoma cells. Arch Biochem Biophys 1984;230(1):383-7.

Hasegawa J, Goto Y, Murata H, Takata M, Saida T, Imokawa G. Downregulated melanogenic paracrine cytokine linkages in hypopigmented palmoplantar skin. Pigment Cell Melanoma Res 2008;21(6):687-99.

Hauschka TS, Jacobs BB, Holdridge BA. Recessive yellow and its interaction with belted in the mouse. J Hered 1968;59(6):339-41.

He L, Eldridge AG, Jackson PK, Gunn TM, Barsh GS. Accessory proteins for melanocortin signaling: attractin and mahogunin. Ann N Y Acad Sci 2003;994:288-98.

He L, Gunn TM, Bouley DM, Lu XY, Watson SJ, Schlossman SF, et al. A biochemical function for attractin in agouti-induced pigmentation and obesity. Nat Genet 2001;27(1):40-7.

Hearing VJ. Biogenesis of pigment granules: a sensitive way to regulate melanocyte function. J Dermatol Sci 2005;37(1):3-14.

Hearing VJ. Determination of melanin synthetic pathways. J Invest Dermatol 2011;131(E1):E8-E11.

Hemesath TJ, Price ER, Takemoto C, Badalian T, Fisher DE. MAP kinase links the transcription factor Microphthalmia to c-Kit signalling in melanocytes. Nature 1998;391(6664):298-301.

Henion PD, Weston JA. Timing and pattern of cell fate restrictions in the neural crest lineage. Development 1997;124(21):4351-9.

Herraiz C, Journe F, Abdel-Malek Z, Ghanem G, Jimenez-Cervantes C, Garcia-Borron JC. Signaling from the human melanocortin 1 receptor to ERK1 and ERK2 mitogen-activated protein kinases involves transactivation of cKIT. Mol Endocrinol 2011;25(1):138-56.

Hill GE. Female House Finches Prefer Colorful Males - Sexual Selection for a ConditionDependent Trait. Anim Behav 1990;40:563-72. 
Hirobe T. How are proliferation and differentiation of melanocytes regulated? Pigment Cell Melanoma Res 2011;24(3):462-78.

Holick MF. Sunlight and vitamin D for bone health and prevention of autoimmune diseases, cancers, and cardiovascular disease. Am J Clin Nutr 2004;80(6 Suppl):1678S-88S.

Hosoda K, Hammer RE, Richardson JA, Baynash AG, Cheung JC, Giaid A, et al. Targeted and natural (piebald-lethal) mutations of endothelin-B receptor gene produce megacolon associated with spotted coat color in mice. Cell 1994;79(7):1267-76.

Hosoda K, Nakao K, Hiroshi A, Suga S, Ogawa Y, Mukoyama M, et al. Cloning and expression of human endothelin-1 receptor cDNA. FEBS Lett 1991;287(1-2):236.

Hou L, Panthier JJ, Arnheiter H. Signaling and transcriptional regulation in the neural crest-derived melanocyte lineage: interactions between KIT and MITF. Development 2000;127(24):5379-89.

Hou L, Pavan WJ. Transcriptional and signaling regulation in neural crest stem cellderived melanocyte development: do all roads lead to Mitf? Cell Res 2008;18(12):1163-76.

Hou L, Pavan WJ, Shin MK, Arnheiter H. Cell-autonomous and cell non-autonomous signaling through endothelin receptor B during melanocyte development. Development 2004;131(14):3239-47.

Hsu YC, Li L, Fuchs E. Emerging interactions between skin stem cells and their niches. Nat Med 2014a;20(8):847-56.

Hsu YC, Li L, Fuchs E. Transit-amplifying cells orchestrate stem cell activity and tissue regeneration. Cell 2014b;157(4):935-49.

Hsu YC, Pasolli HA, Fuchs E. Dynamics between stem cells, niche, and progeny in the hair follicle. Cell 2011;144(1):92-105.

Huang E, Nocka K, Beier DR, Chu TY, Buck J, Lahm HW, et al. The hematopoietic growth factor $\mathrm{KL}$ is encoded by the $\mathrm{Sl}$ locus and is the ligand of the c-kit receptor, the gene product of the W locus. Cell 1990;63(1):225-33.

Huh SH, Narhi K, Lindfors PH, Haara O, Yang L, Ornitz DM, et al. Fgf20 governs formation of primary and secondary dermal condensations in developing hair follicles. Genes Dev 2013;27(4):450-8. 
Hunt G, Kyne S, Ito S, Wakamatsu K, Todd C, Thody A. Eumelanin and phaeomelanin contents of human epidermis and cultured melanocytes. Pigment Cell Res 1995;8(4):202-8.

Imokawa G, Kobayashi T, Miyagishi M, Higashi K, Yada Y. The role of endothelin-1 in epidermal hyperpigmentation and signaling mechanisms of mitogenesis and melanogenesis. Pigment Cell Res 1997;10(4):218-28.

Imokawa G, Kobayasi T, Miyagishi M. Intracellular signaling mechanisms leading to synergistic effects of endothelin-1 and stem cell factor on proliferation of cultured human melanocytes. Cross-talk via trans-activation of the tyrosine kinase c-kit receptor. J Biol Chem 2000;275(43):33321-8.

Imokawa G, Miyagishi M, Yada Y. Endothelin-1 as a new melanogen: coordinated expression of its gene and the tyrosinase gene in UVB-exposed human epidermis. J Invest Dermatol 1995;105(1):32-7.

Imokawa G, Yada Y, Kimura M. Signalling mechanisms of endothelin-induced mitogenesis and melanogenesis in human melanocytes. Biochem J 1996;314 ( Pt 1):305-12.

Ito M, Kawa Y, Ono H, Okura M, Baba T, Kubota Y, et al. Removal of stem cell factor or addition of monoclonal anti-c-KIT antibody induces apoptosis in murine melanocyte precursors. J Invest Dermatol 1999;112(5):796-801.

Jabeen R, Babar ME, Ahmad J, Awan AR. Novel mutations of endothelin-B receptor gene in Pakistani patients with Waardenburg syndrome. Molecular Biology Reports 2012;39(1):785-8.

Jackson IJ. A cDNA encoding tyrosinase-related protein maps to the brown locus in mouse. Proc Natl Acad Sci U S A 1988;85(12):4392-6.

Jackson IJ, Chambers DM, Tsukamoto K, Copeland NG, Gilbert DJ, Jenkins NA, et al. A second tyrosinase-related protein, TRP-2, maps to and is mutated at the mouse slaty locus. EMBO J 1992;11(2):527-35.

Janssen YM, Van Houten B, Borm PJ, Mossman BT. Cell and tissue responses to oxidative damage. Lab Invest 1993;69(3):261-74.

Jiao Z, Mollaaghababa R, Pavan WJ, Antonellis A, Green ED, Hornyak TJ. Direct interaction of Sox 10 with the promoter of murine Dopachrome Tautomerase (Dct) and synergistic activation of Dct expression with Mitf. Pigment Cell Res 2004;17(4):352-62. 
Kadono S, Manaka I, Kawashima M, Kobayashi T, Imokawa G. The role of the epidermal endothelin cascade in the hyperpigmentation mechanism of lentigo senilis. J Invest Dermatol 2001;116(4):571-7.

Kaelin CB, Xu X, Hong LZ, David VA, McGowan KA, Schmidt-Kuntzel A, et al. Specifying and sustaining pigmentation patterns in domestic and wild cats. Science 2012;337(6101):1536-41.

Kaidbey KH, Agin PP, Sayre RM, Kligman AM. Photoprotection by melanin--a comparison of black and Caucasian skin. J Am Acad Dermatol 1979;1(3):249-60.

Kanetsky PA, Swoyer J, Panossian S, Holmes R, Guerry D, Rebbeck TR. A polymorphism in the agouti signaling protein gene is associated with human pigmentation. Am J Hum Genet 2002;70(3):770-5.

Kapur R, Chandra S, Cooper R, McCarthy J, Williams DA. Role of p38 and ERK MAP kinase in proliferation of erythroid progenitors in response to stimulation by soluble and membrane isoforms of stem cell factor. Blood 2002;100(4):1287-93.

Kasamatsu S, Hachiya A, Higuchi K, Ohuchi A, Kitahara T, Boissy RE. Production of the soluble form of KIT, s-KIT, abolishes stem cell factor-induced melanogenesis in human melanocytes. J Invest Dermatol 2008;128(7):1763-72.

Kawaguchi M, Valencia JC, Namiki T, Suzuki T, Hearing VJ. Diacylglycerol kinase regulates tyrosinase expression and function in human melanocytes. J Invest Dermatol 2012;132(12):2791-9.

Kennedy C, ter Huurne J, Berkhout M, Gruis N, Bastiaens M, Bergman W, et al. Melanocortin 1 receptor (MC1R) gene variants are associated with an increased risk for cutaneous melanoma which is largely independent of skin type and hair color. J Invest Dermatol 2001;117(2):294-300.

Keshet E, Lyman SD, Williams DE, Anderson DM, Jenkins NA, Copeland NG, et al. Embryonic RNA expression patterns of the c-kit receptor and its cognate ligand suggest multiple functional roles in mouse development. EMBO J 1991;10(9):2425-35.

Klebig ML, Wilkinson JE, Geisler JG, Woychik RP. Ectopic expression of the agouti gene in transgenic mice causes obesity, features of type II diabetes, and yellow fur. Proc Natl Acad Sci U S A 1995;92(11):4728-32.

Kobayashi N, Nakagawa A, Muramatsu T, Yamashina Y, Shirai T, Hashimoto MW, et al. Supranuclear melanin caps reduce ultraviolet induced DNA photoproducts in human epidermis. J Invest Dermatol 1998;110(5):806-10. 
Korner A, Pawelek J. Mammalian tyrosinase catalyzes three reactions in the biosynthesis of melanin. Science 1982;217(4565):1163-5.

Kunisada T, Yoshida H, Yamazaki H, Miyamoto A, Hemmi H, Nishimura E, et al. Transgene expression of steel factor in the basal layer of epidermis promotes survival, proliferation, differentiation and migration of melanocyte precursors. Development 1998;125(15):2915-23.

Kushimoto T, Basrur V, Valencia J, Matsunaga J, Vieira WD, Ferrans VJ, et al. A model for melanosome biogenesis based on the purification and analysis of early melanosomes. Proc Natl Acad Sci U S A 2001;98(19):10698-703.

Kuzumaki T, Matsuda A, Wakamatsu K, Ito S, Ishikawa K. Eumelanin biosynthesis is regulated by coordinate expression of tyrosinase and tyrosinase-related protein-1 genes. Exp Cell Res 1993;207(1):33-40.

Land EJ, Ito S, Wakamatsu K, Riley PA. Rate constants for the first two chemical steps of eumelanogenesis. Pigment Cell Res 2003;16(5):487-93.

Lane PW. Association of megacolon with two recessive spotting genes in the mouse. J Hered 1966;57(1):29-31.

Le Pape E, Wakamatsu K, Ito S, Wolber R, Hearing VJ. Regulation of eumelanin/pheomelanin synthesis and visible pigmentation in melanocytes by ligands of the melanocortin 1 receptor. Pigment Cell Melanoma Res 2008;21(4):477-86.

Lee HO, Levorse JM, Shin MK. The endothelin receptor-B is required for the migration of neural crest-derived melanocyte and enteric neuron precursors. Dev Biol 2003;259(1):162-75.

Lev S, Blechman J, Nishikawa S, Givol D, Yarden Y. Interspecies molecular chimeras of kit help define the binding site of the stem cell factor. Mol Cell Biol 1993;13(4):2224-34.

Levy V, Lindon C, Harfe BD, Morgan BA. Distinct stem cell populations regenerate the follicle and interfollicular epidermis. Dev Cell 2005;9(6):855-61.

Lin HY, Kaji EH, Winkel GK, Ives HE, Lodish HF. Cloning and functional expression of a vascular smooth muscle endothelin 1 receptor. Proc Natl Acad Sci U S A 1991;88(8):3185-9.

Lu D, Willard D, Patel IR, Kadwell S, Overton L, Kost T, et al. Agouti protein is an antagonist of the melanocyte-stimulating-hormone receptor. Nature 1994;371(6500):799-802. 
Lu HS, Clogston CL, Wypych J, Fausset PR, Lauren S, Mendiaz EA, et al. Amino acid sequence and post-translational modification of stem cell factor isolated from buffalo rat liver cell-conditioned medium. J Biol Chem 1991;266(13):8102-7.

Ludwig A, Rehberg S, Wegner M. Melanocyte-specific expression of dopachrome tautomerase is dependent on synergistic gene activation by the Sox 10 and Mitf transcription factors. FEBS Lett 2004;556(1-3):236-44.

Maan ME, Cummings ME. Poison Frog Colors Are Honest Signals of Toxicity, Particularly for Bird Predators. American Naturalist 2012;179(1):E1-E14.

Manaka L, Kadono S, Kawashima M, Kobayashi T, Imokawa G. The mechanism of hyperpigmentation in seborrhoeic keratosis involves the high expression of endothelin-converting enzyme-1alpha and TNF-alpha, which stimulate secretion of endothelin 1. Br J Dermatol 2001;145(6):895-903.

Marks MS, Seabra MC. The melanosome: membrane dynamics in black and white. Nat Rev Mol Cell Biol 2001;2(10):738-48.

Martin FH, Suggs SV, Langley KE, Lu HS, Ting J, Okino KH, et al. Primary structure and functional expression of rat and human stem cell factor DNAs. Cell 1990;63(1):203-11.

Martinez-Quintana E, Rodriguez-Gonzalez F. LEOPARD Syndrome: Clinical Features and Gene Mutations. Mol Syndromol 2012;3(4):145-57.

Michaud EJ, Bultman SJ, Stubbs LJ, Woychik RP. The embryonic lethality of homozygous lethal yellow mice (Ay/Ay) is associated with the disruption of a novel RNA-binding protein. Genes Dev 1993;7(7A):1203-13.

Milagre C, Dhomen N, Geyer FC, Hayward R, Lambros M, Reis-Filho JS, et al. A mouse model of melanoma driven by oncogenic KRAS. Cancer Res 2010;70(13):554957.

Miller MW, Duhl DM, Vrieling H, Cordes SP, Ollmann MM, Winkes BM, et al. Cloning of the mouse agouti gene predicts a secreted protein ubiquitously expressed in mice carrying the lethal yellow mutation. Genes Dev 1993;7(3):454-67.

Miyazawa K, Williams DA, Gotoh A, Nishimaki J, Broxmeyer HE, Toyama K. Membrane-bound Steel factor induces more persistent tyrosine kinase activation and longer life span of c-kit gene-encoded protein than its soluble form. Blood 1995;85(3):641-9. 
Muller-Rover S, Handjiski B, van der Veen C, Eichmuller S, Foitzik K, McKay IA, et al. A comprehensive guide for the accurate classification of murine hair follicles in distinct hair cycle stages. J Invest Dermatol 2001;117(1):3-15.

Murisier F, Beermann F. Genetics of pigment cells: lessons from the tyrosinase gene family. Histol Histopathol 2006;21(5):567-78.

Murphy G, Young AR, Wulf HC, Kulms D, Schwarz T. The molecular determinants of sunburn cell formation. Exp Dermatol 2001;10(3):155-60.

Myung P, Ito M. Dissecting the bulge in hair regeneration. J Clin Invest 2012;122(2):448-54.

Nakajima H, Wakabayashi Y, Wakamatsu K, Imokawa G. An Extract of Withania somnifera Attenuates Endothelin-1-stimulated Pigmentation in Human Epidermal Equivalents through the Interruption of PKC Activity Within Melanocytes. Phytother Res 2011.

Nan H, Kraft P, Hunter DJ, Han J. Genetic variants in pigmentation genes, pigmentary phenotypes, and risk of skin cancer in Caucasians. Int J Cancer 2009;125(4):90917.

Newton RA, Cook AL, Roberts DW, Leonard JH, Sturm RA. Post-transcriptional regulation of melanin biosynthetic enzymes by cAMP and resveratrol in human melanocytes. J Invest Dermatol 2007;127(9):2216-27.

Nishikawa S, Kusakabe M, Yoshinaga K, Ogawa M, Hayashi S, Kunisada T, et al. In utero manipulation of coat color formation by a monoclonal anti-c-kit antibody: two distinct waves of c-kit-dependency during melanocyte development. EMBO J 1991;10(8):2111-8.

Nishimura EK. Melanocyte stem cells: a melanocyte reservoir in hair follicles for hair and skin pigmentation. Pigment Cell Melanoma Res 2011;24(3):401-10.

Nishimura EK, Suzuki M, Igras V, Du J, Lonning S, Miyachi Y, et al. Key roles for transforming growth factor beta in melanocyte stem cell maintenance. Cell Stem Cell 2010;6(2):130-40.

Ogawa Y, Nakao K, Arai H, Nakagawa O, Hosoda K, Suga S, et al. Molecular cloning of a non-isopeptide-selective human endothelin receptor. Biochem Biophys Res Commun 1991;178(1):248-55.

Okayama Y, Kawakami T. Development, migration, and survival of mast cells. Immunol Res 2006;34(2):97-115. 
Ollmann MM, Lamoreux ML, Wilson BD, Barsh GS. Interaction of Agouti protein with the melanocortin 1 receptor in vitro and in vivo. Genes Dev 1998;12(3):316-30.

Ollmann MM, Wilson BD, Yang YK, Kerns JA, Chen Y, Gantz I, et al. Antagonism of central melanocortin receptors in vitro and in vivo by agouti-related protein. Science 1997;278(5335):135-8.

Opdecamp K, Kos L, Arnheiter H, Pavan WJ. Endothelin signalling in the development of neural crest-derived melanocytes. Biochemistry and Cell Biology-Biochimie Et Biologie Cellulaire 1998;76(6):1093-9.

Opdecamp K, Nakayama A, Nguyen MT, Hodgkinson CA, Pavan WJ, Arnheiter H. Melanocyte development in vivo and in neural crest cell cultures: crucial dependence on the Mitf basic-helix-loop-helix-zipper transcription factor. Development 1997;124(12):2377-86.

Oshimori N, Fuchs E. Paracrine TGF-beta signaling counterbalances BMP-mediated repression in hair follicle stem cell activation. Cell Stem Cell 2012;10(1):63-75.

Pavan WJ, Tilghman SM. Piebald lethal (sl) acts early to disrupt the development of neural crest-derived melanocytes. Proc Natl Acad Sci U S A 1994;91(15):715963.

Peters EM, Tobin DJ, Botchkareva N, Maurer M, Paus R. Migration of melanoblasts into the developing murine hair follicle is accompanied by transient c-Kit expression. $\mathrm{J}$ Histochem Cytochem 2002;50(6):751-66.

Phung B, Sun J, Schepsky A, Steingrimsson E, Ronnstrand L. C-KIT signaling depends on microphthalmia-associated transcription factor for effects on cell proliferation. PLoS One 2011;6(8):e24064.

Pingault V, Ente D, Dastot-Le Moal F, Goossens M, Marlin S, Bondurand N. Review and update of mutations causing Waardenburg syndrome. Hum Mutat 2010;31(4):391-406.

Pino J, Kos L. MC1R, EDNRB, and KIT signaling in pigmentation regulation and related disease. In: Smith J, Haworth M, editors. Skin Pigmentation: Genetics, Geographic Variation and Disorders. In Skin Pigmentation. 2. Nova Science: Nova Sicence Publishers, Inc.; 2013. p. 57-88.

Plikus MV, Mayer JA, de la Cruz D, Baker RE, Maini PK, Maxson R, et al. Cyclic dermal BMP signalling regulates stem cell activation during hair regeneration. Nature 2008;451(7176):340-4. 
Potterf SB, Mollaaghababa R, Hou L, Southard-Smith EM, Hornyak TJ, Arnheiter H, et al. Analysis of SOX10 function in neural crest-derived melanocyte development: SOX10-dependent transcriptional control of dopachrome tautomerase. Dev Biol 2001;237(2):245-57.

Powell MB, Hyman P, Bell OD, Balmain A, Brown K, Alberts D, et al. Hyperpigmentation and melanocytic hyperplasia in transgenic mice expressing the human T24 Ha-ras gene regulated by a mouse tyrosinase promoter. Mol Carcinog 1995;12(2):82-90.

Price ER, Horstmann MA, Wells AG, Weilbaecher KN, Takemoto CM, Landis MW, et al. alpha-Melanocyte-stimulating hormone signaling regulates expression of microphthalmia, a gene deficient in Waardenburg syndrome. J Biol Chem 1998;273(49):33042-7.

Prota G. Recent advances in the chemistry of melanogenesis in mammals. J Invest Dermatol 1980;75(1):122-7.

Puffenberger EG, Hosoda K, Washington SS, Nakao K, deWit D, Yanagisawa M, et al. A missense mutation of the endothelin-B receptor gene in multigenic Hirschsprung's disease. Cell 1994;79(7):1257-66.

Qiu FH, Ray P, Brown K, Barker PE, Jhanwar S, Ruddle FH, et al. Primary structure of c-kit: relationship with the CSF-1/PDGF receptor kinase family--oncogenic activation of v-kit involves deletion of extracellular domain and $\mathrm{C}$ terminus. EMBO J 1988;7(4):1003-11.

Rabbani P, Takeo M, Chou W, Myung P, Bosenberg M, Chin L, et al. Coordinated activation of Wnt in epithelial and melanocyte stem cells initiates pigmented hair regeneration. Cell 2011;145(6):941-55.

Raper HS. The Tyrosinase-tyrosine Reaction: Production from Tyrosine of 5: 6Dihydroxyindole and 5: 6-Dihydroxyindole-2-carboxylic Acid-the Precursors of Melanin. Biochem J 1927;21(1):89-96.

Reid K, Turnley AM, Maxwell GD, Kurihara Y, Kurihara H, Bartlett PF, et al. Multiple roles for endothelin in melanocyte development: regulation of progenitor number and stimulation of differentiation. Development 1996;122(12):3911-9.

Riley PA. Melanogenesis and melanoma. Pigment Cell Res 2003;16(5):548-52.

Robbins LS, Nadeau JH, Johnson KR, Kelly MA, Roselli-Rehfuss L, Baack E, et al. Pigmentation phenotypes of variant extension locus alleles result from point mutations that alter MSH receptor function. Cell 1993;72(6):827-34. 
Ronnstrand L. Signal transduction via the stem cell factor receptor/c-Kit. Cell Mol Life Sci 2004;61(19-20):2535-48.

Saldana-Caboverde A, Kos L. Roles of endothelin signaling in melanocyte development and melanoma. Pigment Cell Melanoma Res 2010;23(2):160-70.

Sato-Jin K, Nishimura EK, Akasaka E, Huber W, Nakano H, Miller A, et al. Epistatic connections between microphthalmia-associated transcription factor and endothelin signaling in Waardenburg syndrome and other pigmentary disorders. FASEB J 2008;22(4):1155-68.

Schauer E, Trautinger F, Kock A, Schwarz A, Bhardwaj R, Simon M, et al. Proopiomelanocortin-derived peptides are synthesized and released by human keratinocytes. J Clin Invest 1994;93(5):2258-62.

Scott G, Leopardi S, Printup S, Madden BC. Filopodia are conduits for melanosome transfer to keratinocytes. J Cell Sci 2002;115(Pt 7):1441-51.

Scott MC, Suzuki I, Abdel-Malek ZA. Regulation of the human melanocortin 1 receptor expression in epidermal melanocytes by paracrine and endocrine factors and by ultraviolet radiation. Pigment Cell Res 2002;15(6):433-9.

Seiji M, Shimao K, Birbeck MS, Fitzpatrick TB. Subcellular localization of melanin biosynthesis. Ann N Y Acad Sci 1963;100:497-533.

Sennett R, Wang Z, Rezza A, Grisanti L, Roitershtein N, Sicchio C, et al. An Integrated Transcriptome Atlas of Embryonic Hair Follicle Progenitors, Their Niche, and the Developing Skin. Dev Cell 2015;34(5):577-91.

Serbedzija GN, Fraser SE, Bronner-Fraser M. Pathways of trunk neural crest cell migration in the mouse embryo as revealed by vital dye labelling. Development 1990;108(4):605-12.

Setchell JM, Smith T, Wickings EJ, Knapp LA. Social correlates of testosterone and ornamentation in male mandrills. Hormones and Behavior 2008;54(3):365-72.

Shin MK, Levorse JM, Ingram RS, Tilghman SM. The temporal requirement for endothelin receptor-B signalling during neural crest development. Nature 1999;402(6761):496-501.

Shishido E, Kadono S, Manaka I, Kawashima M, Imokawa G. The mechanism of epidermal hyperpigmentation in dermatofibroma is associated with stem cell factor and hepatocyte growth factor expression. J Invest Dermatol 2001;117(3):627-33. 
Slominski A, Wortsman J, Plonka PM, Schallreuter KU, Paus R, Tobin DJ. Hair follicle pigmentation. J Invest Dermatol 2005;124(1):13-21.

Spritz RA. Piebaldism, Waardenburg syndrome, and related disorders of melanocyte development. Semin Cutan Med Surg 1997;16(1):15-23.

Sriwiriyanont P, Ohuchi A, Hachiya A, Visscher MO, Boissy RE. Interaction between stem cell factor and endothelin-1: effects on melanogenesis in human skin xenografts. Lab Invest 2006;86(11):1115-25.

Steel KP, Barkway C. Another role for melanocytes: their importance for normal stria vascularis development in the mammalian inner ear. Development 1989;107(3):453-63.

Stenn KS, Paus R. Controls of hair follicle cycling. Physiol Rev 2001;81(1):449-94.

Sulem P, Gudbjartsson DF, Stacey SN, Helgason A, Rafnar T, Jakobsdottir M, et al. Two newly identified genetic determinants of pigmentation in Europeans. Nat Genet 2008;40(7):835-7.

Tamate HB, Takeuchi T. Action of the e locus of mice in the response of phaeomelanic hair follicles to alpha-melanocyte-stimulating hormone in vitro. Science 1984;224(4654):1241-2.

Tanimura S, Tadokoro Y, Inomata K, Binh NT, Nishie W, Yamazaki S, et al. Hair follicle stem cells provide a functional niche for melanocyte stem cells. Cell Stem Cell 2011;8(2):177-87.

Tartaglia M, Gelb BD, Zenker M. Noonan syndrome and clinically related disorders. Best Pract Res Clin Endocrinol Metab 2011;25(1):161-79.

Theos AC, Truschel ST, Raposo G, Marks MS. The Silver locus product Pmel17/gp100/Silv/ME20: controversial in name and in function. Pigment Cell Res 2005;18(5):322-36.

Thomas AJ, Erickson CA. The making of a melanocyte: the specification of melanoblasts from the neural crest. Pigment Cell Melanoma Res 2008;21(6):598-610.

Tsukamoto K, Jackson IJ, Urabe K, Montague PM, Hearing VJ. A second tyrosinaserelated protein, TRP-2, is a melanogenic enzyme termed DOPAchrome tautomerase. EMBO J 1992;11(2):519-26.

Ueno M, Aoto T, Mohri Y, Yokozeki H, Nishimura EK. Coupling of the radiosensitivity of melanocyte stem cells to their dormancy during the hair cycle. Pigment Cell Melanoma Res 2014;27(4):540-51. 
Van Den Bossche K, Naeyaert JM, Lambert J. The quest for the mechanism of melanin transfer. Traffic 2006;7(7):769-78.

Van Raamsdonk CD, Barsh GS, Wakamatsu K, Ito S. Independent regulation of hair and skin color by two G protein-coupled pathways. Pigment Cell Melanoma Res 2009;22(6):819-26.

Van Raamsdonk CD, Fitch KR, Fuchs H, de Angelis MH, Barsh GS. Effects of G-protein mutations on skin color. Nat Genet 2004;36(9):961-8.

Vincent S, Segretain D, Nishikawa S, Nishikawa SI, Sage J, Cuzin F, et al. Stage-specific expression of the Kit receptor and its ligand (KL) during male gametogenesis in the mouse: a Kit-KL interaction critical for meiosis. Development 1998;125(22):4585-93.

Wang ZQ, Si L, Tang Q, Lin D, Fu Z, Zhang J, et al. Gain-of-function mutation of KIT ligand on melanin synthesis causes familial progressive hyperpigmentation. Am J Hum Genet 2009;84(5):672-7.

Wasag B, Chmara M, Legius E. Molecular characterization of two novel KIT mutations in patients with piebaldism. J Dermatol Sci 2012;66(1):78-9.

Wasmeier C, Hume AN, Bolasco G, Seabra MC. Melanosomes at a glance. J Cell Sci 2008;121(Pt 24):3995-9.

Wehrle-Haller B, Meller M, Weston JA. Analysis of melanocyte precursors in Nf1 mutants reveals that $\mathrm{MGF} / \mathrm{KIT}$ signaling promotes directed cell migration independent of its function in cell survival. Dev Biol 2001;232(2):471-83.

Willard DH, Bodnar W, Harris C, Kiefer L, Nichols JS, Blanchard S, et al. Agouti structure and function: characterization of a potent alpha-melanocyte stimulating hormone receptor antagonist. Biochemistry 1995;34(38):12341-6.

Wilson YM, Richards KL, Ford-Perriss ML, Panthier JJ, Murphy M. Neural crest cell lineage segregation in the mouse neural tube. Development 2004;131(24):615362.

Wong TH, Rees JL. The relation between melanocortin 1 receptor (MC1R) variation and the generation of phenotypic diversity in the cutaneous response to ultraviolet radiation. Peptides 2005;26(10):1965-71.

Xu D, Emoto N, Giaid A, Slaughter C, Kaw S, deWit D, et al. ECE-1: a membranebound metalloprotease that catalyzes the proteolytic activation of big endothelin1. Cell 1994;78(3):473-85. 
Yamaguchi Y, Hearing VJ. Physiological factors that regulate skin pigmentation. Biofactors 2009;35(2):193-9.

Yanagisawa M, Kurihara H, Kimura S, Goto K, Masaki T. A novel peptide vasoconstrictor, endothelin, is produced by vascular endothelium and modulates smooth muscle Ca2+ channels. J Hypertens Suppl 1988a;6(4):S188-91.

Yanagisawa M, Kurihara H, Kimura S, Tomobe Y, Kobayashi M, Mitsui Y, et al. A novel potent vasoconstrictor peptide produced by vascular endothelial cells. Nature 1988b;332(6163):411-5.

Yarden Y, Kuang WJ, Yang-Feng T, Coussens L, Munemitsu S, Dull TJ, et al. Human proto-oncogene c-kit: a new cell surface receptor tyrosine kinase for an unidentified ligand. EMBO J 1987;6(11):3341-51.

Yasumoto K, Yokoyama K, Shibata K, Tomita Y, Shibahara S. Microphthalmiaassociated transcription factor as a regulator for melanocyte-specific transcription of the human tyrosinase gene. Mol Cell Biol 1994;14(12):8058-70.

Yoshida H, Hayashi S, Shultz LD, Yamamura K, Nishikawa S, Nishikawa S, et al. Neural and skin cell-specific expression pattern conferred by steel factor regulatory sequence in transgenic mice. Dev Dyn 1996;207(2):222-32.

Zanardo L, Stolz W, Schmitz G, Kaminski W, Vikkula M, Landthaler M, et al. Progressive hyperpigmentation and generalized lentiginosis without associated systemic symptoms: a rare hereditary pigmentation disorder in south-east Germany. Acta Derm Venereol 2004;84(1):57-60.

Zhang Y, Tomann P, Andl T, Gallant NM, Huelsken J, Jerchow B, et al. Reciprocal requirements for EDA/EDAR/NF-kappaB and Wnt/beta-catenin signaling pathways in hair follicle induction. Dev Cell 2009;17(1):49-61.

Zhou BK, Kobayashi T, Donatien PD, Bennett DC, Hearing VJ, Orlow SJ. Identification of a melanosomal matrix protein encoded by the murine si (silver) locus using "organelle scanning". Proc Natl Acad Sci U S A 1994;91(15):7076-80. 
CHAPTER II

TRANSGENIC EDN3 BYPASSES THE REQUIREMENT FOR MC1R SIGNALING IN PIGMENT PRODUCTION 


\section{TRANSGENIC EDN3 BYPASSES THE REQUIREMENT FOR MC1R SIGNALING IN PIGMENT PRODUCTION}

\subsection{Introduction}

Pigment plays a significant role in the overall fitness and survival of the organism (Coker et al., 2009). The coloration and patterning of animals provided by pigment are involved in camouflage, mate selection and provide warning signals to other animals (Hill, 1990; Setchell et al., 2008). Additionally, pigment provides a barrier that acts as a line of defense against ultraviolet (UV) radiation (Kaidbey et al., 1979; Kobayashi et al., 1998; Murphy et al., 2001). Interestingly, melanocytes that produce pigment in response to UV radiation also exhibit increased DNA damage hours after exposure to UV, giving melanin a protective and mutagenic effect in response to UV radiation(Premi et al., 2015). Pigment is produced by melanocytes, which can be divided into cutaneous melanocytes, found in the skin and hair follicles, and non-cutaneous melanocytes, located in other areas of the body such as the eye, heart and inner ear (Aoki et al., 2009; Brito and Kos, 2008; Cable and Steel, 1991).

The melanocytes found in human skin are located in the basal layer of the epidermis and may sometimes be found in the dermis (Gola et al., 2012). Melanocytes contribute to skin pigmentation by transferring melanin in lysosome-like structures to neighboring keratinocytes forming supranuclear melanin caps (Thingnes et al., 2012). Follicular melanocytes are regenerated with each hair cycle and derive from melanocyte stem cells located in the immune-privileged portions of the hair follicle known as the bulge and subbulge (Nishimura, 2011). Melanocytes in the hair follicle surround the hair bulb, the hair shaft and the sebaceous gland (Cichorek et al., 2013). Melanocytes located 
in the bulb transfer melanin granules to the developing hair shaft and contribute to hair color (Greco et al., 2009). In contrast to humans, mice have melanocytes localized in the hair follicles. In some areas with glabrous skin such as the tail, ears and ventral paws melanocytes can be found in the dermis (Gola et al., 2012).

Pigment production is regulated by Mc1r, which controls the switch between production of the yellow/red pigment, pheomelanin, and the black/brown pigment, eumelanin (Gantz and Fong, 2003; Le Pape et al., 2008). Functional Mc1r signaling results from the binding of $\alpha$-msh. Upon binding of $\alpha$-msh, the $G(s)$ protein activates PKA and cAMP is produced leading to an increase in Mitf, which transcribes important melanocytic genes involved in eumelanin production such as Tyr, Trp1, Dct and Pmel17 (d'Ischia et al., 2015; Fuller et al., 1987; Furumura et al., 1996; Halaban et al., 1984; Hearing, 2011; Kuzumaki et al., 1993). Deactivation of the Mc1r receptor through the competitive binding of ASP or the presence of mutations in the receptor prevents the production of eumelanin (Burchill et al., 1986).

The Edn3/Ednrb signaling pathway is required for the proper differentiation, proliferation and migration of melanocyte precursor cells (Saldana-Caboverde and Kos, 2010). Ednrb, is a membrane bound G protein-coupled receptor, whose activation is modulated by its major ligand Edn3. When Edn3 binds to Ednrb, G(q) protein activates PKC, which acts along with RAF activating the MAPK signaling pathway (Imokawa et al., 1997; Imokawa et al., 1996; Sato-Jin et al., 2008). During development Ednrb signaling cooperates with tyrosine kinase receptor Kit signaling to properly differentiate melanocytes, expand the population of precursors, and coordinate their migration to the skin (Saldana-Caboverde and Kos, 2010). Mutations in the Ednrb pathway are 
responsible for human Waardenburg-Shah syndrome and the piebald phenotype in mice while human piebaldism results from mutations in Kit signaling (Giebel and Spritz, 1991).

In addition to its role in melanocyte development, the Edn3/Ednrb signaling cascade is involved in pigmentation. Mice with darkened coat color that resulted from an ENU-mutagenesis screen were found to carry mutations in $G(q)$ that caused its overexpression. The dark phenotype of these mice was found to be independent of an increase in follicular melanocyte number and Mc1r signaling (Van Raamsdonk et al., 2009). However, there have been no studies that have directly examined the direct effect of Ednrb stimulation by ligand activation in pigmentation.

Our laboratory previously constructed a unique tetracycline inducible transgenic mouse model in which Edn3 is placed under control of the keratin 5 promoter (K5$t T A ; T R E-E d n 3-l a c Z$ ) (Garcia et al., 2008). In these mice, tTA protein binds to the TREEdn3-lacZ transgene containing a tetracycline-response tet-operator sequence (tetO), which leads to the transcription of the bidirectional promoters and the ectopic expression of $E d n 3$ and $L a c Z$ in the skin. The overexpression of Edn3 signaling in the skin leads to a hyperpigmentation phenotype by maintaining large numbers of melanocytes in the epidermal-dermal junction (Garcia et al., 2008). Doxycycline (dox) given in the drinking water of the K5-tTA;TRE-Edn3-lacZ mice binds tTA, preventing its binding to tetO and suppressing the transcription of $E d n 3$ and $L a c Z$, allowing for the spatial and temporal manipulation of Edn3 expression. Using the mouse model, Garcia et al. showed that transgenic Edn3 is required by E10.5 for the resulting expansion of the melanoblast population and maintenance of differentiated cells in the skin of transgenic mice 
responsible for the generation of the hyperpigmentation phenotype. In the study by Garcia et al., the role of $E d n 3$ overexpression in hair pigmentation was not investigated (Garcia et al., 2008).

Previously, we showed that the transgenic overexpression of Edn3 is able to darken the yellow coat color of $A^{y}$ mice (Kaelin et al., 2012). The $A^{y}$ mice overexpress ASP inhibiting the binding of $\alpha$-msh and leading to a deficient Mc1r pathway (Ollmann et al., 1998). Gene expression analysis of the skin of $A^{y} ; K 5-t T A ; T R E-E d n 3-l a c Z$ mice showed that Edn3/Ednrb signaling is involved in the control of eumelanin production in vivo by activating important pigment producing genes such as Trp1, Dct, Tyr, and Pmell 7 (Kaelin et al., 2012).

In the present study we explored the role of $E d n 3$ in rescuing a dark pigmentation phenotype in $A^{y}$ mice and extension mutants $\left(M c 1 r^{e / e}\right)$, mice with a spontaneous mutation in the extension locus coding for Mclr (Robbins et al., 1993). We investigated the involvement of the Ednrb signaling pathway in pigment production and show that eumelanin and pheomelanin may be produced simultaneously. We characterized the timing requirement of Edn3 overexpression in the rescue and maintenance of a dark pigmentation phenotype independent of Mc1r signaling.

\subsection{Results}

2.2.1 Overexpression of Edn3 increases overall melanin levels in follicular melanocytes Crosses between $A^{y}$ and $K 5-t T A ; T R E-E d n 3-l a c Z$ mice resulted in litters including $A^{y}$; K5-tTA;TRE-Edn3-lacZ and $A^{y}$ mice. Mice of the $A^{y} ;$ K5-tTA;TRE-Edn3-lacZ genotype displayed a darkening of the coat hairs (Figure 2.1 A-C). To quantify levels of melanin in 
the hairs of light and darker mice, we used high performance liquid chromatography techniques (Ito and Wakamatsu, 2003; Wakamatsu and Ito, 2002). As expected, there was a significant increase in levels of PTCA, a eumelanin marker, in the hairs of $A^{y} ; K 5$ tTA;TRE-Edn3-lacZ mice when compared to $A^{y}$ control littermates (275 ng/mg \pm 73 (SD) ( $n=10)$ vs. $114 \pm 22 ; P<0.001)$. Surprisingly, the concentration of TTCA, a pheomelanin marker, was also higher in the hairs of $A^{y}$; K5-tTA;TRE-Edn3-lacZ mice in comparison to that of control hairs (154 ng/mg \pm 62 (SD) ( $n=10)$ vs. $85 \mathrm{ng} / \mathrm{mg} \pm 17 ; P<0.001$ ) (Figure 2.1 D). Similar results were obtained using the pheomelanin marker 4-AHP (5677 ng/mg \pm 1205 (SD) ( $n=10)$ vs. $3639 \mathrm{ng} / \mathrm{mg} \pm 643 ; P<0.001)$ (Figure 2.1 F). A significant increase $(1.9 \mathrm{ng} / \mathrm{mg} \pm 0.5$ (SD) ( $n=10) v s .1 .4 \mathrm{ng} / \mathrm{mg} \pm 0.3 ; P<0.05)$ in the eumelanin to pheomelanin ratio was also observed in hairs of $A^{y}$; K5-tTA;TRE-Edn3-lacZ mice when compared to hairs of $A^{y}$ control littermates (Figure 2.1 E). These results indicate that the overexpression of $E d n 3$ is capable of increasing the production of eumelanin and pheomelanin concurrently, as well as, the eumelanin to pheomelanin ratio in $A^{y}$ mice.

\subsubsection{Overexpression of Edn3 does not increase the number of follicular melanocytes} A possible explanation for the observed increase in melanin levels in the coat of $A^{y}$; K5tTA;TRE-Edn3-lacZ mice is that Edn3 caused and expansion of the follicular melanocyte population. To quantify melanocyte numbers in hair follicles, skin sections of $K 5$ tTA;TRE-Edn3-lacZ and control animals were immunostained with an antibody against the melanocyte specific marker Trp1 (Figure 2.2 A-B). No significant difference (6.68 cells $/ \mathrm{nm}^{2} \pm 1.32$ (SD) ( $\left.n=3\right) v$ v. 6.64 cells $/ \mathrm{nm}^{2} \pm 0.97 ; P>0.05$ ) was observed in the number of follicular Trp1+ cells per area between transgenic and non-transgenic littermates 
(Figure 2.2 C). Thus, the increased level of melanin in the hairs of Edn3 transgenic animals was not due to the presence of a larger number of melanocytes.

2.2.3 Overexpression of Edn3 increases the expression of melanogenic genes in isolated hair follicles

Another possible reason for the observed increase in the melanin content in the hairs of transgenic animals is that Edn3 upregulates the expression of some of the genes responsible for melanogenesis. In order to test if $E d n 3$ upregulates the expression of melanogenic genes, gene expression analysis of plucked dorsal hairs from $A^{y}$; K5tTA;TRE-Edn3-lacZ and non-transgenic $A^{y}$ littermates was performed. The expression of Edn3 was dramatically higher (290-fold) in the hairs of $A^{y} ; K 5-t T A ; T R E-E d n 3-l a c Z$ when compared to that of control hairs confirming the activity of the transgene. The expression of several important melanogenic genes: Ednrb, Slc7a11, Pmel17, Trp 1, Tyr and Mitf, was also at least two-fold higher in the hairs of Edn3 overexpressing mice. However, two genes involved in the control of eumelanin production, Dct and Mclr, were not upregulated as a result of Edn3 overexpression (Figure 2.3). These results suggest that the darkening of the coat color in Edn3 transgenic animals is due to the upregulation of melanogenic genes.

\subsubsection{Overexpression of Edn3 darkens the skin and coat color of Mclr mutant mice} K5-tTA;TRE-Edn3-lacZ were crossed with $M c 1 r^{e / e}$ in order to determine if Edn3 overexpression was capable of producing a dark pigmentation phenotype independent of functional Mc1r on the cell surface of melanocytes. Litters of the Mc1r $r^{e / e}$ and K5- 
tTA;TRE-Edn3-lacZ cross resulted in litters composed of $M c 1 r^{e / e}$; K5-tTA or Mclr ${ }^{e / e}$; TRE-Edn3-lacZ, K5-tTA;TRE-Edn3-lacZ Mclr ${ }^{e / e}$; K5-tTA;TRE-Edn3-lacZ and K5-tTA or TRE-Edn3-lacZ mice. As for the $A^{y}$; K5-tTA;TRE-Edn3-lacZ mice, mice of the Mclr ${ }^{e / e}$; K5-tTA;TRE-Edn3-lacZ genotype displayed a hyperpigmentation phenotype due to the presence of melanocytes in the skin and darkening of the coat hairs (Figure 2.4 A-D). The effect of Edn3 overexpression on the rescue of the coat color phenotype was much stronger in $M c 1 r^{e / e}$ than in $A^{y}$ mice.

\subsubsection{Sustained overexpression of Edn3 is required to maintain a dark pigmentation} phenotype

To evaluate the timing requirement for Edn3 overexpression in the generation and maintenance of the dark coat phenotype, we took advantage of the transgenic tetracycline inducible system to turn off the expression of Edn3 at different times (Figure 2.5 and Figure 2.6). Crosses between $A^{y}$ and K5-tTA;TRE-Edn3-lacZ were given doxycycline (dox) treatment to turn off transgene expression after birth. Doxycycline treatment was started on postnatal day 0 ( $\mathrm{P} 0$ ) for a period of six weeks (Figure 2.5 A). Gradual loss of the rescued dark pigmentation phenotype was observed over time with full disappearance by the time the treatment was terminated (Figure 2.5 B-F). The loss of the dark coat color in the dox treated animals was due to a decrease in the levels of eumelanin and pheomelanin. At six weeks of age the levels of eumelanin were significantly lower in dox treated when compared to non-treated mice (261 $\mathrm{ng} / \mathrm{mg} \pm 73$ (SD) (n=2) vs. $108 \pm 18.3$ $(n=3) ; P<0.001)$ (Figure $2.5 \mathrm{G})$. The levels of pheomelanin were also lower in the dox treated mice when compared to controls $(235 \mathrm{ng} / \mathrm{mg} \pm 1.4$ (SD) ( $n=2)$ vs. $101 \pm 18.9$ 
$(n=3) ; P<0.05)$ (Figure $2.5 \mathrm{H})$. Similar results were seen using the pheomelanin marker 4-AHP (7736 ng/mg \pm 994 (SD) ( $n=2) v s .3519 \pm 537(n=3) ; P<0.05$ ) (data not shown).

\subsubsection{Overexpression of Edn3 during development is not required for a dark coat} phenotype in the adult

To assess if post-natal Edn3 overexpression is sufficient for rescuing the coat color phenotype of $A^{y}$ mice, $A^{y}$; K5-tTA;TRE-Edn3-lacZ mice were treated with dox to turn off transgene expression during development (Figure 2.6). Doxycycline treatment started on embryonic day 0 (E0) until postnatal day 0 (P0) (Figure 2.6 A). $A^{y}$; K5-tTA;TRE-Edn3lac $Z$ mice were born with similar phenotype as their non-transgenic $A^{y}$ littermates (Figure 2.6 B). During preliminary experiments with two litters, the mice did not display a dark pigmentation phenotype (results not shown). Upon repeating the experiment, mice displayed a light coat color phenotype, as seen at week 1 (Figure 2.6 C) and week 2 (Figure 2.6 D). Dorsal hairs from mice were plucked at four weeks of age to restart and synchronize the hair cycle. After the new hair cycle, a darkened coat color was observed in $A^{y} ; K 5-t T A ; T R E-E d n 3$-lacZ than their non-transgenic $A^{y}$ littermates at 6 weeks of age (Figure 2.6 E). Mice at 6 weeks of age stained negative for $L a c Z$ staining, confirming a deactivated transgene (Figure 2.6 A).

\subsection{Discussion}

The role of Mclr in pigment production has been thoroughly investigated and is well understood. Activation of Mc1r produces a signaling cascade activating PKA ultimately leading to eumelanin production, while a deactivated receptor produces 
pheomelanin (Gantz and Fong, 2003; Le Pape et al., 2008). Our previous finding that overexpression of Edn3 could bypass the requirement for a functional Mc1r signaling pathway for the generation of dark coat color in mice, underscored the importance of the Edn3/Ednrb pathway in pigment production(Kaelin et al., 2012). Although much attention had been paid to the importance of Edn1 as a potential melanogenic factor upon UV induction (Imokawa et al., 1995), the role of Edn3 had not been fully explored.

In the present study we further investigated the role of $E d n 3$ in pigment production by overexpressing $E d n 3$ in $A^{y}$ mice and measuring melanin concentrations in dorsal hairs. We were able to show that the darkening of the coat color was the result of a significant increase in eumelanin production. Surprisingly, Edn3 overexpression in $A^{y}$ mice also resulted in a significant increase in the pheomelanin levels and in the eumelanin/pheomelanin ratio in dorsal hairs. These results demonstrate that the control of eumelanin and pheomelanin can be coupled. The type of regulation is different than what had been previously established for how Mc1r signaling regulates pigment switching: activation of the receptor leads to eumelanin production and deactivation leads to pheomelanin production (Abdel-Malek et al., 2000; Le Pape et al., 2008). When mice that overexpress $\mathrm{G}(\mathrm{q})$ and $\mathrm{G}(11)$, the G proteins that bind Ednrb, were crossed to $M c 1 r$ and $A^{y}$ mutants, the latter showed a darkening of the coat (Van Raamsdonk et al., 2009). These results are similar to the ones reported here for the overexpression of Edn3. Van Raamsdonk et al. did not perform measurements of the concentration of melanin in the hairs so they could not have shown the coupling of eumelanin and pheomelanin production upon the activation of the $\mathrm{G}$ proteins. 
Given the mitogenic effect of Edn3 during melanocyte development we wanted to establish if the dark coat color in the Edn3 transgenic mice was a consequence of increased numbers of melanocytes in the hair follicles (Saldana-Caboverde and Kos, 2010). Our results comparing $E d n 3$ transgenic animals to control animals indicate that the resulting phenotype is not due to increased numbers of follicular melanocytes. We were not able to quantify melanocytes in the hair follicles of $A^{y}$ or $A^{y} ;$ K5-tTA;TRE-Edn3lacZ mice because the presence of pheomelanin interferes with the visualization of fluorescent secondary antibodies (Elleder and Borovansky, 2001; Wakamatsu et al., 2012). Nevertheless, it is unlikely that the results obtained in the K5-tTA;TRE-Edn3-lacZ mice would be different in the $A^{y}$ background. Furthermore, our results corroborate findings from previous studies suggesting that once melanocytes enter the epidermis Ednrb signaling no longer has a proliferative effect (Shin et al., 1999; Van Raamsdonk et al., 2009; Van Raamsdonk et al., 2004).

Previously we showed that the overexpression of Edn3 resulted in a significant increase in the expression of melanocyte genes in the skin of $A^{y} ;$ K5-tTA;TRE-Edn3-lacZ mice (Kaelin et al., 2012). In the present study, we isolated hair follicles of $A^{y}$ and $A^{y} ; K 5$ tTA;TRE-Edn3-lacZ mice and showed that there was a average two-fold increase in Ednrb, Slc7a11, Pmel17, Trp1, Tyr and Mitf but no difference in Mc1r and Dct. Pmel17, Trp1, Try and Mitf (Figure 2.3). Trp1, Pmel17 and Tyr are genes expressed during the production of eumelanin with a functional Mc1r (d'Ischia et al., 2015; Hearing, 2005). Interestingly, we saw an increase in Slc7all, the gene that controls pheomelanin production (Chintala et al., 2005). Of the genes analyzed in this study, Slc7all was the only gene whose expression was not upregulated in the skin of $A^{y} ; K 5-t T A ; T R E-E d n 3-$ 
lacZ mice (Kaelin et al., 2012). The increased expression of Slc7a11 in the hair follicles suggests that Edn3 may have slightly different effects on hair and skin melanocytes, at least during pheomelanin production. Van Raamsdonk et al. showed that Mc1r signaling has different effects in skin melanocytes and follicular melanocytes on how it couples the synthesis of eumelanin and pheomelanin (Van Raamsdonk et al., 2009). Interestingly, Edn3 seems to act in the reverse manner by coupling the production of eumelanin and pheomelanin in hair follicles.

In a study where primary cultures of normal human melanocytes of varying pigmentation levels were induced with Edn1, the expression of Mclr was upregulated. The authors suggested that Ednrb signaling has the ability to cross-talk with the Mc1r pathway by regulating the expression of the receptor in melanocytes (Scott et al., 2002). The darkening of the coat color and skin of $M c 1 r^{e / e} ; K 5-t T A ; T R E-E d n 3-l a c Z$ mice showed that Edn3 is capable of producing eumelanin completely independent of a functional Mc1r. There is a possibility, however, that some of the factors activated downstream of Mc1r responsible for eumelanin production are still the ones promoting the darkening of the coat. Although the full characterization of the signaling cascade downstream of Ednrb has not been carried out in murine melanocytes, in vitro experiments using human melanocytes have linked Ednrb signaling with increased Mitf expression through PKA, cAMP and CREB (Sato-Jin et al., 2008). Additionally, studies in rat astrocytes have shown that MAPK signaling downstream of Ednrb phosphorylates CREB (Schinelli et al., 2001). Furthermore, Ednrb signaling has been linked to activation of adenylyl cyclase in tracheal smooth muscle (El-Mowafy and Biggs, 2001). The convergence of Mc1r and Ednrb signaling pathways may explain why the over activation 
of Edn3 signaling can rescue a dark pigmentation phenotype in the absence of $\mathrm{Mc} 1 \mathrm{r}$ signaling.

Termination of transgenic Edn3 expression through the application of dox in $A^{y}$ mice during postnatal development resulted in the loss of the darkened coat color as the mice aged suggesting that Edn3 overexpression is required in order to maintain a dark pigmentation phenotype in $A^{y}$ mice. A loss in skin pigmentation was also observed when Edn3 overexpression was terminated and attributed to the death of dermal melanocytes. In the skin, Edn3 appears to be required for the survival of the ectopic melanocytes (Garcia et al., 2008). Although it may be possible that some follicular melanocytes undergo apoptosis once the transgene is no longer active, I would have expected the hairs to lose all pigmentation and turn white if all melanocytes were dead. The idea that not all melanocytes are the same and behave according to their location is supported by studies that indicated that cutaneous melanocytes may be divided into distinct dermal and epidermal populations that contribute to skin and hair pigmentation independently and respond to signaling molecules such as Edn3, Hepatocyte growth factor (Hgf), and Kitl differently (Aoki et al., 2009; Van Raamsdonk et al., 2009). Using transgenic mice, the authors found that Edn3 and Hgf signaling selectively maintain dermal melanocytes, while epidermal melanocytes, including those found in the hair follicles, respond to Kitl but not Edn3 or Hgf (Aoki et al., 2009). They did not, however, address the putative role of Edn3 in regulating pigmentation of the epidermal/follicular melanocytes.

We found that transgenic Edn3 expression is not required during development for the generation of a darker coat color in $A^{y}$ mice. Deactivation of transgenic Edn3 during development resulted in mice that initially had pink skin and yellow hair. After depilation 
and the initiation of the next hair cycle the skin remained unpigmented but the hair that grew back darkened when compared to control littermates. The roles for Edn3/Ednrb signaling in the skin and hair can be separated based on the timing requirement. Garcia et al. showed that the timing requirement for transgenic Edn3 to establish cutaneous melanocyte population and generate the hyperpigmentation phenotype in the skin is E10.5, while our results showed that the response of follicular melanocytes is independent of this embryonic role (Garcia et al., 2008). As for Edn3, Kitl has multiple roles in the life of a melanocyte and has recently been implicated in the establishment of the follicular niche. The Kit signaling pathway is required for the survival and migration of melanoblasts up till E11 and plays a role in melanoblasts proliferation later in development (Mackenzie et al., 1997; Yoshida et al., 2001). Transgenic expression of Kitl under the Keratin 14 promoter results in a hyperpigmentation phenotype of the skin due to the survival and maintenance of melanocytes in the epidermis (Liao et al., 2017). In order to establish the melanocyte stem cell niche in the hair follicle, a small population of follicular epithelial cells expressing the transcription factor KROX20 is responsible for expressing Kitl, which regulates pigmentation through the maintenance of mature melanocytes (Liao et al., 2017). Although both signaling pathways interact during development, they are required independently for proper melanocyte development; mice with mutations either in Kit or Ednrb display a white coat color (Bernstein et al., 1990; Hosoda et al., 1994). The function of Mc1r signaling, however, seems to be restricted to regulating mature melanocyte pigmentation, as no developmental role has been observed (Abdel-Malek et al., 2000). Although an embryonic role has not been established for Mc1r, its signaling has been implicated in the response of MSCs to injury. Upon 
wounding or UV radiation, MSCs leave the hair follicles, and migrate to the epidermis to repopulate the skin in a Mc1r-dependent manner (Chou et al., 2013).

Our results showed a requirement of a new hair cycle for the melanogenic effect of $\mathrm{E} d n 3$ to take place when exposure begins at P0. This may suggest that MSCs need to be primed at the time they are generating new mature melanocytes so the latter can respond and make more pigment. Ednrb signaling was shown to be capable of promoting the proliferation and differentiation of MSCs specifically at the onset of anagen and be required for their maintenance. These effects are dependent on interactions of the Ednrb pathway with the Wnt pathway (Takeo et al., 2016). Wnt and BMP signaling may also be regulating KROX20 in keratinocytes that express Kitl in the maintenance of mature follicular melanocytes (Liao et al., 2017). Understanding the activation of the MSC niche in response to other signaling molecules involved in melanocyte biology and how the environment determines the behavior of the stem cell progeny needs further investigation.

The findings of this study have many implications for melanocyte biology. This study gives a better understanding of the involvement of End3/Ednrb signaling in pigment production- and may contribute to potential novel therapies for human hypo and hyper-pigmentary disorders.

\subsection{Materials and Methods}

\subsubsection{Mice}

K5-tTA;TRE-Edn3-lacZ mice were generated in our laboratory as previously described, these mice have been maintained in the C57/bl6 background by crosses into mice from Jackson laboratory (Garcia et al., 2008). Lethal yellow mice $\left(A^{y}\right)$ were maintained in the 
C57/bl6 background by intercrossing mice were purchased from Jackson Laboratories (Michaud et al., 1993). Mc1r ${ }^{\mathrm{e} / \mathrm{e}}$ mice were a generous gift from Dr. John D'orazio (University of Kentucky, Lexington, KY) (Robbins et al., 1993). All mice populations were maintained on $\mathrm{C} 57 \mathrm{BL} / 6 \mathrm{~J}$ genetic background by intercrossing and by outcrossing to C57BL/6J mice (Jackson Laboratories, Bar Harbor, ME). $A^{y}$ and $M c 1 r^{e}$ were maintained and intercrossed with K5-tTA;TRE-Edn3-lacZ to generate $A^{y}$; K5-tTA;TRE-Edn3-lacZ and Mclr $\because: K 5$-tTA;TRE-Edn3-lacZ, respectively. Mice carrying the K5-tTA or TREEdn3-lacZ transgenes were used as controls in all experiments.

All animal work was approved by the Florida International University Institutional Animal Care and Use Committee (Protocol No. 17-003) and performed according to institutional guidelines established by the National Institutes of Health (NIH). All mice used in this study were housed in the Animal Care Facility at Florida International University (Miami, FL).

\subsubsection{Genotyping}

Genomic DNA was isolated from tail or ear biopsies, and used for genotyping by PCR. K5-tTA;TRE-Edn3-lacZ mice were genotyped as previously described with primers for Edn3 (5'-AGGCCTGTGCACACTTCTGT-3' and 5'-TCCTTGTGAAACTGGAGCCT3') and the Keratin5 gene (5'-CCAGGTGGAGTCACAGGATT-3' and 5'-

ACAGAGACTGTGGACCACCC-3') (Garcia et al., 2008). $M c 1 r^{e}$ mice were genotyped with primers for Mc1r (5'-CCAGCACCCTCTTTATCACC-3', 5'-

AGAAAGTGACGAGGCAGAGC-3'), WT Probe (5'-

TACTACAAGCACACAGCCGTTCT-3'), and Mut probe (5'- 
CTACTACAAGCAACAGCCGTTCTG-3') as described on The Jackson Laboratories website. $A^{y}$ mice were not genotypes and were phenotyped based on the yellow coat color.

\subsubsection{Melanin concentration analysis}

15-20 mg hair was collected by plucking the dorsal aspect of $A^{y}$ and $A^{y}$; K5-tTA;TREEdn3-lacZ at four weeks of age. Hair samples were then sent to Dr. Ito and Dr. Wakamatsu at the Fujita Health University School of Health Sciences. Hair samples were homogenized in water with a Ten-Broeck instrument to reach a concentration of 10 $\mathrm{mg} / \mathrm{mL}$. Aliquots of $100 \mu \mathrm{L}$ were subject to Soluene-350 solubilization (Ozeki et al., 1996), alkaline hydrogen oxidation (Ito et al., 2011) and hydroiodic acid hydrolysis (Wakamatsu et al., 2002). Values of PTCA as a marker for eumelanin, and TTCA and 4AHP as pheomelanin markers, were used for High Performance Liquid Chromatography (HPLC) (Ito et al., 2011). PTCA and TTCA were quantified using UV detection, while 4AHP was quantified by electrochemical detection (Wakamatsu and Ito, 2002). Student's $\mathrm{t}$-test was used to determine statistical significance $(\mathrm{p}<0.05)$.

\subsubsection{Dox treatment}

Dox was administered as previously described (Garcia et al., 2008) to the progeny of $A^{y}$ and $K 5-t T A$; TRE-Edn3-lacZ crosses. In brief, dox treated water contained $3 \mathrm{mg} / \mathrm{mL}$ of doxycycline hyclate (Sigma, St Louis, MO) and 5\% sucrose (5\%) and was administered to mice subjected to transgene repression studies on the morning of the indicated experiment via their drinking water. Based on the assumption that mice drink $5 \mathrm{~mL}$ of 
water every 24 hours, treated mice received $15 \mathrm{mg}$ of dox daily. For timed experiments, dox water was given either at the time of conception, E0, and P0. Embryonic dox treatment was terminated at P0. Postnatal dox treatment was terminated at P49. Deactivation or activation of transgenic Edn3 was confirmed on ear tissues with $\beta$ galactosidase according to standard protocols (Furth et al., 1994). Each experiment was represented by at least three litters and contained three dox-responsive mice and littermate controls.

\subsubsection{Sample collection and numerical analysis of melanocyte numbers in hair follicles}

The numbers of melanocytes in individual hair follicles were quantified by immunofluorescence. Dorsal skin samples were collected from four-week-old K5tTA;TRE-Edn3-lacZ mice and non-transgenic littermates. Samples were fixed in $4 \%$ paraformaldehyde, embedded in OCT Compound (Ted-Pella, USA Scientific), frozen at $80{ }^{\circ} \mathrm{C}$, and sectioned at $10 \mu \mathrm{m}$. Sections were washed and blocked with $10 \%$ goat serum (Gibco, Invitrogen, 16210-064), 5\% Bovine Serum Albumin (BSA) (Amresco, 0332), $0.1 \%$ Triton X-100 (Sigma, T-8787) in $1 \mathrm{X}$ PBS (pH 7.4) for 1 hour and 15 minutes at room temperature and incubated with the primary antibody anti-TRP1 (1:50, rabbit antimouse $\alpha$-PEP1 antibody, Vincent Hearing, NIH) diluted in 5\% Goat Serum, $1 \%$ BSA, 0.1\% Tween 20 (Fisher Biotetch, BP337) in 1X PBS (pH 7.4) solution, for one hour. After washing, sections were incubated with secondary antibody Alexa Flour 488 (green) (1:200, goat anti-rabbit, Life Technologies, A11008). Sections were washed and counterstained with propidium iodide. The staining was visualized using Leica DMRB compound fluorescent microscope and photographed with Leica DC500 Camera. Trp1+ 
cells were quantified by counting 30 hair follicles over 10 sections. The average of the number of Trp1+ cells per area within each hair follicle was taken and compared between experimental and control littermates. Student's t-test was used to determine statistical significance $(\mathrm{p}<0.05)$.

\subsubsection{Gene expression analysis of follicular melanocytes}

Hair samples were collected by plucking the dorsal aspect of $A^{y}$; K5-tTA;TRE-Edn3-lacZ and $A^{y}$ littermates at four weeks of age. Hairs were cut at the base to isolate hair follicles. RNA extraction was performed using Trizol Reagent and QIAGEN RNeasy Mini Kit (Qiagen, 74104) and treated with DNaseI (Qiagen, 79254). Synthesis of cDNA was performed using RevertAid First Strand cDNA synthesis Kit (Thermo Scientific, K1621). qRT-PCR was run using the Applied Biosystems 7500 Real-time PCR System. Samples were prepared for qRT-PCR using Maxima SYBR Green/ROX qRT-PCR Master Mix (Life Technologies, K0221) and primers specific for Dct, Mc1r. Ednrb, Slc7a11, Pmel17, Trp1, Edn3 and Tyr and were used (Table 2.1) (Corre et al., 2004; Kaelin et al., 2012; Mattei et al., 1994). Target genes were normalized to Gapdh and an average fold-change greater than 2 was used to determine significant changes in gene expression. 


\begin{tabular}{|l|l|}
\hline Primer & Sequence \\
\hline Pmel Fwd & GCACCCAACTTGTTGTTCCT \\
\hline Pmel Rev & AGAGATGCAAGGACCACAGC \\
\hline Tyr Fwd & AAATCATCAAGCCCAAGAGC \\
\hline Tyr Rev & TGCCCCTGACACTATCACAC \\
\hline Edn3 Fwd & AGGCCTGTGCACACTTCTGT \\
\hline Edn3 Rev & CAGTCTCCCGCATCTCTTCT \\
\hline Det Fwd & GCGTGCTGAACAAGGAATG \\
\hline Det Rev & CCAGGGTCTGGTGTCTGTTT \\
\hline Trp1 Fwd & TGCTCCAGACAATCTGGGATA \\
\hline Trp1 Rev & AACGCAGCCACTACAGCAAT \\
\hline Slc7a11 Fwd & GGCACCTTTGTTCTGGTGAT \\
\hline Slc7A11 Rev & ACGTGAGGAACGCAGAGAAC \\
\hline Ednrb Fwd & TGAAGTTTAAATTCCATGTGTTCAAC \\
\hline Ednrb Rev & AAGTTGGTAGTATGCCTCCGAG \\
\hline Mitf Fwd & ATTTAACATAAACGACCGCATTAAG \\
\hline Mitf Rev & ATGGTACCGTCCGTGAGATCCAG \\
\hline Mc1r Fwd & CTCTGCCTCGTCACTTTCTTTCTA \\
\hline Mc1r Rev & TCGTGAACATGTGGGCATACA \\
\hline Gapdh Fwd & ATTTGCAGTGGCAAAGTGGAGATTG \\
\hline Gapdh Rev & TGGTTCACACCCATCACAAACATG \\
\hline
\end{tabular}

Table 2.1. List of Primers used for gene expression analysis studies. 


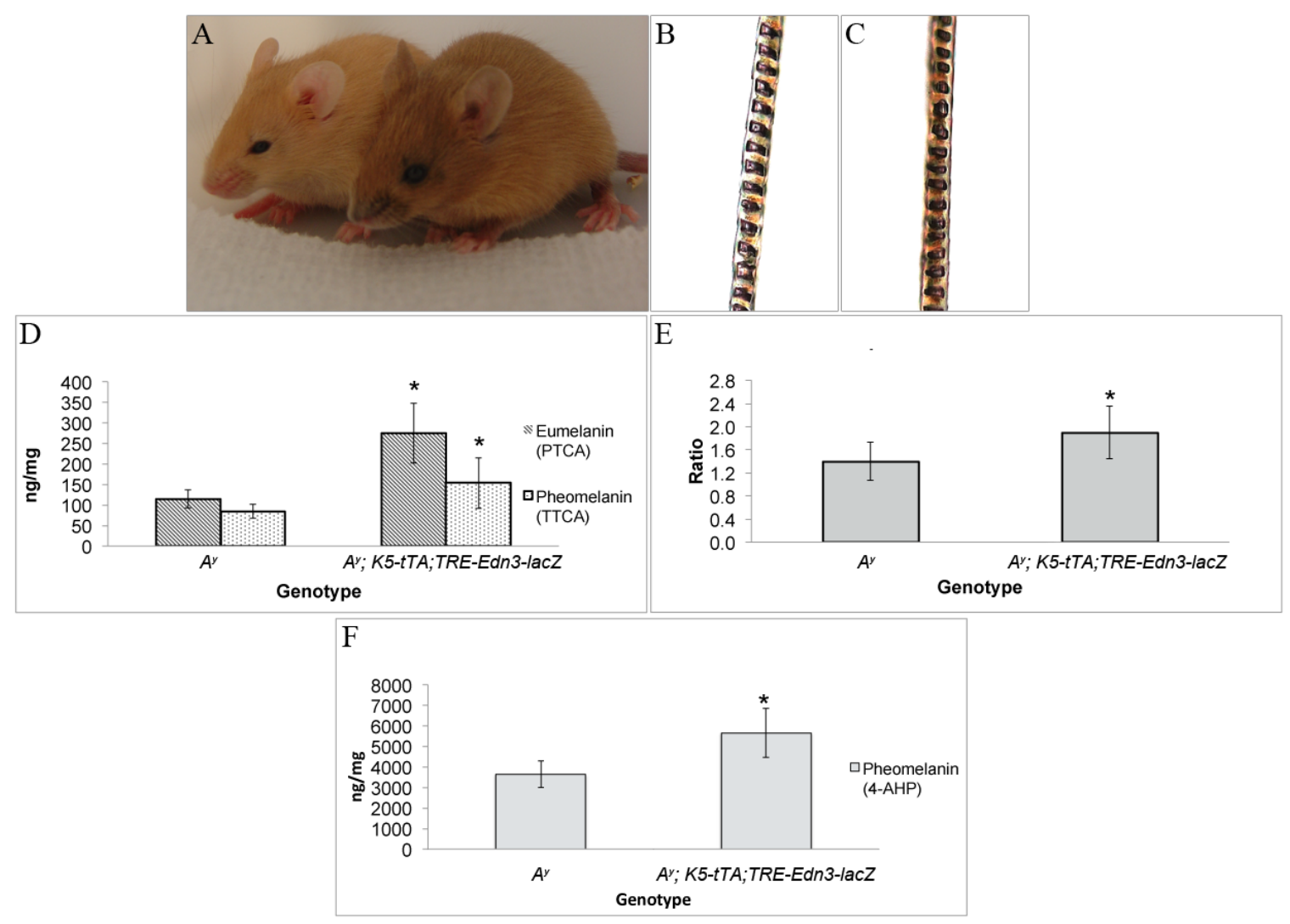

Figure 2.1. Dark coat color and hair melanin levels of $A^{y}$; K5-tTA;TRE-Edn3-lacZ mice. (A) $A^{y} ; K 5-t T A ; T R E-E d n 3-l a c Z$ (right) display a darker coat color than non-transgenic $A^{y}$ littermates (left). (B) Hair shaft of dorsal hair collected from non-transgenic $A^{y}(40 \mathrm{X})$ and (C) $A^{y} ;$ K5-tTA;TRE-Edn3-lacZ (40X) littermates. (D) Eumelanin and pheomelanin concentration analysis of $A^{y}$; K5-tTA;TRE-Edn3-lacZ and non-transgenic $A^{y}$ control littermates. Significant increases (asterisks, $P<0.001$ ) are seen in both eumelanin and pheomelanin levels in dorsal hairs of $A^{y}$; K5-tTA;TRE-Edn3-lacZ mice. (E) Eumelanin to pheomelanin concentration analysis of $A^{y} ; K 5-t T A ; T R E-E d n 3-l a c Z$ and non-transgenic $A^{y}$ control littermates. Significant increase (asterisks, $P<0.05$ ) is seen in the eumelanin and pheomelanin ratio in the dorsal hairs of $A^{y}$; K5-tTA;TRE-Edn3-lacZ mice. (F) Pheomelanin concentration analysis using HI Hydrolysis of $A^{y}$; K5-tTA;TRE-Edn3-lacZ and non-transgenic $A^{y}$ control littermates. Significant increases (asterisks, $P<0.001$ ) is seen in pheomelanin levels using the 4-AHP marker in dorsal hairs of $A^{y}$; K5-tTA;TREEdn3-lacZ mice. 


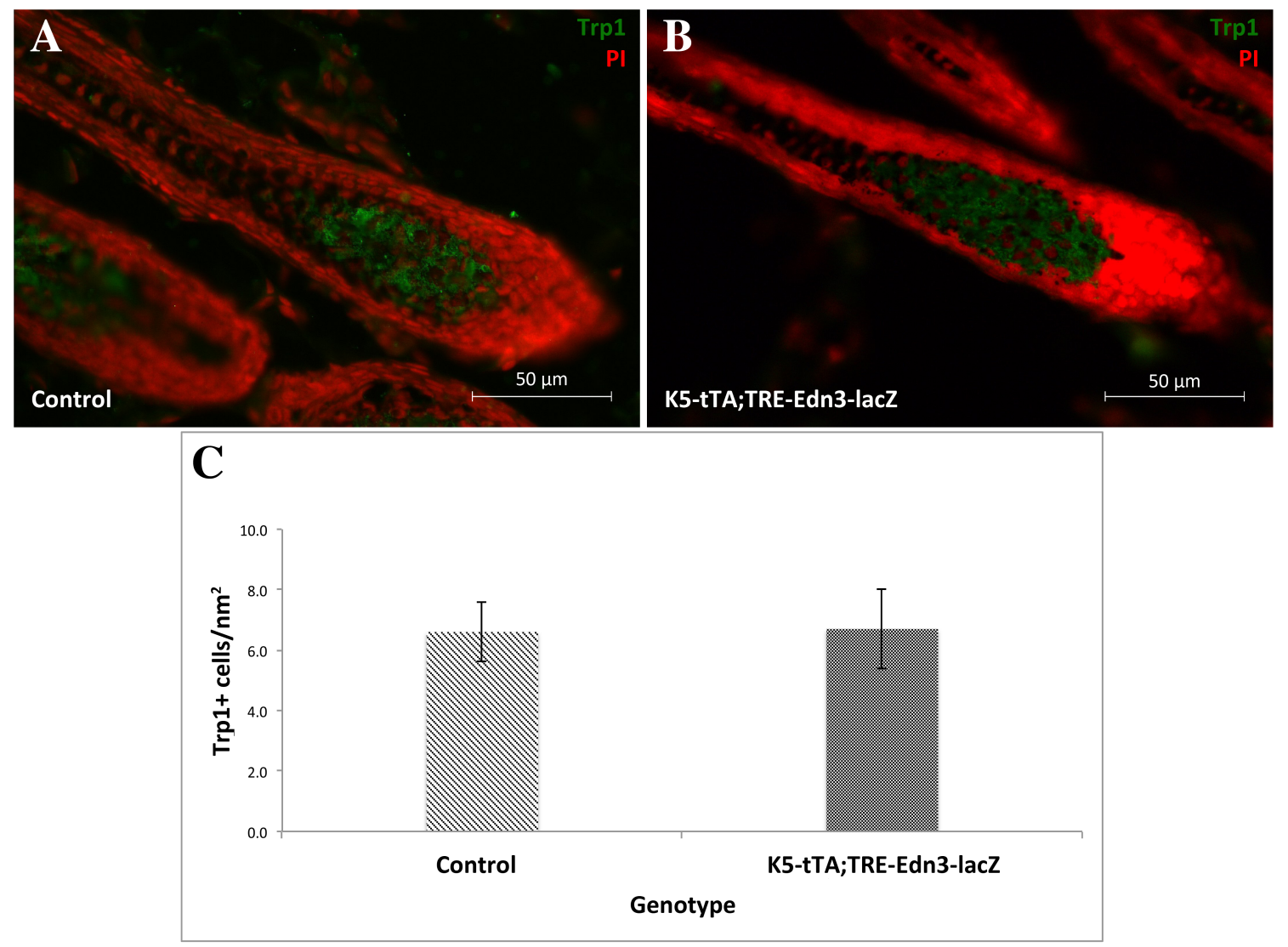

Figure 2.2. Transgenic $E d n 3$ overexpression does not increase the number of Trp1+ cells. (A) Trp1 antibody staining (green) with propidium iodide counterstain (red) of $K 5$ tTA;TRE-Edn3-lacZ and (B) non-transgenic control mice (40X). (C) No significant difference in the numbers of follicular melanocytes was observed between K5-tTA;TREEdn3-lacZ and non-transgenic control mice. 


\section{Gene expression in hair follciles}

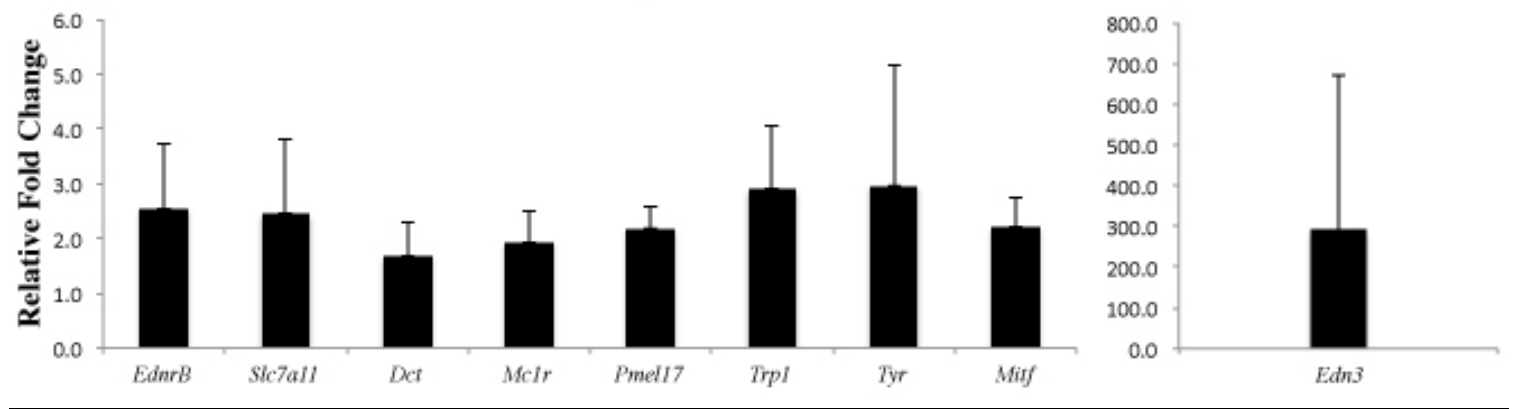

Figure 2.3. Gene expression analysis of isolated hair follicles from $A^{y}$; K5-tTA;TRE-

$E d n 3-l a c Z$ and non-transgenic $A^{y}$ littermates. Relative mRNA levels (mean $\pm \mathrm{SD}$ ) for the indicated genes from qRTPCR of cDNA from $A^{y} ; K 5-t T A ; T R E-E d n 3-l a c Z(\mathrm{n}=4)$ mice compared to values of control mice $(\mathrm{n}=4)$ set to 1 . All expression values were normalized to Gapdh. 

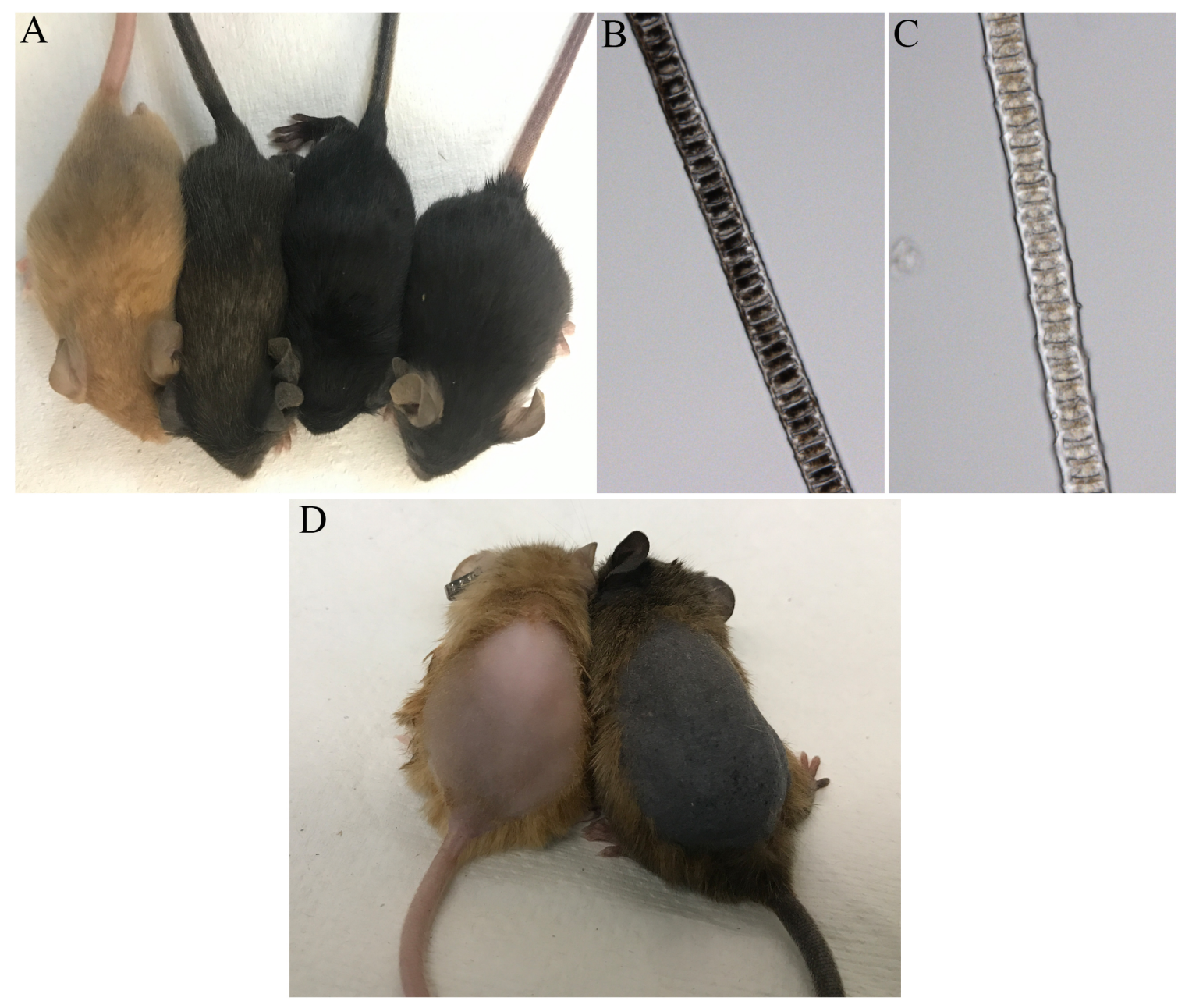

Figure 2.4. $M c 1 r^{e / e}$; K5-tTA;TRE-Edn3-lacZ mice display a dark pigmentation phenotype. (A) Mice genotypes from left to right $M c 1 r^{e / e}, M c 1 r^{e / e}$; K5-tTA;TRE-Edn3lacZ, K5-tTA;TRE-Edn3-lacZ and non-transgenic littermates. (B) Hair shaft of dorsal hair collected from Mclr ${ }^{e / e} ; K 5-t T A ; T R E-E d n 3-l a c Z(40 \mathrm{X})$ and (C) non-transgenic $M c 1 r^{e / e}$ (40X) littermates. (D) Skin pigmentation of depilated $M c 1 r^{e / e}$ and $M c 1 r^{e / e} ; K 5-t T A ; T R E-$ Edn3-lacZ mice.. 
A
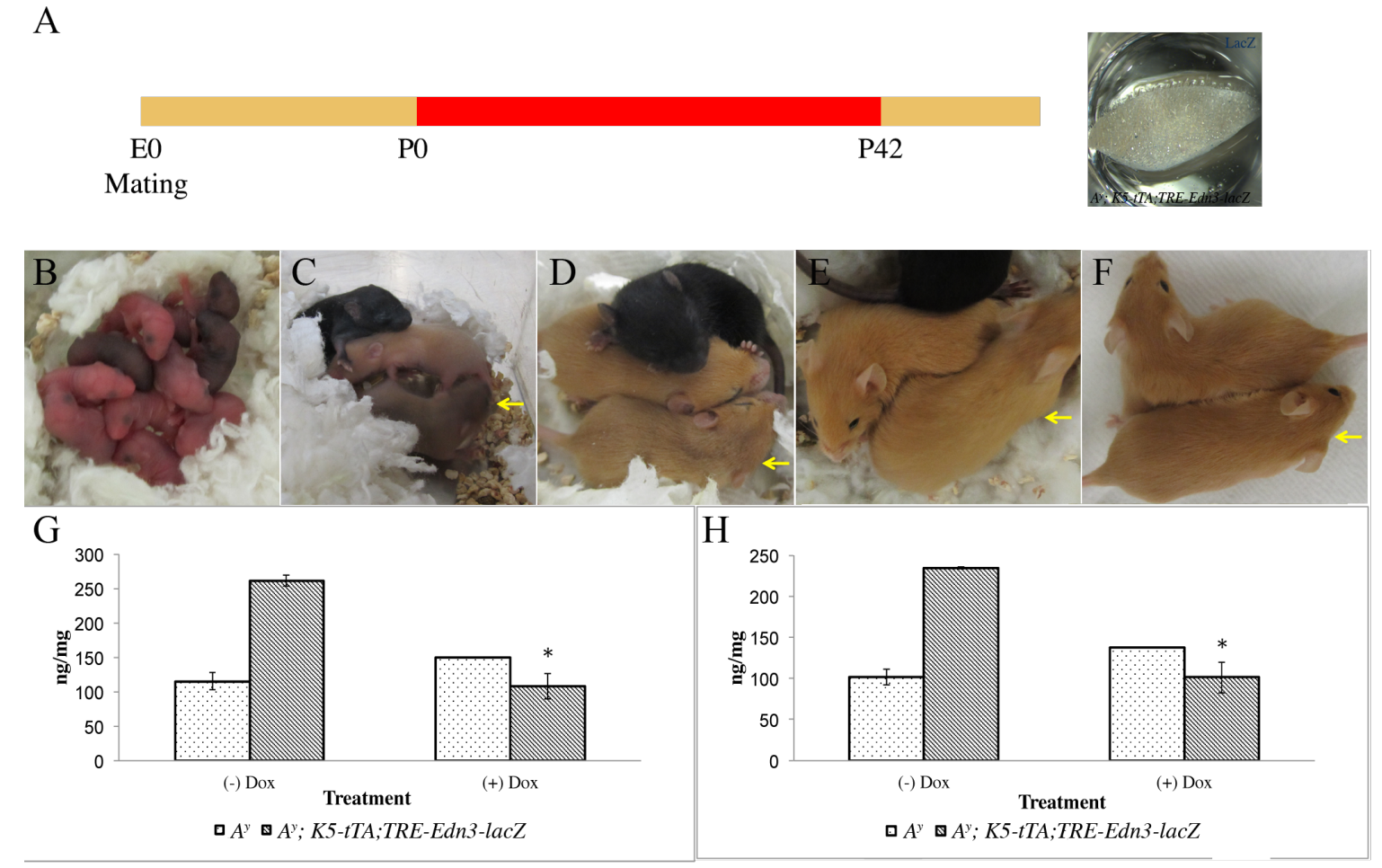

Figure 2.5. Dox treatment of $A^{y} ; K 5$-tTA;TRE-Edn3-lac $Z$ and non-transgenic $A^{y}$ littermates. (A) Confirmed deactivation of transgenic $E d n 3$ by a negative $L a c Z$ staining of $A^{y}$; K5-tTA;TRE-Edn3-lacZ mouse ear biopsy at P42.. Deactivation of transgenic $E d n 3$ expression by dox treatment at postnatal (B) day 0, (C) week 1, (D) week 2, (E) week 4, (F) week 6 leads to $A^{y}$; K5-tTA;TRE-Edn3-lacZ mice (arrow) gradually resembling their $A^{y}(n=3)$ littermates. $(\mathrm{G})$ Eumelanin and $(\mathrm{H})$ pheomelanin concentration analysis of $A^{y}$; TRE-Edn3-lacZ and $A^{y}$ control littermates with and without dox treatment. Both eumelanin and pheomelanin levels decreased in dox treated $A^{y}$; TRE-Edn3-lacZ mice $(n=3)$ compared to non-dox treated mice $(n=2)$. 


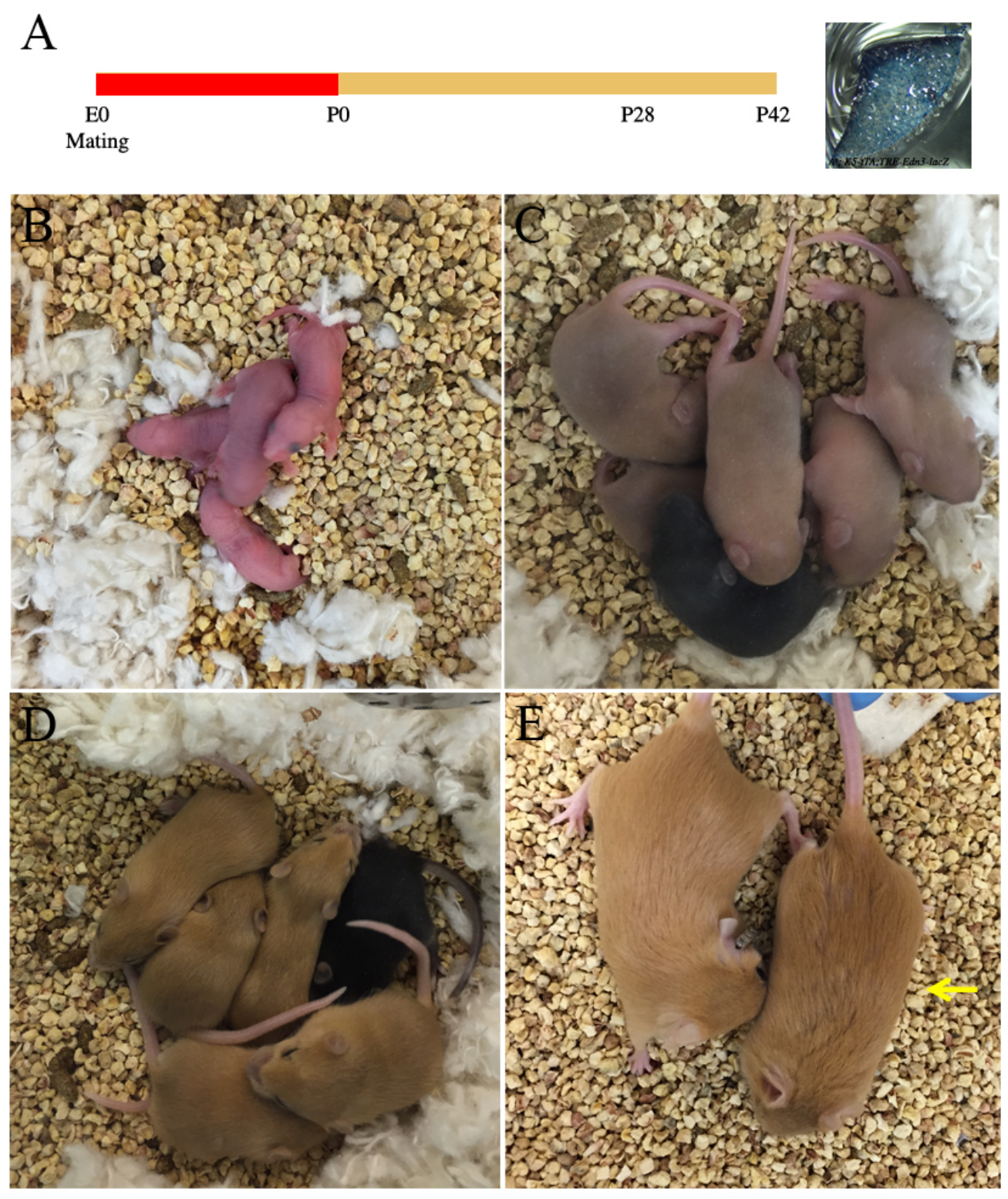

Figure 2.6. E0 to $\mathrm{P} 0$ Dox treatment of $A^{y} ; K 5$-tTA;TRE-Edn3-lac $Z$ and non-transgenic $A^{y}$ littermates. (A) Confirmed activation of transgenic $E d n 3$ by LacZ staining of $A^{y} ; K 5$ tTA;TRE-Edn3-lacZ mouse ear biopsy at P42. (B) Progeny of crosses between $A^{y}$ and $K 5-t T A ; T R E-E d n 3-l a c Z$ mice were born with a light skin color phenotype. Progeny maintained a yellow coat color at during (C) week 1 and (D) week 2. (E) $A^{y} ; K 5$ $t T A$;TRE-Edn3-lacZ mouse (arrow) displays a darker coat color than $A^{y}$ littermate at 6 weeks of age, two weeks after depilation. 


\subsection{References}

Abdel-Malek, Z., M.C. Scott, I. Suzuki, A. Tada, S. Im, L. Lamoreux, S. Ito, G. Barsh, and V.J. Hearing. 2000. The melanocortin-1 receptor is a key regulator of human cutaneous pigmentation. Pigment Cell Res. 13 Suppl 8:156-162.

Aoki, H., Y. Yamada, A. Hara, and T. Kunisada. 2009. Two distinct types of mouse melanocyte: differential signaling requirement for the maintenance of noncutaneous and dermal versus epidermal melanocytes. Development. 136:25112521.

Bernstein, A., B. Chabot, P. Dubreuil, A. Reith, K. Nocka, S. Majumder, P. Ray, and P. Besmer. 1990. The mouse W/c-kit locus. Ciba Found Symp. 148:158-166; discussion 166-172.

Brito, F.C., and L. Kos. 2008. Timeline and distribution of melanocyte precursors in the mouse heart. Pigment Cell Melanoma Res. 21:464-470.

Burchill, S.A., A.J. Thody, and S. Ito. 1986. Melanocyte-stimulating hormone, tyrosinase activity and the regulation of eumelanogenesis and phaeomelanogenesis in the hair follicular melanocytes of the mouse. Journal of Endocrinology. 109:15-21.

Cable, J., and K.P. Steel. 1991. Identification of two types of melanocyte within the stria vascularis of the mouse inner ear. Pigment Cell Res. 4:87-101.

Chintala, S., W. Li, M.L. Lamoreux, S. Ito, K. Wakamatsu, E.V. Sviderskaya, D.C. Bennett, Y.M. Park, W.A. Gahl, M. Huizing, R.A. Spritz, S. Ben, E.K. Novak, J. Tan, and R.T. Swank. 2005. Slc7a11 gene controls production of pheomelanin pigment and proliferation of cultured cells. Proc Natl Acad Sci U S A. 102:1096410969.

Chou, W.C., M. Takeo, P. Rabbani, H. Hu, W. Lee, Y.R. Chung, J. Carucci, P. Overbeek, and M. Ito. 2013. Direct migration of follicular melanocyte stem cells to the epidermis after wounding or UVB irradiation is dependent on Mc1r signaling. Nat Med. 19:924-929.

Cichorek, M., M. Wachulska, A. Stasiewicz, and A. Tyminska. 2013. Skin melanocytes: biology and development. Postepy Dermatol Alergol. 30:30-41.

Coker, D.J., M.S. Pratchett, and P.L. Munday. 2009. Coral bleaching and habitat degradation increase susceptibility to predation for coral-dwelling fishes. Behavioral Ecology. 20:1204-1210. 
Corre, S., A. Primot, E. Sviderskaya, D.C. Bennett, S. Vaulont, C.R. Goding, and M.D. Galibert. 2004. UV-induced expression of key component of the tanning process, the POMC and MC1R genes, is dependent on the p-38-activated upstream stimulating factor-1 (USF-1). J Biol Chem. 279:51226-51233.

d'Ischia, M., K. Wakamatsu, F. Cicoira, E. Di Mauro, J.C. Garcia-Borron, S. Commo, I. Galvan, G. Ghanem, K. Kenzo, P. Meredith, A. Pezzella, C. Santato, T. Sarna, J.D. Simon, L. Zecca, F.A. Zucca, A. Napolitano, and S. Ito. 2015. Melanins and melanogenesis: from pigment cells to human health and technological applications. Pigment Cell Melanoma Res. 28:520-544.

El-Mowafy, A.M., and D.F. Biggs. 2001. ET(B) receptor activates adenylyl cyclase via a c-PLA(2)-dependent mechanism: a novel counterregulatory mechanism of ETinduced contraction in airway smooth muscle. Biochem Biophys Res Commun. 286:388-393.

Elleder, M., and J. Borovansky. 2001. Autofluorescence of melanins induced by ultraviolet radiation and near ultraviolet light. A histochemical and biochemical study. Histochem J. 33:273-281.

Fuller, B.B., J.B. Lunsford, and D.S. Iman. 1987. Alpha-melanocyte-stimulating hormone regulation of tyrosinase in Cloudman S-91 mouse melanoma cell cultures. J Biol Chem. 262:4024-4033.

Furth, P.A., L. St Onge, H. Boger, P. Gruss, M. Gossen, A. Kistner, H. Bujard, and L. Hennighausen. 1994. Temporal control of gene expression in transgenic mice by a tetracycline-responsive promoter. Proc Natl Acad Sci U S A. 91:9302-9306.

Furumura, M., C. Sakai, Z. Abdel-Malek, G.S. Barsh, and V.J. Hearing. 1996. The interaction of agouti signal protein and melanocyte stimulating hormone to regulate melanin formation in mammals. Pigment Cell Res. 9:191-203.

Gantz, I., and T.M. Fong. 2003. The melanocortin system. Am J Physiol Endocrinol Metab. 284:E468-474.

Garcia, R.J., A. Ittah, S. Mirabal, J. Figueroa, L. Lopez, A.B. Glick, and L. Kos. 2008. Endothelin 3 induces skin pigmentation in a keratin-driven inducible mouse model. J Invest Dermatol. 128:131-142.

Giebel, L.B., and R.A. Spritz. 1991. Mutation of the KIT (mast/stem cell growth factor receptor) protooncogene in human piebaldism. Proc Natl Acad Sci U S A. 88:8696-8699.

Gola, M., R. Czajkowski, A. Bajek, A. Dura, and T. Drewa. 2012. Melanocyte stem cells: biology and current aspects. Med Sci Monit. 18:RA155-159. 
Greco, V., T. Chen, M. Rendl, M. Schober, H.A. Pasolli, N. Stokes, J. Dela Cruz-Racelis, and E. Fuchs. 2009. A two-step mechanism for stem cell activation during hair regeneration. Cell Stem Cell. 4:155-169.

Halaban, R., S.H. Pomerantz, S. Marshall, and A.B. Lerner. 1984. Tyrosinase activity and abundance in Cloudman melanoma cells. Arch Biochem Biophys. 230:383-387.

Hearing, V.J. 2005. Biogenesis of pigment granules: a sensitive way to regulate melanocyte function. J Dermatol Sci.37:3-14.

Hearing, V.J. 2011. Determination of melanin synthetic pathways. J Invest Dermatol. 131:E8-E11.

Hill, G.E. 1990. Female House Finches Prefer Colorful Males - Sexual Selection for a Condition-Dependent Trait. Anim Behav. 40:563-572.

Hosoda, K., R.E. Hammer, J.A. Richardson, A.G. Baynash, J.C. Cheung, A. Giaid, and M. Yanagisawa. 1994. Targeted and natural (piebald-lethal) mutations of endothelin-B receptor gene produce megacolon associated with spotted coat color in mice. Cell. 79:1267-1276.

Imokawa, G., T. Kobayashi, M. Miyagishi, K. Higashi, and Y. Yada. 1997. The role of endothelin-1 in epidermal hyperpigmentation and signaling mechanisms of mitogenesis and melanogenesis. Pigment Cell Res. 10:218-228.

Imokawa, G., M. Miyagishi, and Y. Yada. 1995. Endothelin-1 as a new melanogen: coordinated expression of its gene and the tyrosinase gene in UVB-exposed human epidermis. J Invest Dermatol. 105:32-37.

Imokawa, G., Y. Yada, and M. Kimura. 1996. Signalling mechanisms of endothelininduced mitogenesis and melanogenesis in human melanocytes. Biochemical Journal. 314 ( Pt 1):305-312.

Ito, S., Y. Nakanishi, R.K. Valenzuela, M.H. Brilliant, L. Kolbe, and K. Wakamatsu. 2011. Usefulness of alkaline hydrogen peroxide oxidation to analyze eumelanin and pheomelanin in various tissue samples: application to chemical analysis of human hair melanins. Pigment Cell Melanoma Res. 24:605-613.

Ito, S., and K. Wakamatsu. 2003. Quantitative analysis of eumelanin and pheomelanin in humans, mice, and other animals: a comparative review. Pigment Cell Res. 16:523-531. 
Kaelin, C.B., X. Xu, L.Z. Hong, V.A. David, K.A. McGowan, A. Schmidt-Kuntzel, M.E. Roelke, J. Pino, J. Pontius, G.M. Cooper, H. Manuel, W.F. Swanson, L. Marker, C.K. Harper, A. van Dyk, B. Yue, J.C. Mullikin, W.C. Warren, E. Eizirik, L. Kos, S.J. O'Brien, G.S. Barsh, and M. Menotti-Raymond. 2012. Specifying and sustaining pigmentation patterns in domestic and wild cats. Science. 337:15361541.

Kaidbey, K.H., P.P. Agin, R.M. Sayre, and A.M. Kligman. 1979. Photoprotection by melanin--a comparison of black and Caucasian skin. J Am Acad Dermatol. 1:249260.

Kobayashi, N., A. Nakagawa, T. Muramatsu, Y. Yamashina, T. Shirai, M.W. Hashimoto, Y. Ishigaki, T. Ohnishi, and T. Mori. 1998. Supranuclear melanin caps reduce ultraviolet induced DNA photoproducts in human epidermis. J Invest Dermatol. 110:806-810.

Kuzumaki, T., A. Matsuda, K. Wakamatsu, S. Ito, and K. Ishikawa. 1993. Eumelanin biosynthesis is regulated by coordinate expression of tyrosinase and tyrosinaserelated protein-1 genes. Exp Cell Res. 207:33-40.

Le Pape, E., K. Wakamatsu, S. Ito, R. Wolber, and V.J. Hearing. 2008. Regulation of eumelanin/pheomelanin synthesis and visible pigmentation in melanocytes by ligands of the melanocortin 1 receptor. Pigment Cell Melanoma Res. 21:477-486.

Liao, C.P., R.C. Booker, S.J. Morrison, and L.Q. Le. 2017. Identification of hair shaft progenitors that create a niche for hair pigmentation. Genes Dev. 31:744-756.

Mackenzie, M.A., S.A. Jordan, P.S. Budd, and I.J. Jackson. 1997. Activation of the receptor tyrosine kinase Kit is required for the proliferation of melanoblasts in the mouse embryo. Developmental Biology. 192:99-107.

Mattei, S., M.P. Colombo, C. Melani, A. Silvani, G. Parmiani, and M. Herlyn. 1994. Expression of cytokine/growth factors and their receptors in human melanoma and melanocytes. Int J Cancer. 56:853-857.

Michaud, E.J., S.J. Bultman, L.J. Stubbs, and R.P. Woychik. 1993. The embryonic lethality of homozygous lethal yellow mice (Ay/Ay) is associated with the disruption of a novel RNA-binding protein. Genes Dev. 7:1203-1213.

Murphy, G., A.R. Young, H.C. Wulf, D. Kulms, and T. Schwarz. 2001. The molecular determinants of sunburn cell formation. Experimental Dermatology. 10:155-160.

Nishimura, E.K. 2011. Melanocyte stem cells: a melanocyte reservoir in hair follicles for hair and skin pigmentation. Pigment Cell Melanoma Res. 24:401-410. 
Ollmann, M.M., M.L. Lamoreux, B.D. Wilson, and G.S. Barsh. 1998. Interaction of Agouti protein with the melanocortin 1 receptor in vitro and in vivo. Genes Dev. 12:316-330.

Ozeki, H., S. Ito, K. Wakamatsu, and A.J. Thody. 1996. Spectrophotometric characterization of eumelanin and pheomelanin in hair. Pigment Cell Res. 9:265270 .

Premi, S., S. Wallisch, C.M. Mano, A.B. Weiner, A. Bacchiocchi, K. Wakamatsu, E.J. Bechara, R. Halaban, T. Douki, and D.E. Brash. 2015. Photochemistry. Chemiexcitation of melanin derivatives induces DNA photoproducts long after UV exposure. Science. 347:842-847.

Robbins, L.S., J.H. Nadeau, K.R. Johnson, M.A. Kelly, L. Roselli-Rehfuss, E. Baack, K.G. Mountjoy, and R.D. Cone. 1993. Pigmentation phenotypes of variant extension locus alleles result from point mutations that alter MSH receptor function. Cell. 72:827-834.

Saldana-Caboverde, A., and L. Kos. 2010. Roles of endothelin signaling in melanocyte development and melanoma. Pigment Cell Melanoma Res. 23:160-170.

Sato-Jin, K., E.K. Nishimura, E. Akasaka, W. Huber, H. Nakano, A. Miller, J. Du, M. Wu, K. Hanada, D. Sawamura, D.E. Fisher, and G. Imokawa. 2008. Epistatic connections between microphthalmia-associated transcription factor and endothelin signaling in Waardenburg syndrome and other pigmentary disorders. Faseb Journal. 22:1155-1168.

Schinelli, S., P. Zanassi, M. Paolillo, H. Wang, A. Feliciello, and V. Gallo. 2001. Stimulation of endothelin B receptors in astrocytes induces cAMP response element-binding protein phosphorylation and c-fos expression via multiple mitogen-activated protein kinase signaling pathways. J Neurosci. 21:8842-8853.

Scott, M.C., I. Suzuki, and Z.A. Abdel-Malek. 2002. Regulation of the human melanocortin 1 receptor expression in epidermal melanocytes by paracrine and endocrine factors and by ultraviolet radiation. Pigment Cell Res. 15:433-439.

Setchell, J.M., T. Smith, E.J. Wickings, and L.A. Knapp. 2008. Social correlates of testosterone and ornamentation in male mandrills. Hormones and Behavior. 54:365-372.

Shin, M.K., J.M. Levorse, R.S. Ingram, and S.M. Tilghman. 1999. The temporal requirement for endothelin receptor-B signalling during neural crest development. Nature. 402:496-501. 
Takeo, M., W. Lee, P. Rabbani, Q. Sun, H. Hu, C.H. Lim, P. Manga, and M. Ito. 2016. EdnrB Governs Regenerative Response of Melanocyte Stem Cells by Crosstalk with Wnt Signaling. Cell Rep. 15:1291-1302.

Thingnes, J., T.J. Lavelle, E. Hovig, and S.W. Omholt. 2012. Understanding the melanocyte distribution in human epidermis: an agent-based computational model approach. PLoS One. 7:e40377.

Van Raamsdonk, C.D., G.S. Barsh, K. Wakamatsu, and S. Ito. 2009. Independent regulation of hair and skin color by two G protein-coupled pathways. Pigment Cell Melanoma Res. 22:819-826.

Van Raamsdonk, C.D., K.R. Fitch, H. Fuchs, M.H. de Angelis, and G.S. Barsh. 2004. Effects of G-protein mutations on skin color. Nat Genet. 36:961-968.

Wakamatsu, K., and S. Ito. 2002. Advanced chemical methods in melanin determination. Pigment Cell Res. 15:174-183.

Wakamatsu, K., S. Ito, and J.L. Rees. 2002. The usefulness of 4-amino-3hydroxyphenylalanine as a specific marker of pheomelanin. Pigment Cell Res. 15:225-232.

Wakamatsu, K., Y. Nakanishi, N. Miyazaki, L. Kolbe, and S. Ito. 2012. UVA-induced oxidative degradation of melanins: fission of indole moiety in eumelanin and conversion to benzothiazole moiety in pheomelanin. Pigment Cell Melanoma Res. 25:434-445.

Yoshida, H., T. Kunisada, T. Grimm, E.K. Nishimura, E. Nishioka, and S.I. Nishikawa. 2001. Review: melanocyte migration and survival controlled by SCF/c-kit expression. J Investig Dermatol Symp Proc. 6:1-5. 
CHAPTER III

CONCLUSIONS, FUTURE DIRECTIONS AND IMPLICATIONS 


\section{CONCLUSIONS, FUTURE DIRECTIONS AND IMPLICATIONS}

\subsection{Conclusions, Future Directions and Implications}

The beauty and vast array of coloration and patterning seen around the globe in all living organisms including plants, birds, insects and mammals is due to the production of pigments. Pigment plays a significant role in camouflage and in the overall fitness and survival of the organism (Coker et al., 2009). The coloration and patterning of animals allow them to blend in with their environment to avoid predation, attract mates and give warning signals to other animals (Hill, 1990; Setchell et al., 2008). Understanding the different pathways involved in pigment production will not only give us a better idea on patterning and coloration but also has important implications in human health.

The pigment produced in the human skin has both protective and damaging effects depending on the quantity and type of melanin. The amount of cell damage caused by UV radiation is inversely related to the amount of pigment found in the skin (Tadokoro et al., 2003). Higher levels of pigment give greater protection from DNA damage by preventing the formation of pyrimidine dimers and other photoproducts that may cause mutations (Smit et al., 2001). Pigment in the upper epidermis of the human skin protects underlying cells within the epidermis from UV damage but also promotes apoptosis in individuals with darker skin (Yamaguchi et al., 2006). The increased apoptosis allows for a higher turnover of cells preventing mutated cells from turning carcinogenic. Genetic studies suggest that evolutionarily, humans who lived closer to the equatorial line had darker skin pigmentation in order to protect the skin from UV exposure in comparison to those in higher latitudes where UV exposure is less (Jablonski, 2012; Jablonski and Chaplin, 2000). 
In this study I characterized an alternate way of producing the dark pigment, eumelanin, independent of Mc1r signaling. I found that when Edn3 is overexpressed in mice that have a nonfunctional pigmentation pathway because of the inactivation of Mc1r, the coat color could be partially restored. I also found that Edn3 signaling is not required during embryonic development or during early post-natal development for its role in regulating pigment production in hairs. Thus, the developmental role of Edn3 regulating the expansion of the melanocyte precursor population can be separated from the effect it has on the follicular melanocytes.

Interestingly, I found that when transgenic expression of Edn3 was removed during embryonic development but was restored upon birth, $A^{y} ;$ K5-tTA;TRE-Edn3-lacZ mice only displayed a dark pigmentation phenotype after the start of a new hair cycle. These results correlate with a recent finding by Takeo et al. that Ednrb signaling downstream of Wnt signaling activates and maintains MSCs in the hair bulge during early anagen which will repopulate the hair follicle (Takeo et al., 2016). Based on my results and those of Takeo et al., I propose that further investigations should be carried out to evaluate the behavior of MSCs in the bulge and sub bulge of hair follicles upon Edn3 overexpression. I predict that Edn3 can only have an effect on mature follicular melanocytes and regulate their levels of eumelanin production if the stem cell precursors are also exposed to Edn3 signaling.

Although I was able to show that Mc1r activation is not required for the effects of Edn3 overexpression on the rescuing of coat color phenotype, some of its downstream targets may be engaged by Ednrb activation. To elucidate the intracellular events required 
downstream of Ednrb activation to promote coat color rescue, both in vitro and in vivo experiments will need to be performed. Melanocyte cells lines that respond to Edn3 by increasing pigmentation levels can be incubated with chemical inhibitors to various kinases known to function downstream of Ednrb or Mc1r such as PKA, PKC, MAPK and AKT (Chapter 1, Figure 1.1). The inhibitors that are capable of preventing the Edn3induced increase in pigmentation will provide information of the pathway(s) being used by Edn3. In attempted preliminary studies, I induced immortalized murine melanocyte cell lines, Melan-a, Melan-e, Melb-a, and B16, with $1 \mathrm{~nm}$ and $10 \mathrm{~nm}$ Edn3 (Bennett et al., 1987; Riley, 1963; Robbins et al., 1993; Sviderskaya et al., 1995). Based on previous studies carried out with primary human melanocytes that had been exposed to Edn1 and showed activation of the downstream effectors of Ednrb, I expected to see increases in pigmentation levels in the murine cells upon Edn3 induction (Kadekaro et al., 2005; Swope and Abdel-Malek, 2016; von Koschembahr et al., 2015). Unfortunately, the murine cell lines did not respond to Edn3 or Edn1 by showing increases in pigmentation levels or proliferation rates. It is likely that these cells do not express Ednrb (Juliano Freitas, personal communication). The ability to perform the pathway inhibition experiments in vitro will require the identification of other cell lines that do express Ednrb or possibly the utilization of primary melanocyte cultures. It would, however, be more informative if similar types of experiments could be performed in vivo. Park et al. successfully inhibited pigment production and lighten the skin and coat of pigmented guinea pigs by topically applying $100 \mu \mathrm{M}$ PKC inhibitor in a 25\% Dimethylsulfoxide and $75 \%$ propylene glycol solution (Park et al., 2004). .Topical application of inhibitors to the skins of depilated $A^{y} ;$ K5-tTA;TRE-Edn3-lacZ and Mclr ${ }^{e / e} ;$ K5-tTA;TRE-Edn3-lacZ mice 
could be done until new hair is protruding through the skin and the coat color can be analyzed.

Further experiments may be performed by overexpressing $E d n 3$ in other mouse strains with varying pigmentation phenotypes. It would be of interest to see if Edn3 will be able to rescue phenotypes in mice that have mutations in genes directly involved in pigment regulation. The effects of Edn3 overexpression may be investigated with dox treatments similar to the ones performed in this study by turning on transgenic expression during development and at time of birth. By manipulating Edn3 overexpression during development and early post-natal development in different mouse mutants, we will be able to understand how Edn3 interacts alongside or independent of signaling molecules downstream of Mc1r signaling that affect pigmentation.

Since $A^{y}$ mice overexpress ASP and have functional Mc1r on the cell surface, the manipulation of Edn3 overexpression in $M c 1 r^{e / e}$ mice at different time points will allow for a visualization of the phenotypes completely independent of a functional Mclr and comparison with the $A^{y}$ results. These results will verify the timing requirement of Ednrb signaling in pigmentation completely independent of Mc1r signaling.

Additionally, experiments crossing K5-tTA;TRE-Edn3-lacZ mice into mice with mutations in genes involved the biochemical pathway of pigment production such as $D c t$, Trp1 and Pmel17 may be done. Mice with mutations in the Slaty locus encoding for Dct have decreased Tyr activity, a diluted coat color, decreased differentiation of melanocytes, fewer numbers of mature melanoblasts and display time-specific changes in eumelanin and pheomelanin levels (Hirobe and Abe, 2006; Hirobe et al., 2006). Mutations in the Brown locus encoding for Trpl affect tyrosinase activity in the 
melanosome, decrease the number of mature melanosomes, compromise melanocyte proliferation and have a brown coat color (Lamoreux et al., 2001; Sarangarajan et al., 2000). Mutations in the Silver locus encoding for Pmell7 affects melanin levels, dysfunctional melanosome formation and a diluted coat color (Theos et al., 2005). If Edn3 overexpression is capable of rescuing the coat color phenotype of these mice, its overall role in eumelanin production will be further underscored and its relationship to other aspects of pigmentation such as melanosome maturation and trafficking unraveled. Furthermore, the outcome of these studies may be very relevant to human disease since mice containing mutations in the silver, brown, and other loci such as albino and pinkeyed are homologous to human gene mutations found in different types of albinism (Oetting and King, 1999). As such, its usefulness as a potential therapeutic molecule for hypopigmentary disorders will be enhanced.

Eumelanin has various protective roles against UV-induced DNA damage. It acts as a natural sunscreen by creating supranuclear caps in keratinocytes shielding their DNA, and preventing UV rays from reaching cells deeper in the skin (Kadekaro et al., 2003). Eumelanin was shown to scatter and absorb up to about 50-75\% of UV-radiation (Thody et al., 1991) and protect against oxidative stress by acting as a scavenger for reactive oxygen species (ROS) with similar activity to superoxide dismutase (Brenner and Hearing, 2008).

People with fairer skin tend to have higher susceptibility to UV-induced cell damage than those with darker skin. In humans, the red hair phenotype results from specific $M C l R$ variants and has been linked to a higher risk of cancer development independent of UV exposure because of the increased production of superoxides 
associated with pheomelanin production and the instability of pheomelanin intermediates (Mitra et al., 2012; Panzella et al., 2010; van Nieuwpoort et al., 2004). Upon UV exposure, pheomelanin increases oxidative stress, and pheomelansomes are degraded and become "melanin dust" in the suprabasal area of the skin becoming cytotoxic and mutagenic (Chedekel et al., 1978; Felix et al., 1978). Since pheomelanin is degraded upon UV exposure, the ability to protect against UV radiation is diminished, which is not seen in individuals who produce eumelanin (Armstrong and Kricker, 2001; Pennello et al., 2000; Riley, 2003).

Apart from increasing protection through pigment production, activation of the Mc1r signaling pathway has also been shown to aid in the UV-damage response. Mc1r increases repair of DNA photoproducts through enhancement of nucleotide excision repair (NER) and reduction of ROS levels in the cell (Abdel-Malek et al., 2008; Kadekaro et al., 2005; Kadekaro et al., 2010). When human melanocytes are induced with $\alpha-\mathrm{MSH}$ in vitro, an increase in the repair of CPDs occurs and antiapoptotic pathways are activated resulting in a reduction of UV-induced cell death (Corre et al., 2004; Kadekaro et al., 2005; von Koschembahr et al., 2015). Similarly, when human melanocytes are exposed to UV, treatment with Edn1 increases cell survival and decreases the production of $\mathrm{H}_{2} \mathrm{O}_{2}$ and DNA photoproducts. These effects are mediated by the activation of the Phosphoinositide 3-kinase/ Protein Kinase B (PI3K/AKT) pathway and increase in Mitf and regulation of B-cell Lymphoma 2 (Bcl2) (Kadekaro et al., 2005; von Koschembahr et al., 2015). In contrast to $\alpha-\mathrm{MSH}$, the effects mediated by Edn1 seem to be elicited independent of cAMP production in vitro. 
Currently, very little information is available regarding the activation of NER downstream of Ednrb and its putative role in DNA repair. Furthermore, there is no description in the literature about base excision repair (BER) activity in response to Mclr or Ednrb signaling after UV induced cell damage. Based on the findings that the Mclr pathway is involved both in pigment production and DNA repair, I propose that the same are likely effects of the endothelin pathway. In order to understand the role of Edn3 signaling in response to UV-induced DNA damage, future studies using $M c 1 r^{e / e} ; \mathrm{K} 5$ tTA;TRE-Edn3-lacZ mice in an albino background should be carried out. The albino background will allow us to isolate the effects of Edn3 in response to UV-radiation independent of melanin and Mc1r signaling. At four weeks of age, mice could be exposed to UV at a dose equivalent to a minor sunburn at mid-latitudes (Noonan et al., 2001). Mice should be euthanized 24 hours after UV exposure and dorsal skin samples collected and sectioned in order to perform antibody staining against 8-oxo-7,8-dihydroxyguanine and cyclobutane pyrimidine dimers (Benaduce et al., 2014). I expect the results to be different than those reported by Benaduce at al. using the K5-tTA;TRE-Edn3-lacZ mice. Their results showed that K5-tTA;TRE-Edn3-lacZ mice had an increased amount of DNA damage due to the increased pigmentation on the skin of mice. Based on the Edn1 in vitro data reported by von Koschembahr et al., I believe that both K5-tTA;TRE-Edn3-lacZ and $M c 1 r^{e / e} ; K 5-t T A ; T R E-E d n 3-l a c Z$ mice in an albino background will have less DNA damage than non-transgenic controls since pigment will not contribute to a higher levels of oxidative stress.

Additional studies investigating protein activity of enzymes involved in DNA repair can also be performed. Overexpressing Edn3 in mice and melanocyte cell lines 
along with UV radiation will allow for the study of the activity of repair proteins using biochemical assays (Beaver et al., 2016; Deng et al., 2017; Lai et al., 2016; Liu et al., 2007). These studies would determine if Edn 3 has a putative role on protein activity after UV radiation. Some of the proteins of interest are the BER-related apurinic/apyrimidinic endonuclease 1(Ape1) and Flap endonuclease 1 (Fen1) and he NER-related ERCC1, and Xeroderma Pigmentosum (XP).

Edn3 has vasoconstriction functions and may not be the ideal molecule for use in therapy. Thus, I suggest a high-throughput screening approach to identify small molecules that share Edn3's capacity to regulate eumelanin production on melanocytes but cannot affect vascular smooth muscle cells. Studies in mice using topical application of small-molecules can effect pigment production in mice. Application of smallmolecules for CREB-regulated transcription co-activators (CRTC) to mice skin can positively regulate MITF and produce eumelanin, while addition of small-molecule saltinducible kinases (SIK) inhibit MITF expression resulting in a loss of eumelanin production (Clark et al., 2012; Horike et al., 2010; Mujahid et al., 2017). A recent study was able to produce dark pigmentation by using small-molecule inhibitors against SIK in $M c 1 r^{e / e}$ mice and human melanocytes in vitro (Mujahid et al., 2017). Topical treatment using small-molecules that regulate pigmentation will give us the ability to control skin and hair pigmentation independent of UV exposure. These treatments would in turn increase protection against $\mathrm{UV}$ radiation and have the potential to prevent skin cancer.

The role of Edn3 in pigment production and in response to UV-induced DNA damage has many promising implications in human health. In this study I was able to describe a novel role for Edn3 signaling in pigment production independent of Mc1r 
signaling. Additionally, I described that pigment production regulation by Edn3 signaling is independent of its well-established developmental role. These findings expand our knowledge of pigment production and provide us with novel ways to address human pigmentary disorders and possibly UV independent protective skin tanning.

\subsection{References}

Abdel-Malek, Z.A., J. Knittel, A.L. Kadekaro, V.B. Swope, and R. Starner. 2008. The melanocortin 1 receptor and the UV response of human melanocytes--a shift in paradigm. Photochem Photobiol. 84:501-508.

Armstrong, B.K., and A. Kricker. 2001. The epidemiology of UV induced skin cancer. $J$ Photochem Photobiol B. 63:8-18.

Beaver, J.M., Y. Lai, S.J. Rolle, and Y. Liu. 2016. Proliferating cell nuclear antigen prevents trinucleotide repeat expansions by promoting repeat deletion and hairpin removal. DNA Repair (Amst). 48:17-29.

Benaduce, A.P., D. Batista, G. Grilo, K. Jorge, D. Cardero, C. Milikowski, and L. Kos. 2014. Novel UV-induced melanoma mouse model dependent on Endothelin3 signaling. Pigment Cell Melanoma Res. 27:839-842.

Bennett, D.C., P.J. Cooper, and I.R. Hart. 1987. A line of non-tumorigenic mouse melanocytes, syngeneic with the B16 melanoma and requiring a tumour promoter for growth. Int J Cancer. 39:414-418.

Brenner, M., and V.J. Hearing. 2008. The protective role of melanin against UV damage in human skin. Photochem Photobiol. 84:539-549.

Chedekel, M.R., S.K. Smith, P.W. Post, A. Pokora, and D.L. Vessell. 1978. Photodestruction of pheomelanin: role of oxygen. Proc Natl Acad Sci U S A. 75:5395-5399.

Clark, K., K.F. MacKenzie, K. Petkevicius, Y. Kristariyanto, J. Zhang, H.G. Choi, M. Peggie, L. Plater, P.G. Pedrioli, E. McIver, N.S. Gray, J.S. Arthur, and P. Cohen. 2012. Phosphorylation of CRTC 3 by the salt-inducible kinases controls the interconversion of classically activated and regulatory macrophages. Proc Natl Acad Sci U S A. 109:16986-16991. 
Coker, D.J., M.S. Pratchett, and P.L. Munday. 2009. Coral bleaching and habitat degradation increase susceptibility to predation for coral-dwelling fishes. Behavioral Ecology. 20:1204-1210.

Corre, S., A. Primot, E. Sviderskaya, D.C. Bennett, S. Vaulont, C.R. Goding, and M.D. Galibert. 2004. UV-induced expression of key component of the tanning process, the POMC and MC1R genes, is dependent on the p-38-activated upstream stimulating factor-1 (USF-1). J Biol Chem. 279:51226-51233.

Deng, X.D., Q. Gao, W. Zhang, B. Zhang, Y. Ma, L.X. Zhang, C. Muer, Y. Xie, and Y. Liu. 2017. The age-related expression decline of ERCC1 and XPF for forensic age estimation: A preliminary study. J Forensic Leg Med. 49:15-19.

Felix, C.C., J.S. Hyde, T. Sarna, and R.C. Sealy. 1978. Melanin photoreactions in aerated media: electron spin resonance evidence for production of superoxide and hydrogen peroxide. Biochem Biophys Res Commun. 84:335-341.

Hill, G.E. 1990. Female House Finches Prefer Colorful Males - Sexual Selection for a Condition-Dependent Trait. Anim Behav. 40:563-572.

Hirobe, T., and H. Abe. 2006. The slaty mutation affects the morphology and maturation of melanosomes in the mouse melanocytes. Pigment Cell Res. 19:454-459.

Hirobe, T., K. Wakamatsu, S. Ito, Y. Kawa, Y. Soma, and M. Mizoguchi. 2006. The slaty mutation affects eumelanin and pheomelanin synthesis in mouse melanocytes. Eur J Cell Biol. 85:537-549.

Horike, N., A. Kumagai, Y. Shimono, T. Onishi, Y. Itoh, T. Sasaki, K. Kitagawa, O. Hatano, H. Takagi, T. Susumu, H. Teraoka, K. Kusano, Y. Nagaoka, H. Kawahara, and H. Takemori. 2010. Downregulation of SIK2 expression promotes the melanogenic program in mice. Pigment Cell Melanoma Res. 23:809-819.

Jablonski, N.G. 2012. The evolution of human skin colouration and its relevance to health in the modern world. $J$ R Coll Physicians Edinb. 42:58-63.

Jablonski, N.G., and G. Chaplin. 2000. The evolution of human skin coloration. J Hum Evol. 39:57-106.

Kadekaro, A.L., R. Kavanagh, H. Kanto, S. Terzieva, J. Hauser, N. Kobayashi, S. Schwemberger, J. Cornelius, G. Babcock, H.G. Shertzer, G. Scott, and Z.A. Abdel-Malek. 2005. alpha-Melanocortin and endothelin-1 activate antiapoptotic pathways and reduce DNA damage in human melanocytes. Cancer Res. 65:42924299. 
Kadekaro, A.L., R.J. Kavanagh, K. Wakamatsu, S. Ito, M.A. Pipitone, and Z.A. AbdelMalek. 2003. Cutaneous photobiology. The melanocyte vs. the sun: who will win the final round? Pigment Cell Res. 16:434-447.

Kadekaro, A.L., S. Leachman, R.J. Kavanagh, V. Swope, P. Cassidy, D. Supp, M. Sartor, S. Schwemberger, G. Babcock, K. Wakamatsu, S. Ito, A. Koshoffer, R.E. Boissy, P. Manga, R.A. Sturm, and Z.A. Abdel-Malek. 2010. Melanocortin 1 receptor genotype: an important determinant of the damage response of melanocytes to ultraviolet radiation. Faseb Journal. 24:3850-3860.

Lai, Y., H. Budworth, J.M. Beaver, N.L. Chan, Z. Zhang, C.T. McMurray, and Y. Liu. 2016. Crosstalk between MSH2-MSH3 and polbeta promotes trinucleotide repeat expansion during base excision repair. Nat Commun. 7:12465.

Lamoreux, M.L., K. Wakamatsu, and S. Ito. 2001. Interaction of major coat color gene functions in mice as studied by chemical analysis of eumelanin and pheomelanin. Pigment Cell Res. 14:23-31.

Liu, Y., R. Prasad, W.A. Beard, P.S. Kedar, E.W. Hou, D.D. Shock, and S.H. Wilson. 2007. Coordination of steps in single-nucleotide base excision repair mediated by apurinic/apyrimidinic endonuclease 1 and DNA polymerase beta. $J$ Biol Chem. 282:13532-13541.

Mitra, D., X. Luo, A. Morgan, J. Wang, M.P. Hoang, J. Lo, C.R. Guerrero, J.K. Lennerz, M.C. Mihm, J.A. Wargo, K.C. Robinson, S.P. Devi, J.C. Vanover, J.A. D'Orazio, M. McMahon, M.W. Bosenberg, K.M. Haigis, D.A. Haber, Y. Wang, and D.E. Fisher. 2012. An ultraviolet-radiation-independent pathway to melanoma carcinogenesis in the red hair/fair skin background. Nature. 491:449-453.

Mujahid, N., Y. Liang, R. Murakami, H.G. Choi, A.S. Dobry, J. Wang, Y. Suita, Q.Y. Weng, J. Allouche, L.V. Kemeny, A.L. Hermann, E.M. Roider, N.S. Gray, and D.E. Fisher. 2017. A UV-Independent Topical Small-Molecule Approach for Melanin Production in Human Skin. Cell Rep. 19:2177-2184.

Noonan, F.P., J.A. Recio, H. Takayama, P. Duray, M.R. Anver, W.L. Rush, E.C. De Fabo, and G. Merlino. 2001. Neonatal sunburn and melanoma in mice. Nature. 413:271-272.

Oetting, W.S., and R.A. King. 1999. Molecular basis of albinism: mutations and polymorphisms of pigmentation genes associated with albinism. Hum Mutat. 13:99-115. 
Panzella, L., G. Szewczyk, M. d'Ischia, A. Napolitano, and T. Sarna. 2010. Zinc-induced structural effects enhance oxygen consumption and superoxide generation in synthetic pheomelanins on UVA/visible light irradiation. Photochem Photobiol. $86: 757-764$.

Park, H.Y., J. Lee, S. Gonzalez, M.A. Middelkamp-Hup, S. Kapasi, S. Peterson, and B.A. Gilchrest. 2004. Topical application of a protein kinase $\mathrm{C}$ inhibitor reduces skin and hair pigmentation. J Invest Dermatol. 122:159-166.

Pennello, G., S. Devesa, and M. Gail. 2000. Association of surface ultraviolet B radiation levels with melanoma and nonmelanoma skin cancer in United States blacks. Cancer Epidemiol Biomarkers Prev. 9:291-297.

Riley, P.A. 2003. Melanogenesis and melanoma. Pigment Cell Res. 16:548-552.

Riley, V. 1963. Enzymatic determination of transmissible replicating factors associated with mouse tumors. Ann N Y Acad Sci. 100:762-790.

Robbins, L.S., J.H. Nadeau, K.R. Johnson, M.A. Kelly, L. Roselli-Rehfuss, E. Baack, K.G. Mountjoy, and R.D. Cone. 1993. Pigmentation phenotypes of variant extension locus alleles result from point mutations that alter MSH receptor function. Cell. 72:827-834.

Sarangarajan, R., Y. Zhao, G. Babcock, J. Cornelius, M.L. Lamoreux, and R.E. Boissy. 2000. Mutant alleles at the brown locus encoding tyrosinase-related protein-1 (TRP-1) affect proliferation of mouse melanocytes in culture. Pigment Cell Res. $13: 337-344$.

Setchell, J.M., T. Smith, E.J. Wickings, and L.A. Knapp. 2008. Social correlates of testosterone and ornamentation in male mandrills. Hormones and Behavior. 54:365-372.

Smit, N.P., A.A. Vink, R.M. Kolb, M.J. Steenwinkel, P.T. van den Berg, F. van Nieuwpoort, L. Roza, and S. Pavel. 2001. Melanin offers protection against induction of cyclobutane pyrimidine dimers and 6-4 photoproducts by UVB in cultured human melanocytes. Photochem Photobiol. 74:424-430.

Sviderskaya, E.V., W.F. Wakeling, and D.C. Bennett. 1995. A cloned, immortal line of murine melanoblasts inducible to differentiate to melanocytes. Development. 121:1547-1557.

Swope, V.B., and Z.A. Abdel-Malek. 2016. Significance of the Melanocortin 1 and Endothelin B Receptors in Melanocyte Homeostasis and Prevention of SunInduced Genotoxicity. Front Genet. 7:146. 
Tadokoro, T., N. Kobayashi, B.Z. Zmudzka, S. Ito, K. Wakamatsu, Y. Yamaguchi, K.S. Korossy, S.A. Miller, J.Z. Beer, and V.J. Hearing. 2003. UV-induced DNA damage and melanin content in human skin differing in racial/ethnic origin. Faseb Journal. 17:1177-1179.

Takeo, M., W. Lee, P. Rabbani, Q. Sun, H. Hu, C.H. Lim, P. Manga, and M. Ito. 2016. EdnrB Governs Regenerative Response of Melanocyte Stem Cells by Crosstalk with Wnt Signaling. Cell Rep. 15:1291-1302.

Theos, A.C., S.T. Truschel, G. Raposo, and M.S. Marks. 2005. The Silver locus product Pmel17/gp100/Silv/ME20: controversial in name and in function. Pigment Cell Res. 18:322-336.

Thody, A.J., E.M. Higgins, K. Wakamatsu, S. Ito, S.A. Burchill, and J.M. Marks. 1991. Pheomelanin as well as eumelanin is present in human epidermis. $J$ Invest Dermatol. 97:340-344.

van Nieuwpoort, F., N.P. Smit, R. Kolb, H. van der Meulen, H. Koerten, and S. Pavel. 2004. Tyrosine-induced melanogenesis shows differences in morphologic and melanogenic preferences of melanosomes from light and dark skin types. J Invest Dermatol. 122:1251-1255.

von Koschembahr, A.M., V.B. Swope, R.J. Starner, and Z.A. Abdel-Malek. 2015. Endothelin-1 protects human melanocytes from UV-induced DNA damage by activating JNK and p38 signalling pathways. Experimental Dermatology. 24:269274.

Yamaguchi, Y., K. Takahashi, B.Z. Zmudzka, A. Kornhauser, S.A. Miller, T. Tadokoro, W. Berens, J.Z. Beer, and V.J. Hearing. 2006. Human skin responses to UV radiation: pigment in the upper epidermis protects against DNA damage in the lower epidermis and facilitates apoptosis. Faseb Journal. 20:1486-1488. 
IV. APPENDIX

Failed Experimental Approaches 


\section{APPENDIX}

\subsection{Failed Experimental Approaches}

4.1.1 Quantification of follicular melanocytes in Lethal Yellow mice

In Chapter 2 I showed that the increased levels of melanin in the hairs of Edn3 transgenic animals was not due to the presence of a larger number of melanocytes in their hair follicles. The experiments performed where carried out with K5-tTA;TRE-Edn3-lacZ and control animals. Ideally, I would have liked to also compare $A^{y} ; K 5$-tTA;TRE-Edn3lac $Z$ mice with $A^{y}$ mice but due to experimental difficulties this was not possible.

Dorsal skin samples were collected from four-week-old $A^{y} ;$ K5-tTA;TRE-Edn3lacZ mice and non-transgenic littermates. Samples were fixed in 4\% paraformaldehyde, embedded in OCT Compound (Ted-Pella, USA Scientific), frozen at $80{ }^{\circ} \mathrm{C}$, and sectioned at $10 \mu \mathrm{m}$. Sections were washed and blocked with 10\% goat serum (Gibco, Invitrogen, 16210-064), 5\% Bovine Serum Albumin (BSA) (Amresco, 0332), 0.1\% Triton X-100 (Sigma, T-8787) in 1X PBS (pH 7.4) for 1 hour and 15 minutes at room temperature and incubated with the primary antibody anti-TRP1 (1:50, rabbit anti-mouse $\alpha$-PEP1 antibody, Vincent Hearing, NIH) diluted in 5\% Goat Serum, $1 \%$ BSA, $0.1 \%$ Tween 20 (Fisher Biotetch, BP337) in 1X PBS (pH 7.4) solution, for one hour. After washing, sections were incubated with secondary antibody Alexa Flour 488 (green) (1:200, goat anti-rabbit, Life Technologies, A11008). Sections were washed and counterstained with propidium iodide. I attempted to visualize the staining using the Leica DMRB compound fluorescent microscope and photograph it with the Leica DC500 Camera.

Immunofluorescent antibody staining on the skins of $A^{y}$ mice with or without the K5-tTA;TRE-Edn3-lacZ transgene resulted in a cloudy discolored staining (Figure 1). It 
appears that the high pheomelanin content found in the skin of these mice interferes with the fluorescence staining process. I repeated this experiment with multiple secondary antibodies including Alexa Fluor 488 (green) (Life Technologies, A11008) (Figure 4.1A) and Alexa Fluor 594 (red) (Thermo Fisher, R37117) (Figure 4.1B) and obtained very similar results.

In an attempt to bypass the autofluorescence issue caused by pheomelanin, I attempted to perform immunohistochemistry staining with horseradish tagged secondary antibodies. The staining was carried out with samples that were bleached with hydrogen peroxide and samples that were not bleached. In either case, I was not able to quantify the number of follicular melanocytes due to the overlap between the residual pigment found in the skin sections and the antibody staining.

\subsubsection{In vivo inhibition of downstream effectors of Edn3 signaling}

To determine the downstream effectors of Edn3 signaling in the darkening of the coat and skin color of $A^{y}$ mice, chemical inhibitors were topically applied to the dorsal skin of $A^{y}$; K5-tTA;TRE-Edn3-lacZ mice. Prior to topical application, the dorsal hairs of the mice were plucked at four weeks of age. Three days after plucking, $100 \mu \mathrm{M}$ of Protein Kinase

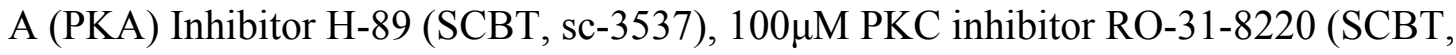
sc-200619) or 100 $\mu$ M MAPK Inhibitor SB203580 (Calbiochem, 559389) was applied topically using a paint brush twice a day for a period of ten days to a small portion on the dorsal skin of the mice (Park et al., 2004). Inhibitors were diluted in a $25 \%$ dimethylsulfoxide, $75 \%$ propylene glycol solution. Neither the skin nor hair became visibly lighter after the 10 day application period with any of the three inhibitors. The 
negative results may be due to the high amounts of pigment present in the skin and hair of the K5-tTA;TRE-Edn3-lacZ and/or the time for the accumulated pigment to degrade. The topical application of inhibitors may be more successful if newborn pups are used prior to the establishment of a full coat so that the inhibitors can better penetrate the skin. It is also possible that an extended application time may be necessary for the lighting of the skin and coat become noticeable.

\subsubsection{In vitro studies to determine Base Excision Repair activity}

The increase in pigmentation levels caused by Edn3 signaling may lead to a very deleterious environment for melanocytes given the excessive amount of reactive oxygen species released during the biochemical reaction to produce melanin. I hypothesized that this may be compensated by a direct effect of Edn3 on the DNA repair pathway. In order to investigate if Edn3 directly increases DNA repair in melanocytes, I attempted to use a biochemical assay (add some reference from one of Dr. Liu's papers) to measure the activity of Base Excision Repair (BER) proteins. Melan-a cells (Bennett et al., 1987) were grown in RPMI 1640 stock media (Cellgro, Fisher) containing cholera toxin (Resink et al., 1990). Cells were induced with 1nM of Edn3 for four days prior to UVexposure to $21 \mathrm{~mJ} / \mathrm{cm}^{2}$ of UV light using fluorescent UV lamps (Kadekaro et al., 2005). Non-UV induced or cell that were not treated with Edn3 were used as controls.

To obtain a baseline for the activity of proteins involved in BER, extracts of melan-a cells were collected and subjected to the biochemical assay to measure apurinic/apyrimidinic endonuclease 1 (APE1) and flap endonuclease 1 (FEN1) activities. Oligonucleotides BERsub-8-oxoG and BERsub-THF (Integrated DNA Technologies 
(IDT) Inc) were annealed with their template strands to produce the substrate used in the assay. Substrate was pre-incubated with $50 \mathrm{nM}$ 8-oxoguanine DNA glycosylase 1 (OGG1), a DNA repair enzyme, and $\mathrm{APE} 1$ at $37^{\circ} \mathrm{C}$ for 30 minutes to generate ssDNA break intermediates. BER was measured by incubating $60 \mu \mathrm{g}$ of cell extract with $25 \mathrm{nM}$ of substrate at $37^{\circ} \mathrm{C}$ for 30 minutes. The reaction was terminated by increasing temperature to $95^{\circ} \mathrm{C}$ for 5 minutes and the reaction was subsequently subjected to protease $\mathrm{K}$ digestion at $55^{\circ} \mathrm{C}$ for 30 minutes. DNA was precipitated and dissolved into buffer containing 95\% formamide and 2 mM EDTA. Substrate and repair products were separated by $15 \%$ urea-denaturing PAGE and detected using a Pharos FX Plus PhosphorImager from Bio-Rad.

Our results showed clear FEN1 cleavage products (lower position than APE1 precut product) and repaired product (at the same level with substrate only). Although we detected repair products, the amount of repaired product was very low due to low protein amounts (Figure 4.2). We repeated these experiments multiple times but were not able to obtain sufficient protein. We estimate that we would need at least 6 T-75 flasks to obtain the right amount of protein for a single experiment and this would be cost prohibitive when considering all the biological replicates we would need to obtain statistically significant data.

\subsubsection{In vivo studies to determine Base Excision Repair Activity}

Since we were unable to obtain sufficient protein from the cell lines, we attempted to run the assay using extracts from mouse skin. For the in vivo experiments, K5$t T A ; T R E-E d n 3-l a c Z$ mice were compared to nontransgenic littermates (Figure 4.3). Mice 
were exposed to UV at three weeks of age. The UV exposure dose used was $3.31 \mathrm{KJ} / \mathrm{m}^{-2}$ of UV-A (320-400 nm), $6.24 \mathrm{KJ} / \mathrm{m}^{-2}$ of UV-B (280-320nm) and $0.03 \mathrm{KJ} / \mathrm{M}^{-2}$ of UV-C (250-280nm) for a total UV dose of $9.58 \mathrm{KJ} / \mathrm{m}^{-2}$ of UV using six Phillips F40 UV lamps, the equivalent of a minor sunburn at midlattitudes (Noonan et al., 2001). Mice were euthanized and dorsal skin samples were collected. Skin samples were lysed using a sonicator and processed for the same assay used for the extracts of melan-a cells.

We encountered detection problems and were not able to visualize repair intermediates or products. Since the skin samples contain a lot of connective tissue, extracting sufficient protein without denaturing it was very difficult. We tried various methods using the sonicator but samples continued to yield low active protein levels.

\subsubsection{In vitro studies to determine Nucleotide Excision Repair activity}

Previous in vitro experiments using human primary melanocytes from neonatal foreskin showed a role for the MC1R and EDN1 pathways in NER (Abdel-Malek et al., 2008; Kadekaro et al., 2005; Song et al., 2009). To assay for a putative role for Edn3 in NER in murine melanocytes, we chose to employ the comet assay. Melan-a and Melan-e (Hida et al., 2009) cell lines were grown and maintained in T-75 Flasks (USA Scientific, 5665-8170) at $37^{\circ} \mathrm{C}$ in $10 \% \mathrm{CO}_{2}$ using RPMI 1640 cell media (Fisher, 10-041-CV), containing 10\% FBS, 200nM of TPA (Sigma, D9628) and 200 pM CT (Sigma, C-2432) (Bennett et al., 1989; Sviderskaya et al., 1997). Two to three days prior to Edn3 treatment, cell lines were grown in starvation media lacking TPA and FBS which downregulates endothelin receptors and upregulates melanocortins, respectively (AbdelMalek et al., 1995; Resink et al., 1990). Starvation media contained RPMI 1640, 4\% 
FBS, $0.6 \mathrm{ng} / \mathrm{mL}$ bFgf (Life Technologies, 1263344A) and 1\% Pen Strep (Thermo Fisher, 15070-063) (Medrano and Nordlund, 1990). Cells were induced with 1nM of Edn3 or not for four days prior and immediately after UV exposure (von Koschembahr et al., 2015). Prior to UV, culture media was replaced with PBS pH 7.4. Cells were exposed to $90 \mathrm{~mJ} / \mathrm{cm}^{2}$ using UV lamps with peak emission of $313 \mathrm{nM}$, with $75 \%$ emission in UVB range and 25\% emission in UVA range using FS20 lamps with a filter against UVC (Kadekaro et al., 2010). Immediately after UV exposure cells were collected to measure initial damage. To measure the amount of repair after UV exposure, media containing 1nM Edn3 was reapplied to cells for 30 minutes, cells were washed in PBS pH 7.4. For both experimental groups, 30,000 cells were suspended in $0.6 \%$ low-melting-point agarose (Invitrogen, Paisley) and were mounted on slides. Slides were placed on ice to solidify, and placed in incubation buffer overnight. Slides were then incubated in a 1:500 dilution of enzyme/buffer solution using the enzymes: T4Endo5 (New England Biolabs, M0308) to quantify Thymine- dimers, and hogg1 (New England Biolabs, M0241) to quantify 8-oxodG. Slides were placed in $300 \mathrm{mM} \mathrm{NaOH}$ and $1 \mathrm{mM}$ disodium Na EDTA pH 13 alkaline electrophoresis buffer for 20 minutes and gel electrophoresis was run for 20 minutes at $21 \mathrm{~V}$. Slides were added to the $0.4 \mathrm{M}$ Tris- $\mathrm{HCl}, \mathrm{pH} 7.5$ neutralizing buffer for 20 minutes and washed. Nuclei were stained with propidium iodide (Collins and Dusinska, 2002; Karbaschi and Cooke, 2014). Slides were observed and scored by fluorescent microscopy and percentage of tail DNA of comets were recorded using Comet Assay IV analysis Software (Perceptive Instruments, Haverhill, Suffolk). Comets were analyzed using the Kruskal-Wallis and Dunn's Multiple Comparison Test and statistical analyses were performed using GraphPad Prism, version 6.02 (GraphPad, 
CA)(Karbaschi and Cooke, 2014).

Our preliminary results seem to indicate that Edn3 was not having an effect on the DNA repair capacity in the murine cell lines. I attempted exposing the cells to varying concentrations of Edn3 $0.1 \mathrm{nM}, 1 \mathrm{nM}$, or $10 \mathrm{nM}$ ) and was still not able to detect any phenotypic change. I also performed gene expression analysis with pigmentation genes such as Mitf and could not detect any difference in response to Edn3. It is possible that these cells lines do not express Ednrb or are unable to respond to Edn3. In the future, other murine cells lines should be tested. 

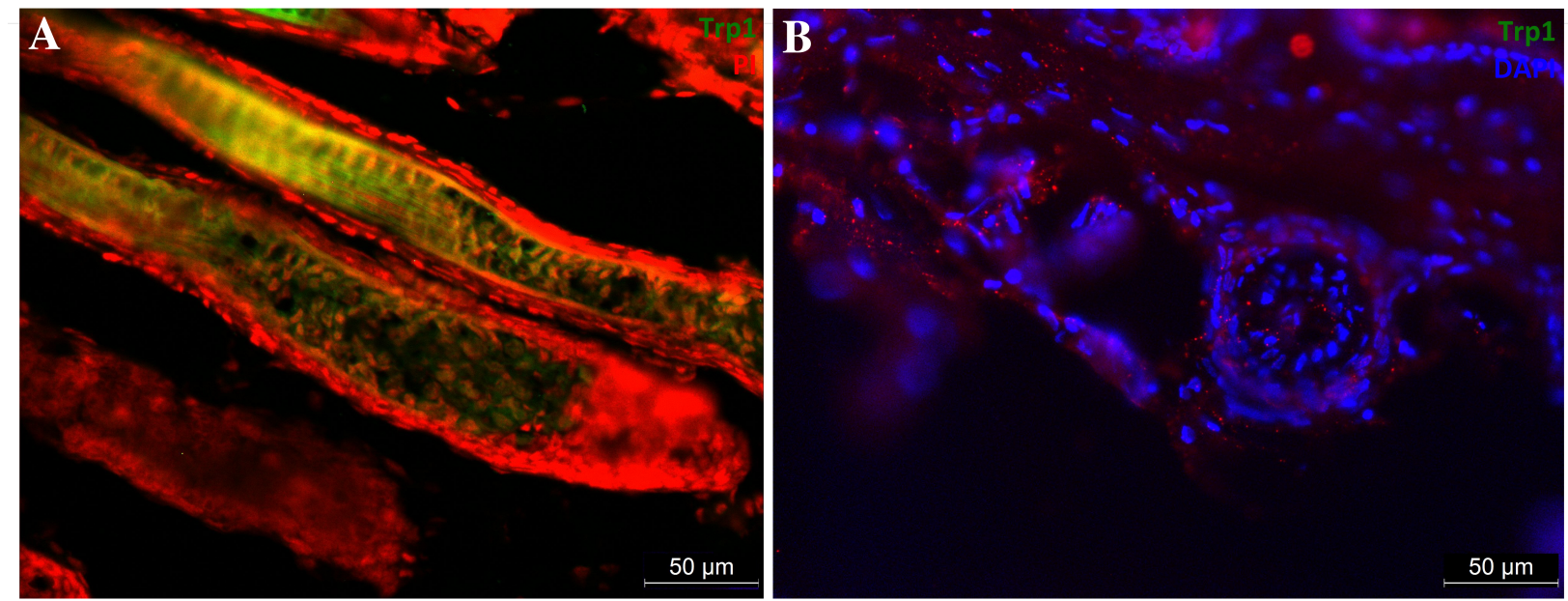

Figure 4.1. Trp1 antibody staining of Lethal Yellow mouse skin. (A) Trp1 antibody staining with Alexa Flour 488 secondary antibody (green) counterstained with propidium iodide (Red). (B) Trp1 antibody staining with Alexa Flour 598 secondary antibody (red) counter stained with DAPI (blue). 


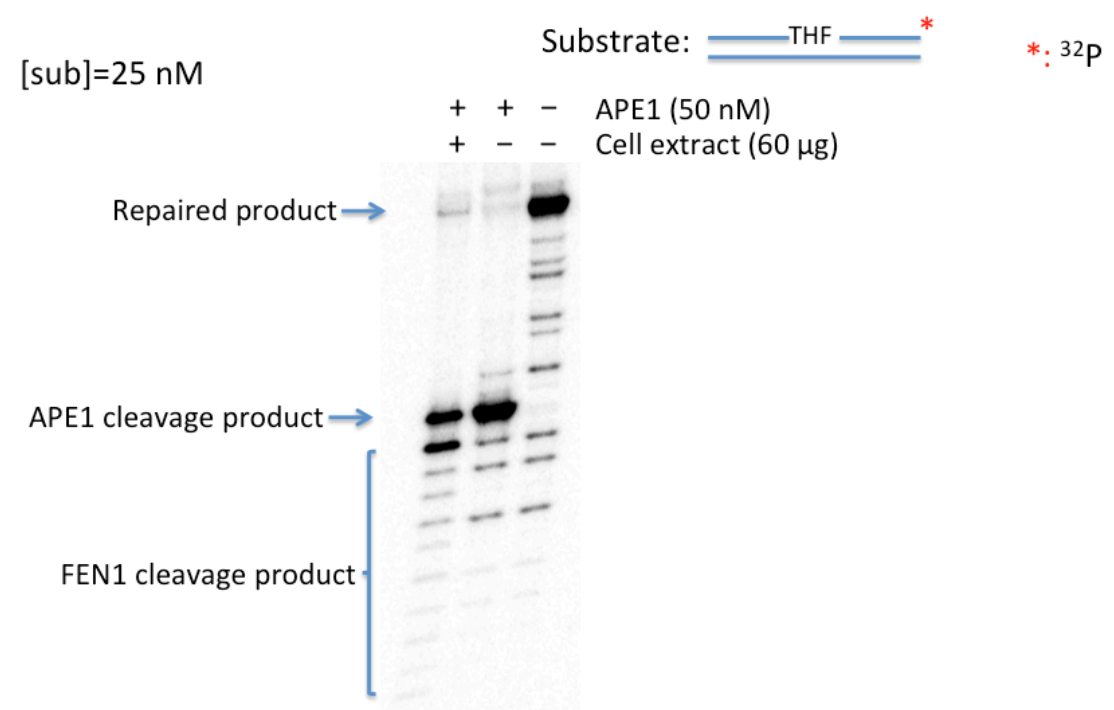

Figure 4.2. BER protein activity biochemical assay in melan-a cell line. Clear FEN1 cleavage products (lower position than APE1 pre-cut product) and repaired product (at the same level with substrate only). 


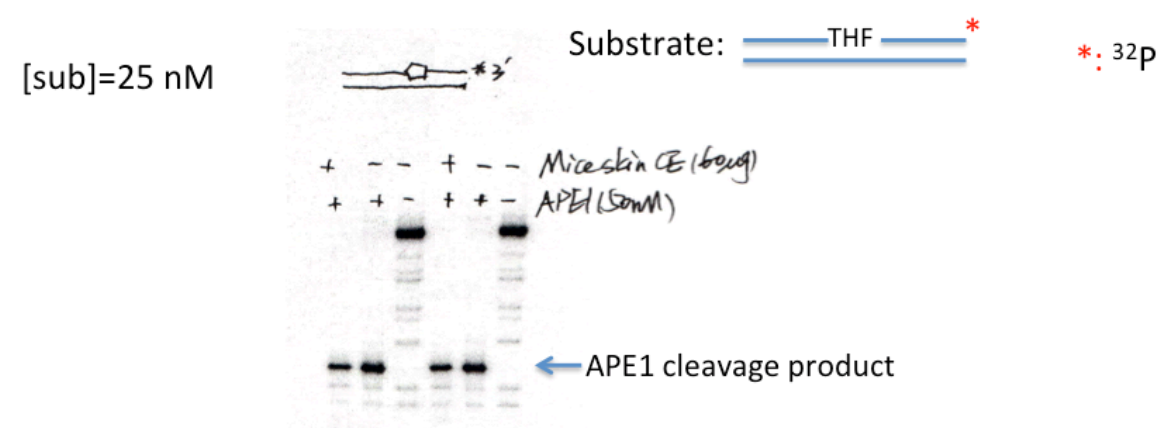

Figure 4.3. BER protein activity biochemical assay in K5-tTA;TRE-Edn3-lacZ mice. No FEN1 cleave products or repair intermediates were detected. 


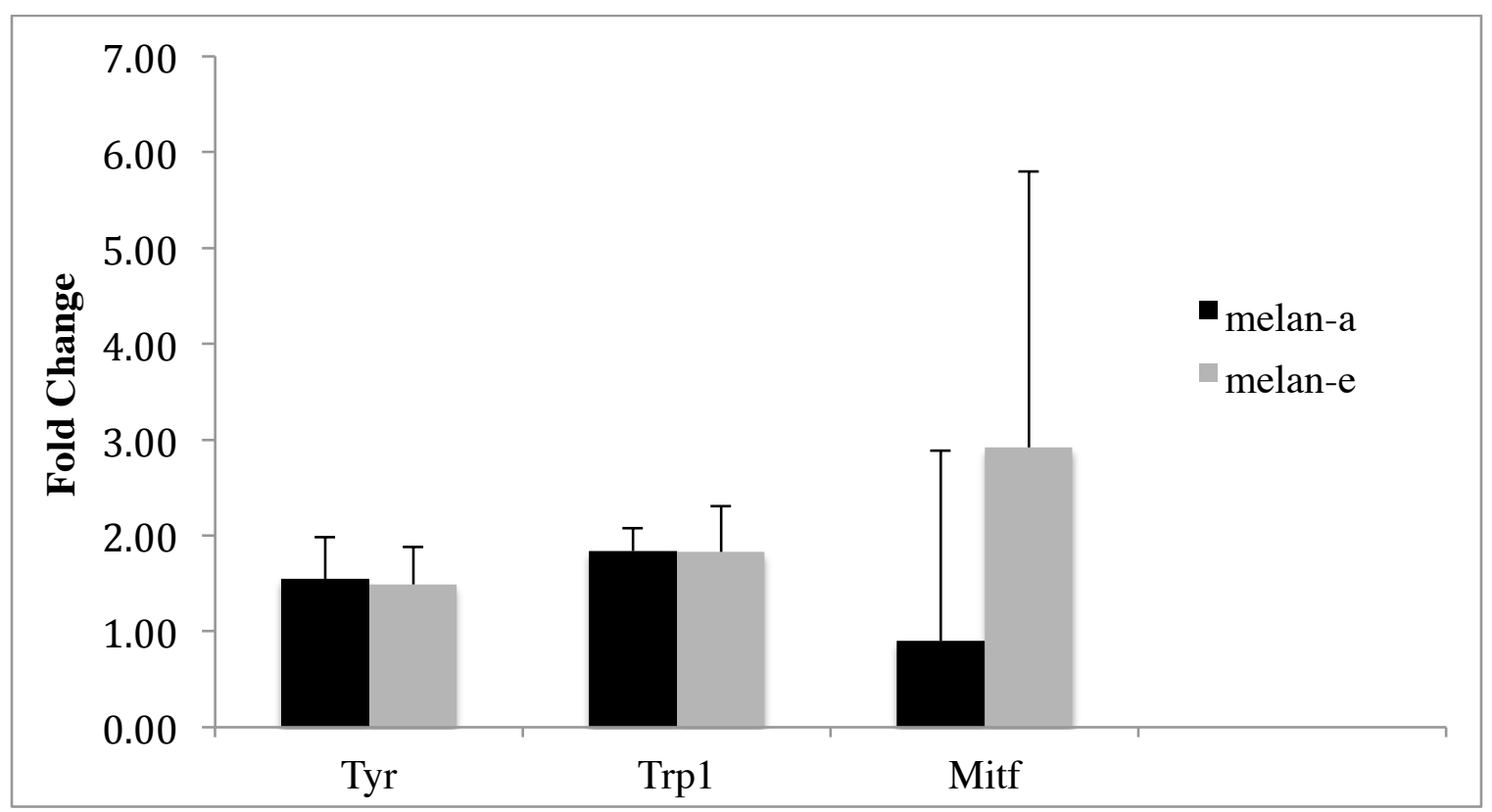

Figure 4.4. Gene expression analysis of melan-a and melan-e cells induced with Edn3. Relative mRNA levels (mean $\pm \mathrm{SD}$ ) for the indicated genes from qRTPCR of cDNA from melan-a $(n=3)$ and melan-e $(n=4)$ induced with $10 \mathrm{nM}$ of Edn3 compared to control values. All expression values were normalized to Gapdh. 


\subsection{References}

Abdel-Malek, Z., V.B. Swope, I. Suzuki, C. Akcali, M.D. Harriger, S.T. Boyce, K. Urabe, and V.J. Hearing. 1995. Mitogenic and melanogenic stimulation of normal human melanocytes by melanotropic peptides. Proc Natl Acad Sci US A. 92:1789-1793.

Abdel-Malek, Z.A., J. Knittel, A.L. Kadekaro, V.B. Swope, and R. Starner. 2008. The melanocortin 1 receptor and the UV response of human melanocytes--a shift in paradigm. Photochem Photobiol. 84:501-508.

Bennett, D.C., P.J. Cooper, T.J. Dexter, L.M. Devlin, J. Heasman, and B. Nester. 1989. Cloned mouse melanocyte lines carrying the germline mutations albino and brown: complementation in culture. Development. 105:379-385.

Bennett, D.C., P.J. Cooper, and I.R. Hart. 1987. A line of non-tumorigenic mouse melanocytes, syngeneic with the B16 melanoma and requiring a tumour promoter for growth. Int J Cancer. 39:414-418.

Collins, A.R., and M. Dusinska. 2002. Oxidation of cellular DNA measured with the comet assay. Methods Mol Biol. 186:147-159.

Hida, T., K. Wakamatsu, E.V. Sviderskaya, A.J. Donkin, L. Montoliu, M. Lynn Lamoreux, B. Yu, G.L. Millhauser, S. Ito, G.S. Barsh, K. Jimbow, and D.C. Bennett. 2009. Agouti protein, mahogunin, and attractin in pheomelanogenesis and melanoblast-like alteration of melanocytes: a cAMP-independent pathway. Pigment Cell Melanoma Res. 22:623-634.

Kadekaro, A.L., R. Kavanagh, H. Kanto, S. Terzieva, J. Hauser, N. Kobayashi, S. Schwemberger, J. Cornelius, G. Babcock, H.G. Shertzer, G. Scott, and Z.A. Abdel-Malek. 2005. alpha-Melanocortin and endothelin-1 activate antiapoptotic pathways and reduce DNA damage in human melanocytes. Cancer Res. 65:42924299.

Kadekaro, A.L., S. Leachman, R.J. Kavanagh, V. Swope, P. Cassidy, D. Supp, M. Sartor, S. Schwemberger, G. Babcock, K. Wakamatsu, S. Ito, A. Koshoffer, R.E. Boissy, P. Manga, R.A. Sturm, and Z.A. Abdel-Malek. 2010. Melanocortin 1 receptor genotype: an important determinant of the damage response of melanocytes to ultraviolet radiation. Faseb Journal. 24:3850-3860.

Karbaschi, M., and M.S. Cooke. 2014. Novel method for the high-throughput processing of slides for the comet assay. Sci Rep. 4:7200.

Medrano, E.E., and J.J. Nordlund. 1990. Successful culture of adult human melanocytes obtained from normal and vitiligo donors. J Invest Dermatol. 95:441-445. 
Noonan, F.P., J.A. Recio, H. Takayama, P. Duray, M.R. Anver, W.L. Rush, E.C. De Fabo, and G. Merlino. 2001. Neonatal sunburn and melanoma in mice. Nature. 413:271-272.

Park, H.Y., J. Lee, S. Gonzalez, M.A. Middelkamp-Hup, S. Kapasi, S. Peterson, and B.A. Gilchrest. 2004. Topical application of a protein kinase $\mathrm{C}$ inhibitor reduces skin and hair pigmentation. $J$ Invest Dermatol. 122:159-166.

Resink, T.J., T. Scott-Burden, E. Weber, and F.R. Buhler. 1990. Phorbol ester promotes a sustained down-regulation of endothelin receptors and cellular responses to endothelin in human vascular smooth muscle cells. Biochem Biophys Res Commun. 166:1213-1219.

Song, X., N. Mosby, J. Yang, A. Xu, Z. Abdel-Malek, and A.L. Kadekaro. 2009. alphaMSH activates immediate defense responses to UV-induced oxidative stress in human melanocytes. Pigment Cell Melanoma Res. 22:809-818.

Sviderskaya, E.V., D.C. Bennett, L. Ho, T. Bailin, S.T. Lee, and R.A. Spritz. 1997. Complementation of hypopigmentation in p-mutant (pink-eyed dilution) mouse melanocytes by normal human P cDNA, and defective complementation by OCA2 mutant sequences. J Invest Dermatol. 108:30-34.

von Koschembahr, A.M., V.B. Swope, R.J. Starner, and Z.A. Abdel-Malek. 2015. Endothelin-1 protects human melanocytes from UV-induced DNA damage by activating JNK and p38 signalling pathways. Experimental Dermatology. 24:269274. 
VITA

\title{
JAVIER PINO
}

\author{
EDUCATION \\ 2021 Doctor of Veterinary Medicine Candidate \\ Purdue University - West Lafayette, Indiana \\ 2017 Doctor of Philosophy Candidate, Biology \\ Florida International University - Miami, Florida \\ $2016 \quad$ Master of Biology \\ Florida International University - Miami, Florida \\ 2012 Bachelor of Science in Biological Sciences, 2012 \\ Florida International University - Miami, Florida
}

\section{PUBLICATIONS AND PRESENTATIONS:}

Kaelin CB, Xu X, Hong LZ, David VA, McGowan KA, Schmidt-Küntzel A, Roelke ME, Pino J, Pontius J, Cooper GM, Manuel H, Swanson WF, Marker L, Harper CK, Van Dyk A, Yue B, Mulikin JC, Warren WC, Eizirik E, Kos L, O'Brien SJ, Barsh GS, MenottiRaymond M. (2012) Specifying and sustaining pigmentation patterns in domestic and wild cats. Science 337, 1536-1541

Pino J, Kos, L (2013) The regulation of skin and hair pigmentation by signaling pathways and related disorders. Skin Pigmentation: Genetics, Geographic Variation and Disorders. NY: Nova Science Publishers, 57-88

Pino, J, Durango, A, Kos, L (2017) Transgenic expression of Endothelin 3 regulates murine coat color. $19^{\text {th }}$ Annual Biomedical and Comparative Immunology Symposium, Florida International University, Miami, Florida (Oral Presentation)

Pino, J, Durango, A, Kos, L (2016) Transgenic expression of Endothelin 3 regulates murine coat color. $18^{\text {th }}$ Annual Biomedical and Comparative Immunology Symposium, Florida International University, Miami, Florida (Oral Presentation)

Pino, J, Durango, A, Kos, L (2016) Regulation of murine coat color by transgenic expression of endothelin 3. The Allied Genetics Conference, Orlando, Florida (Oral Presentation and Poster)

Pino, J, Ito, S, Wakamatsu, K, Kos, L (2015) Transgenic expression of Endothelin 3 regulates murine coat color. 2015 PanAmerican Society for Pigment Cell Research Meeting, Orange, CA (Oral Presentation) 
Pino, J, Ito, S, Wakamatsu, K, Kos, L (2015) Endothelin 3 Regulates Pigment Production and Coat Color in Mice. 14 ${ }^{\text {th }}$ International Conference on Endothelin: Physiology, Pathophysiology and Therapeutics, Savannah, GA (Oral Presentation, Poster Presentation, 1-minute Hot Topics)

Pino J, Kos, L (2014) Transgenic Expression of Edn3 increases the production of hair pigments. 2014 FIU MBRS RISE \& MARC U*STAR STUDENT Mini-Symposium, Florida International University, Miami, Florida (Oral Presentation)

Pino J, Kos, L.(2014) Regulation of murine pigment production by Edn3. International Pigment Cell Conference, Singapore, Singapore (Oral Presentation)

Pino J, Kos, L (2014) Production of eumelanin and pheomelanin is regulated by Edn3. $16^{\text {th }}$ Annual Biomedical and Comparative Immunology Symposium, Florida International University, Miami, Florida (Oral Presentation)

Pino J, Kos, L (2014) Edn3 overexpression rescues a dark pigmentation phenotype in lethal yellow mice, MBRS/RISE Middle School Outreach, Pinecrest Preparatory Charter School, Miami, Fl

Pino J, Kos, L (2014) Endothelin 3 regulates the production of both eumelanin and pheomelanin in lethal yellow mice. 2014 Biology Research Symposium, Florida International University, North Miami, Florida (Oral Presentation)

Pino J, Kos, L (2013) Endothelin 3 regulates the production of both eumelanin and pheomelanin in the hair of agouti yellow mice. MARC U*STAR \& MBRS RISE MiniSymposium, Florida International University, Miami, Florida (Oral Presentation)

Pino J, Kos, L (2013) Endothelin 3 overexpression rescues a dark pigmentation phenotype in lethal yellow mice. Meet the Scientists- community outreach series, Coral Shores High School, Tavernier, Florida (Oral Presentation)

Pino, J, Ito, S, Wakamatsu, K, Kos, L (2013) Endothelin 3 affects murine coat color by regulating the production of both eumelanin and pheomelanin. 2013 PanAmerican Society for Pigment Cell Research Meeting, University of Wisconsin Madison, Madison, Wisconsin (Poster Presentation) 